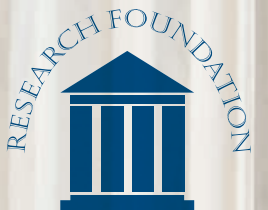

OF CFA INSTITUTE

\title{
A NEW LOOK AT CURRENCY INVESTING
}

Momtchil Pojarliev, CFA

Richard M. Levich 


\section{Named Endowments}

The Research Foundation of CFA Institute acknowledges with sincere gratitude the generous contributions of the Named Endowment participants listed below.

Gifts of at least US\$100,000 qualify donors for membership in the Named Endowment category, which recognizes in perpetuity the commitment toward unbiased, practitioneroriented, relevant research that these firms and individuals have expressed through their generous support of the Research Foundation of CFA Institute.

Ameritech

Anonymous

Robert D. Arnott

Theodore R. Aronson, CFA

Asahi Mutual Life

Batterymarch Financial Management

Boston Company

Boston Partners Asset Management, L.P.

Gary P. Brinson, CFA

Brinson Partners, Inc.

Capital Group International, Inc.

Concord Capital Management

Dai-Ichi Life Company

Daiwa Securities

Mr. and Mrs. Jeffrey Diermeier

Gifford Fong Associates

Investment Counsel Association

of America, Inc.

Jacobs Levy Equity Management

John A. Gunn, CFA

Jon L. Hagler Foundation

Long-Term Credit Bank of Japan, Ltd.

Lynch, Jones \& Ryan
Meiji Mutual Life Insurance Company

Miller Anderson \& Sherrerd, LLP

John B. Neff, CFA

Nikko Securities Co., Ltd.

Nippon Life Insurance Company of Japan

Nomura Securities Co., Ltd.

Payden \& Rygel

Provident National Bank

Frank K. Reilly, CFA

Salomon Brothers

Sassoon Holdings Pte. Ltd.

Scudder Stevens \& Clark

Security Analysts Association of Japan

Shaw Data Securities, Inc.

Sit Investment Associates, Inc.

Standish, Ayer \& Wood, Inc.

State Farm Insurance Companies

Sumitomo Life America, Inc.

T. Rowe Price Associates, Inc.

Templeton Investment Counsel Inc.

Travelers Insurance Co.

USF\&G Companies

Yamaichi Securities Co., Ltd.

\section{Senior Research Fellows}

Financial Services Analyst Association

For more on upcoming Research Foundation

publications and webcasts, please visit

www.cfainstitute.org/about/foundation/.

Research Foundation monographs

are online at www.cfapubs.org. 
Momtchil Pojarliev, CFA Hathersage Capital Management LLC

Richard M. Levich New York University Stern School of Business

\section{A New Look at Currency Investing}

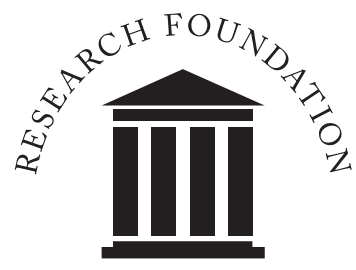

OF CFA INSTITUTE 


\title{
Statement of Purpose
}

\author{
The Research Foundation of CFA Institute is a \\ not-for-profit organization established to promote \\ the development and dissemination of relevant \\ research for investment practitioners worldwide.
}

Neither the Research Foundation, CFA Institute, nor the publication's editorial staff is responsible for facts and opinions presented in this publication. This publication reflects the views of the author(s) and does not represent the official views of the Research Foundation or CFA Institute.

The Research Foundation of CFA Institute and the Research Foundation logo are trademarks owned by The Research Foundation of CFA Institute. CFA ${ }^{\circledR}$, Chartered Financial Analyst ${ }^{\circledR}$, AIMR-PPS $^{\circledR}$, and GIPS ${ }^{\circledR}$ are just a few of the trademarks owned by CFA Institute. To view a list of CFA Institute trademarks and the Guide for the Use of CFA Institute Marks, please visit our website at www.cfainstitute.org.

(C) 2012 The Research Foundation of CFA Institute

All rights reserved. No part of this publication may be reproduced, stored in a retrieval system, or transmitted, in any form or by any means, electronic, mechanical, photocopying, recording, or otherwise, without the prior written permission of the copyright holder.

This publication is designed to provide accurate and authoritative information in regard to the subject matter covered. It is sold with the understanding that the publisher is not engaged in rendering legal, accounting, or other professional service. If legal advice or other expert assistance is required, the services of a competent professional should be sought.

ISBN 978-1-934667-54-5

21 December 2012

\section{Editorial Staff}

Elizabeth Collins

Book Editor

\author{
Mary-Kate Hines \\ Assistant Editor \\ Mike Dean \\ Publishing Technology Specialist \\ Cindy Maisannes \\ Christina Hampton \\ Manager, Publications Production \\ Publishing Technology Specialist \\ Randy Carila \\ Publishing Technology Specialist
}




\section{Biographies}

Momtchil Pojarliev, CFA, is a senior portfolio manager for Hathersage Capital Management LLC and also serves as the chief investment officer of Cambex Holdings. He joined Hathersage after a decade of experience managing foreign exchange (FX) portfolios as the head of currencies at Hermes Pension Fund Management, senior FX portfolio manager at Pictet \& Cie, and senior FX portfolio manager at Invesco. In addition, Dr. Pojarliev has advised various asset management firms, including PIMCO and Goldman Sachs Asset Management, in the area of currency return analytics. He has published extensively in finance and investment journals. He is a member of The Economic Club of New York and the Swiss Society for Financial Market Research. He currently serves on the Editorial Board of the Financial Analysts Journal. Dr. Pojarliev received an MSc in finance from the Vienna University of Economics and Business and $\mathrm{ahD}$ with honors in financial econometrics from the University of Basel.

Richard M. Levich is professor of finance and international business and deputy chairman of the Department of Finance at New York University's Leonard N. Stern School of Business. Previously, he served as chairman of the International Business Program at Stern. He is also a research associate with the National Bureau of Economic Research in Cambridge, Massachusetts, and a founding editor of the Journal of International Financial Management and Accounting. Professor Levich has been a visiting faculty member at many distinguished universities in the United States and abroad. He is the author or editor of 15 books dealing with international finance and more than 50 scholarly articles, in addition to numerous other published writings. In 1997, Professor Levich received a CDC Award for Excellence in Applied Portfolio Theory from the Caisse Des Dépôts Group, France. He received his $\mathrm{PhD}$ from the University of Chicago. 


\section{Acknowledgments}

We received helpful comments from Emmanuel Acar, Robert Kosowski, Dori Levanoni, Peter Meier, Sam Nasypbek, and in particular, Laurence Siegel, who reviewed the entire manuscript and made many valuable suggestions. The views expressed herein are those of the authors and do not necessarily reflect the views of Hathersage Capital Management, New York University, or the Research Foundation of CFA Institute. We gratefully acknowledge financial assistance from the Research Foundation of CFA Institute for the preparation of this book. 


\section{Contents}

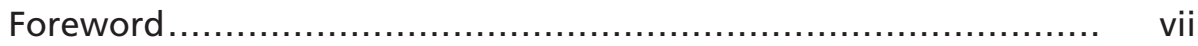

1. Introduction ..................................................... 1

Motivation: The Case for and against Currency Investing ....... 2

Overview........................................................ 7

2. The Landscape of Active Currency Management .................... 10

The Foreign Exchange Market..................................... 10

The Currency Management Mandate ............................. 32

Currency Investment Strategies ................................ 38

Currency Investment Processes ................................. 41

3. A Model of Alpha and Beta Returns from Currency

Management.............................................................. 43

4. Empirical Evidence................................................... 48

Proxies for Currency Investment Returns and Risk Factors ....... $\quad 48$

Results for the Barclay Currency Traders Index, 1990-2010...... 56

Results for the Deutsche Bank dbSelect Platform, 2005-2010 ... 69

Summary of Empirical Results.................................... 74

5. Currency Alpha and Beta for Institutional Investors ............... 76

6. Conclusions and Implications for Investment Management......... 82

Appendix A: Currency Indices and Style Factors .................... 86

References ................................................................ 89

CE Qualified $=0$ 步 CFA Institute This publication qualifies for $5 \mathrm{CE}$ credits under the guidelines Activity 



\section{Foreword}

The history of modern currency management serves as an excellent example of Andrew Lo's adaptive markets hypothesis. In the beginning, currency trading occurred independently of institutional portfolio management. It mainly served to hedge the exchange rate risk of international business transactions or to enable speculation. But as the benefits of global diversification of investment portfolios became apparent, investors increasingly diversified these portfolios beyond their own borders, which led them to pay more attention to the portfolio's currency exposure.

Two contradictory views emerged. Some argued that currency exposure should be hedged away completely because it introduced uncompensated risk to a portfolio. Others argued that currency exposure was good for a portfolio because it provided diversification. Eventually, thoughtful investors recognized that currency exposure introduced both risk and diversification, and they solved for optimal currency exposures as they did for other portfolio assets.

As investors became more comfortable with the mechanics of currency options, futures, and forward contracts, they began to explore strategies for profiting from currencies. Early active currency managers looked to exchange rate models based on macroeconomic variables, such as prices, interest rates, and output, for guidance. Then, they followed the lead of the equity literature and began to search for anomalies.

One of the more commonly exploited anomalies was the serial dependence of currency returns. Investors exploited this anomaly by purchasing a currency as it appreciated and selling it as it depreciated. Perhaps the most widely exploited anomaly was the violation of the theory of uncovered interest arbitrage. This theory predicted that changes in exchange rates would offset interest differentials so that investors could not profit by overweighting discount currencies and underweighting premium currencies.

Investors first ventured into active currency management by tilting their hedges; they underhedged currencies that had positive expected returns and overhedged currencies with negative expected returns. But they seldom took positions that increased currency exposure beyond the embedded exposure of the portfolio or reduced it to a net negative exposure. They soon realized that it was inefficient to constrain their currency bets to the portfolio's embedded currency exposures. But not only did they disconnect their currency strategies from the portfolio's exposures; they separated the hedging decision from the search for alpha. Going into the financial crisis of 2008-2009, investors 
typically managed currencies independently as a separate asset class or as part of a broader global macro strategy. Then the crisis came, which called into question many previously held views about investing, such as the efficacy of diversification.

This historical inflection point serves as the starting point for Momtchil Pojarliev and Richard Levich. They set out to re-examine the purpose and practice of currency management in the wake of the global financial crisis, and the result is an extraordinarily comprehensive and lucid book.

Among their many contributions is an up-to-date taxonomy of the foreign exchange market, which focuses on the instruments, participants, and pricing principles. They also review the various types of currency mandates, the expectations of the parties, and relevant operational issues. Then, Pojarliev and Levich get into the heart of the matter, which is to review and analyze the main currency management strategies and to model currency returns. The end result is a clear and concise, but far from superficial, review and analysis of foreign exchange markets and currency management practices, together with original research that offers valuable insights into the factors that determine currency performance.

Pojarliev and Levich, both independently and jointly, have contributed extensively to the study of foreign exchange markets and currency management. Their far-reaching knowledge of these topics is evident throughout this excellent book, which is destined to serve as an essential resource for finance scholars, as well as for those who provide and consume currency management services. Momtchil Pojarliev and Richard Levich deserve our gratitude for producing this fine book.

Mark P. Kritzman, CFA

President and CEO, Windham Capital Management Former Research Director, Research Foundation of CFA Institute (2000-2005) 


\section{Introduction}

Prior to the global financial crisis in 2007-2008, conventional wisdom among investment professionals was that market exposure (beta return) is easy to obtain, excess return (or alpha) is hard to find, and taking correlation of returns into account is important for enhancing overall investment performance. As a consequence of this thinking, many institutional investors adopted a core-satellite investment approach. The bulk of their assets (the core) were invested in long-only managers with large exposure to equities and fixed income; a small proportion of assets were invested in satellite portfolios, such as hedge funds, real estate, and commodities. The historical correlation of these satellites with equities was nearly zero. Therefore, institutional investors expected that the satellites would provide exposure to alternative beta returns (hence diversification of equity beta) and possibly alpha returns as well.

As the global financial crisis unfolded, however, investors discovered that they were less diversified than they thought. Many hedge funds declined in value along with equity markets, suggesting that what investors had perceived to be either alpha or new and unrelated sources of beta returns turned out to behave like equity beta. The recent crisis experience confirmed a pattern that had been previously documented in academic research a decade earlier (see Chow, Jacquier, Kritzman, and Lowry 1999): In turbulent markets, all asset returns generally become more volatile and more highly correlated. Thus, diversification tends to fail exactly when it is most needed-that is, in falling markets. ${ }^{1}$

Although most institutional investors still subscribe to this conventional wisdom, some investors in the postcrisis period are beginning to suspect that the expected return on equity beta might be lower than previously thought and that what alternative asset managers sometimes label "alpha" may actually behave more like beta.

\footnotetext{
${ }^{1}$ For example, when both hedge funds and global equities produce returns greater than one standard deviation above their means, their correlation is $-11 \%$. When both markets generate returns more than one standard deviation below their means, their correlation rises to $58 \%$. These correlations are based on monthly returns of the MSCI World Index (in local currencies) and the MSCI Hedge Fund Index from the period since inception of the Hedge Fund Index (January 1994) until June 2010. Kritzman and Li (2010) report a similar pattern in the correlation between U.S. equities (S\&P 500 Index) and non-U.S equities (MSCI World ex US Index)—that is, $-17 \%$ and $76 \%$, respectively.
} 


\section{Motivation: The Case for and against Currency Investing}

As investors rethink asset allocation, various questions come to mind with respect to a potential role for currency. Do alternative investments such as currency really bring diversification benefits to institutional investors? How much of the return generated by currency managers should be classified as alpha, and how much is beta? Are currency returns predictable to any extent, and is managerial performance or management style persistent? Should plan sponsors actively select currency managers on the basis of past performance, or should they rely on a naive approach based on a passive assortment of all available strategies? Should plan sponsors index their currency investments? If so, what index should they use, and how should they implement an index strategy?

Perhaps because the answers to these questions are unclear, currencies often have been overlooked as an additional source of return. Although funds assigned to a currency investment mandate have grown, growth has been less pronounced than for the overall hedge fund industry. ${ }^{2}$

More fundamental reasons may underlie the reluctance of institutional investors to treat currency as a viable asset class. A number of factors-some historical, some institutional, and others grounded in economic theory and policy making - have tended to make currency investing be viewed differently from the way equity investing is viewed. We review these factors here.

- Currency values are often pegged rather than allowed to fuctuate. During the Bretton-Woods period (1948-1971), currency values were officially pegged to the U.S. dollar and were changed only periodically, when policymakers could acknowledge that the values were fundamentally misaligned. Even after 1973, when the floating exchange rate period was ushered in, most currencies were pegged to something - generally, the U.S. dollar but sometimes the British pound (GBP), German mark (DEM), or French franc (FRF). ${ }^{3}$

\footnotetext{
${ }^{2}$ Whereas a mere handful of currency managers existed in the mid-1980s, at least 150 currency funds exist today and the actual number could be 300 or higher. In 2010, the Barclay Currency Traders Index tracked 119 managers in the currency domain. In 2010, Deutsche Bank FXSelect, a proprietary trading platform, offered 67 professionally managed currency funds. Other hedge fund databases, such as those maintained by Lipper TASS and Crédit Agricole Structured Asset Management/Center for International Securities and Derivatives Markets (CISDM), reveal an additional 200 or so currency funds, many of which are not included in the other two sources. The hedge fund sector has been one of fastest-growing sectors of the financial services industry (see Lo 2005). A survey conducted by the National Association of College and University Business Officers (NACUBO 2008) found that U.S. university endowments larger than USD1 billion allocated more than $20 \%$ of their assets to hedge funds.

${ }^{3}$ Taylor (2010) shows that in the 65-year period after World War II, the fraction of currencies on pegged-rate systems varied between about $65 \%$ in the early 1980 s to about $85 \%$ from the mid-1990s onward.
} 
Therefore, currency returns depended on one-off jumps or realignments that (1) might be difficult to forecast and (2) could not be relied upon for ongoing investment returns. In 1999, the arrival of the euro (EUR) as the new official currency of the (then) 11-nation European Monetary Union replaced the DEM, FRF, Italian lire (ITL), and Dutch guilder (NLG), among others, and helped shrink the investable currency universe.

- Currency offers too few investment choices. Although equity investors see a universe of thousands of publicly traded companies in the United States, and many thousands more in other countries, only a dozen or so major currencies are available from developed market economies today- too few currencies, perhaps, to regularly offer good investment opportunities or an adequately diversified portfolio of currency positions.

- In emerging markets, international capital mobility is limited and capital controls are prevalent. Limited capital mobility and capital controls reduce the appeal of many currency and international investments. Although the development of offshore financial markets in the 1960s and 1970s did increase international capital mobility, offshore markets were primarily for instruments denominated in the short list of developed economy currencies. Constraints on borrowing and lending in emerging financial markets (referred to at the time as "less developed countries" or even "underdeveloped markets") implied that forward markets and other means of currency speculation were off the table. Investors might be able to shift funds into a foreign market but not be able to repatriate them because of capital controls, making these countries unsuitable for financial investments that depend on liquidity.

- Currencies are difficult to model, and valuation can be elusive. Equity analysis, although challenging, relies on the well-known principle that a security's value depends on the cash flows that can be returned back to the shareholder. An equity share is a claim on the underlying assets of the company. In contrast, the underlying source of value for currency is elusive. Economic models often represent the equilibrium, or "fair value," of a currency as a present discounted value of fundamental variables, such as the national money supply, real income, and the current account balance. ${ }^{4}$ Parity conditions, such as covered interest parity, uncovered interest parity, and purchasing power parity (discussed in Chapter 2), may also be useful in gauging a currency's fair value today and in the future. Ultimately, however, currency is only a claim on purchasing future goods and services and

\footnotetext{
${ }^{4}$ An economic model of currency valuation usually depends on the relative values of these national, macroeconomic variables for the two countries in the currency pair. See Chapter 4 in Sarno and Taylor (2002) for a summary of theories and empirical evidence on economic models of exchange rate determination.
} 
a means of denominating accumulated wealth. Moreover, currency holders do not exercise voting rights or corporate control in ways analogous to shareholders of a public corporation. ${ }^{5}$

- Currencies may be subject to central bank intervention and can be used as a political and/or economic policy instrument. Shares in public corporations trade, for the most part, in heavily regulated markets with strict rules against insider trading. The U.S. Securities and Exchange Commission and similar bodies in other countries mandate the release of fundamental information about public corporations and fair disclosure about material events that affect companies. In contrast, currency is a creature of government, and the exchange rate is sometimes used as a political and/or economic policy instrument to manage the economy rather than allowed to be "merely a price" (like a share price) determined by management decisions and an exogenous economic environment. Interventions to retard a trend (a strong currency getting stronger [e.g., China] or a weak currency getting weaker) and interventions to reverse a trend (to cool off an overly strong currency [e.g., Switzerland] or put a floor under an undesirably weak currency) are familiar central bank tactics. Unlike a corporate official who would face legal sanctions for misleading investors, a treasury or ministry of finance official may offer public statements that support an official government position but are at odds with how economic and policy fundamentals are likely to evolve. Both the United States and the International Monetary Fund (IMF) may label a country a "currency manipulator," but in practice, the United States has never gone to this extreme.

- Currency is a bighly specialized market for professionals. The preceding points suggest why currency has, in some quarters, earned a reputation as a highly specialized market for professionals. Part of that reputation (often referenced in the academic literature) is that short-run currency movements cannot be forecast more accurately than a random walk with no drift (Meese and Rogoff 1983). The implication is that currency behaves like a pure speculation with zero expected rate of return whereas equity represents investment in real assets and is entitled to earn a risk premium over time.

\footnotetext{
${ }^{5}$ In recent years, China has accumulated vast amounts of USD-denominated international reserves. Current estimates are that China holds roughly USD1.1 trillion in U.S. Treasury securities, or nearly $8 \%$ of all outstanding U.S. Treasury debt and $13 \%$ of all privately held U.S. Treasury debt. Chinese officials are clearly interested in preserving the value of their holdings and, from time to time, offer economic advice to underscore their role as a major stakeholder in the U.S. economy.
} 
Although some (or all) of these factors may have played a role in reducing the appeal of currencies for institutional investors, in our view, many of these arguments are either outdated or susceptible to robust counterarguments, such as the following:

- The major currencies are allowed to fuctuate. Although only 14 countries of the 195 members of the IMF allow their currencies to be determined by a "pure float," this short list includes all the major currencies (the AUD [Australian dollar], CAD [Canadian dollar], CHF [Swiss franc], EUR, GBP, JPY [Japanese Yen], NZD [New Zealand dollar], and USD) and accounts for $95 \%$ or more of global trading activity. ${ }^{6}$ In addition, institutional and financial development in many emerging market (EM) countries has enabled trading volume to advance substantially, making many EM currencies viable investment opportunities in a well-structured program.

- International capital mobility has been on the increase. Despite the Asian financial crisis of the late 1990s and the subsequent Russian and Latin American financial crises, international capital mobility has increased dramatically over the past 20 years. As the number of so-called investable foreign equity markets has grown, a parallel advance has occurred in the variety, liquidity, and investability of short-term money market instruments, including currency markets, in many countries that were until recently off-limits. Even in China, the development of offshore Chinese currency bonds and a nondeliverable forward market provide fresh opportunities in the renminbi.

- Although equilibrium pricing of currency and models for currency forecasting continue to be debated in academic research, empirical regularities have emerged with immediate applications for currency investors. These empirical regularities include (1) the profitability of technical, or trend-following, strategies, (2) the tendency for carry trading strategies to be profitable, and (3) the tendency for currencies to return to a fundamental equilibrium value in the long run, even though prices may diverge substantially from this equilibrium in the short run. These regularities suggest that profit opportunities in currency markets have been available but have been subject to levels of risk that need to be carefully evaluated.

- The fact that currencies may be prone to central bank intervention and can be used as political and/or economic policy instruments does not necessarily binder the viability of currency as an asset class. Interest rate targeting and quantitative measures in short-term and long-term U.S. Treasury securities are typical means of implementing monetary policy. Investors take current

${ }^{6}$ Data here are from the IMF (2010). The classification for each country is based on the country's actual (de facto) exchange rate policy as determined by the IMF. For some countries, the classification differs from the country's stated, official (de jure) policy (Pugel 2011). 
and prospective monetary policy measures into account when structuring a fixed-income portfolio strategy. Although policymakers can at times surprise the market, they are often alleged to fall "behind the curve." In this case, future policy actions become more predictable-a potentially profitable situation for professional investors who can gauge the current policy stance relative to some desired future level.

- Recent research supports the idea that currency investing has similarities to investing in other acknowledged asset classes. Currency markets are indeed highly specialized and provide no counterpart to the buy-and-hold approach that supports the investment strategy of many small retail equity investors. ${ }^{7}$ Even the most basic currency strategies are relative value trades. For example, a manager goes long currency ABC only by going short currency $\mathrm{XYZ}$, which makes currency investment more suited to professional investors than retail investors. Financial statements for an equity mutual fund might simply list holdings by asset type (stocks, bonds, and cash), sector, and country, which makes assessing the fund's exposure and risk profile fairly easy. An analogous statement for a currency fund would be more complex; it might include long and short positions in various currencies and derivative instruments. Thus, it is more difficult for anyone other than a currency professional to gauge the strategy and risk-return opportunities embedded in the portfolio. Despite these important differences, both academic and practitioner research over the past decade support the argument that currency investment may be a perennial source of return that is garnered subject to risk and amenable to measurement using performance metrics comparable with those in other, acknowledged asset classes.

Our motivation for writing this book is to reconcile some of the conventional suspicions of currency investment with the results of recent academic and professional research. It is time to take a fresh look at the role of currencies and currency management and what currency investing means for the broader practice of institutional investment management. Our analysis will highlight several features of currency returns that may make currency an attractive asset class for institutional investors.

\footnotetext{
${ }^{7}$ In the equity market, buying and holding a basket of equities should produce an expected return associated with the equity risk premium. In the currency market, however, buying and holding a basket of foreign currency-denominated cash instruments need not produce any additional expected return. The reason is that in many economic models, the higher (or lower) interest earned on foreign currency is simply an offset for the expected depreciation (or appreciation) of foreign currency. This statement summarizes the principle of uncovered interest parity, which we discuss in Chapter 2. At most, buying and holding a basket of foreign currencies might be seen as an inflation hedge (against high or unpredictable inflation in the home country) or as a hedge against planned consumption in a basket of goods from various countries other than the home country.
} 
First, various established currency-trading strategies have tended to produce consistent returns, which can be proxied as style or risk factors and have the nature of beta returns. These returns tend to be imperfectly correlated with traditional equity market returns and can be thought of as providing a beta benchmark against which returns from a more active or idiosyncratic style of currency management can be compared. Second, we show in Chapter 4 that some currency managers produce true alpha, even relative to a demanding expected return benchmark, such as those we propose in Chapter 3. That is, some managers produce a positive residual return after the effects of beta-like factors have been removed. The potential to earn both alpha- and beta-like returns heightens the appeal of currency as an asset class. Finally, we stress that the global currency market offers enormous liquidity; it continued to function uninterrupted throughout the depths of the global financial crisis. ${ }^{8}$ Although certain currency strategies fared poorly during the crisis-in particular, when trades in those strategies were "crowded" - the volume of activity continued to be strong, allowing nimble players to navigate the market. ${ }^{9}$

\section{Overview}

Following this introductory chapter, we develop in Chapter 2 a thorough description of the foreign exchange market. The chapter covers the structure of the market and the nature of currency management mandates in recent years. We also provide a detailed review of the principal currency investment strategies in wide use.

In Chapter 3, we propose using style or risk factors to model currency returns in a manner analogous to the application of such factors in other investment contexts. This approach offers a natural way to decompose returns into alpha and beta components in currency management. The approach also allows us to investigate the question of what drives returns from currency speculation and whether currency managers demonstrate an ability to generate positive alpha. Traditionally, currency alpha has been defined as any return above the risk-free rate for funded mandates and above zero for unfunded mandates (see Strange 1998). Recent research, however, has shown that four factors (or styles) explain a significant part of the variability of the returns of professional

\footnotetext{
${ }^{8}$ Levich (2009) notes that the volume of currency trading actually increased in the early stages of the crisis period, aided in large measure by the CLS Bank, which eliminated settlement risk issues between counterparties. Following the Lehman Brothers bankruptcy, currency trading activity declined sharply, then recovered from October 2009 onward to reach record trading volume of USD4 trillion per day in April 2010 (King and Rime 2010).

${ }^{9}$ Pojarliev and Levich (2011a) propose a technique for measuring crowdedness in trading styles. The authors conjecture that crowded trades pose increased risk for investors, especially when a change in fundamentals or sentiment induces liquidation of positions.
} 
currency managers (see Pojarliev and Levich [henceforth, P-L] 2008). ${ }^{10}$ Three of the factors represent the return on well-known currency-trading strategies, and the fourth is foreign exchange volatility. In the P-L framework, currency alpha is what remains after accounting for exposure to these risk factors. ${ }^{11}$

Why should institutional investors be concerned about how much of the currency return is alpha and how much is beta? First, proper return attribution could lead to some repricing for "active" currency products. Investors should not pay alpha fees for exposure to currency style betas that could be earned more cheaply. Second, currency beta might be less well-suited than alpha when the goal is to diversify global equity exposure. For example, the correlation of carry beta with global equities is $-9.3 \%$ when global equities produce returns greater than one standard deviation above their mean, but it rises to $28.5 \%$ when equities generate returns more than one standard deviation below their mean. ${ }^{12}$

Chapter 4 presents empirical evidence on the returns of currency hedge funds operated by professional managers. Evaluating hedge fund performance is challenging because of the usual biases affecting hedge fund databases. To address backfill and survivorship biases, we make use of daily return data for currency managers listed on the Deutsche Bank dbSelect trading platform, which is the same database as that used in P-L (2010). ${ }^{13}$ Deutsche Bank $\mathrm{dbSelect}$ is unique among hedge fund databases in that it provides actual return data, made possible because gains and losses are computed by Deutsche Bank on the basis of real trades processed through Deutsche Bank prime

\footnotetext{
${ }^{10}$ The factors are proxies for returns on the carry trade, trend-following trades, value trading, and currency market volatility. An extensive literature demonstrates that mechanical ways of implementing the carry trade, trend-following trades, and value trading have been profitable in the currency market in the post-Bretton Woods era. Whether the profitability of these trades provides a normal or super-normal compensation for exposure to risk remains an open question that we will consider. These results may seem unlikely in light of another piece of conventional wisdom in foreign exchange (see Rogoff 2002), namely, that currency movements are almost impossible to predict so a random walk offers the best available short-term forecast. We also discuss this issue.

${ }^{11}$ Waring and Siegel (2006) show that the returns of any portfolio can be broken down into market (beta) components and an alpha component. Currency fund returns offer another example of this principle.

${ }^{12}$ These correlations are based on monthly returns of the MSCI World Index (in local currencies) and the FTSE Currency Forward Rate Bias Index (Bloomberg ticker: FRB5USDE) from January 1980 until September 2010. Correlations computed by using different proxies for currency beta exhibit a similar pattern.

${ }^{13}$ From its launch in 2005 until 2011, the trading platform was known as Deutsche Bank FXSelect. Details about the Deutsche Bank dbSelect trading platform are provided in Chapter 4.
} 
brokerage. The return data are audited by an independent third party. Other hedge fund databases simply collect return data submitted by managers and are thus affected by numerous biases. ${ }^{14}$

The complete dataset allows us to investigate a variety of questions: First, do currency managers generate alpha? Second, is past performance any indication of future performance (i.e., are alphas persistent)? Third, are investment styles (beta exposures) persistent? We examine these questions by using the Barclay Currency Traders Index and also dbSelect as an alternative database of currency managers, which serves as a robustness check.

In Chapter 5, we continue our empirical investigation and examine the usefulness of currency managers for investors with substantial equity exposure. The issues we consider include whether currency managers provide meaningful diversification and/or incremental returns to investors with large equity exposure. A related question is whether all currency managers are equally adept at offering diversification benefits or, alternatively, whether one can identify the managers better suited to providing diversification for institutional managers with global equity exposure.

The final chapter summarizes our main results and presents the implications of our findings for the asset management industry. We find that a substantial proportion of returns earned by active currency managers can be explained by indices of three common currency strategies (carry, trend, and value) and a fourth factor that proxies for volatility in currency markets. The style factor regression methodology allowed us to decompose overall returns into beta returns that reflect exposure to the three common strategies and alpha returns that reflect excess performance. As a group, currency managers do not earn excess returns. But some managers do achieve excess returns, and many managers exhibit style persistence over time.

We conclude that adding a relatively small allocation of currency exposure to a global equity portfolio can have a meaningful impact on the portfolio's overall performance characteristics. Not surprisingly, adding currency managers who are alpha generators has a larger impact than adding currency managers who are only generating beta returns from the common currency strategies. But adding currency exposure even in the form of a naive application of the common strategies helps to enhance the overall performance of a global equity portfolio.

\footnotetext{
${ }^{14}$ Fung and Hsieh (2000) examine various biases that affect the estimate of average hedge fund returns. More recently, Aggarwal and Jorion (2010) investigate bias that resulted from the merger of the Tremont database into the TASS database. Aiken, Clifford, and Ellis (2010) measured the self-reporting bias attributable to funds that choose to report versus those that do not.
} 


\section{The Landscape of Active Currency Management}

Just as every country has its own national flag, its own national anthem, and often its own national airline and soccer team, every country (with a few exceptions) issues its own national currency. ${ }^{15}$ In tandem, the country also decides whether to control its currency's market price in some way (by pegging its price either rigidly or with some flexibility to another currency) or to allow the currency's value to be determined largely by market forces (in what is called a "floating" or "flexible" exchange rate system).

\section{The Foreign Exchange Market}

The market for currencies, commonly referred to as the foreign exchange (FX) market, plays several important roles. Most visibly, the FX market provides a medium of exchange to facilitate trade in goods and services between countries and also to facilitate the cross-border purchase and sale of securities. A contract between a U.S. citizen and an Australian to trade a million bushels of corn or a million shares of stock will, by necessity, be settled in one currency, and that currency will be foreign from the viewpoint of either the buyer or seller or both. In addition, FX transactions allow corporations and investors to redenominate and manage the currency risk in their existing or anticipated asset and liability positions. As we will explore, the FX market is one of the world's largest and most liquid financial markets.

Contracts: Spot, Swap, and Forward. Three types of contracts account for nearly all FX transactions. A spot contract is an agreement between two counterparties for an exchange of two currencies with "immediate delivery." Market practice defines "immediate delivery" as $T+2$ days, except for exchanges between North American currencies, which are usually $T+1$ day. ${ }^{16}$

Price quotations for foreign exchange follow a set of conventions that, unfortunately, are not consistent across all currency pairs. For example, the U.S. dollar price of 1 euro is usually quoted as EUR/USD1.40 (not the reciprocal, USD/EUR 0.71). The Japanese yen price of 1 U.S. dollar, however, is usually quoted as USD/JPY90.0. Although a rise in IBM's share price from USD140 to USD150 is unambiguously reported as an appreciation and a gain for IBM shareholders, a change in the EUR/USD rate from 1.40 to 1.50

\footnotetext{
${ }^{15}$ Some countries, such as the 17 members of the European Monetary Union that use the euro, have no separate national currency. In addition, Ecuador and Panama use the U.S. dollar.

${ }^{16}$ Spot contracts for same-day delivery can be arranged, usually for an extra fee. U.S. equity market transactions clear and settle on a $T+3$ business-day schedule.
} 
could be described in two ways-either an appreciation of the euro (because each euro is worth a larger number of U.S. dollars) or a depreciation of the U.S. dollar (because more dollars are required to purchase one euro). In the same vein, a decrease in the USD/JPY rate from 90.0 to 85.0 could be described as an appreciation of the yen or a depreciation of the U.S. dollar.

A foreign exchange swap entails a simultaneous borrowing and lending of short-term bank balances in two currencies. For example, consider the following transactions for an FX swap when the spot rate is GBP/USD1.50:

- Bank A borrows USD15 million from Bank B for one month, and

- Bank B borrows GBP10 million from Bank A for one month.

In this simple example, Banks A and B exchange bank balances of equal value (somewhat like a person who exchanges a USD10 bill for two USD5 bills). ${ }^{17}$ Even so, the FX swap has considerable value to both parties, usually as a means to manage their balance sheet or position risks or to construct forward contracts for clients. The price of the swap (often called the "swap points") is the interest differential between the USD interest rate that Bank A pays to Bank B and the GBP interest rate that Bank B pays to Bank A. ${ }^{18}$ FX swaps typically have short maturities-only one, two, or seven days or one, two, or three months-although longer maturities can be arranged.

A forward contract is an agreement made today for an obligatory exchange of two currencies at a specified time in the future, typically $1,2,3$, 6 , or 12 months from today. In an interbank forward contract, no exchange of funds occurs on the agreement date or at any time until the settlement date. ${ }^{19}$ Forward contracts are sometimes quoted on an outright basis similar to spot rate quotations. For example, a six-month forward euro contract could be quoted at EUR/USD1.414. If the spot rate were EUR/USD1.40, a trader could also describe the six-month quote as a $2 \%$ forward premium, meaning that the forward price of the euro is $1 \%$ higher than the spot price for sixmonth delivery, or $2 \%$ higher on an annual basis. ${ }^{20}$ As the reader will later see, the close connection between forward quotations and FX swap points corresponds to the general cost-of-carry model.

\footnotetext{
${ }^{17} \mathrm{Of}$ course, more complex FX swap examples are possible. Because the swap will be reversed at a future date, one party could require collateral or an up-front payment to enter into the swap. ${ }^{18}$ In the example, suppose Bank A borrows U.S. dollars from Bank B at $0.2 \%$ a year while Bank $\mathrm{B}$ borrows pounds from Bank $\mathrm{A}$ at $1.4 \%$ a year. The cost of borrowing the pounds is $1.2 \%$ a year higher than the cost of borrowing the dollars, which implies that Bank B would pay $0.1 \%$ to Bank $\mathrm{A}$ as the cost of the one-month swap.

${ }^{19} \mathrm{~A}$ currency futures contract traded on a centralized exchange, in contrast, would require each counterparty to post margin (a performance bond) and also be subject to mark-to-market conventions that would require more (or less) margin as market prices change.

${ }^{20}$ Strict day counting conventions apply in the FX market, so these calculations are only approximate and intended to illustrate the basic concept.
} 
Dimensions of the FX Market. By some measures, the foreign exchange market is the largest financial market in the world. The Bank for International Settlements (BIS), with the assistance of national central banks around the world, conducts a triennial survey of FX trading activity. The most recent survey, in April 2010 (see Table 1), estimated global FX trading at approximately USD3.73 trillion per day. ${ }^{21}$ This volume is more than a sixfold increase over the estimated trading volume in 1989 and more than a threefold increase over the estimated trading volume in 2001. With 250 trading days per year, USD4 trillion in FX trading per day implies roughly USD1,000 trillion in FX trading per year, or roughly 20 times annual global GDP. ${ }^{22}$ As another benchmark of market size, large trading days on the NYSE and NASDAQ total about 2 billion and 4 billion shares, respectively. At an average share price of USD30 per share, a very large trading day in U.S. equities constitutes about USD180 billion in trading, or less than 5\% as much as in the global FX market.

Table 1. Growth in Global FX Trading, 1989-2010 (USD billion per day)

\begin{tabular}{lc}
\hline Year & Amount \\
\hline 1989 & 590 \\
1992 & 820 \\
1995 & 1,190 \\
1998 & 1,490 \\
2001 & 1,200 \\
2004 & 1,880 \\
2007 & 3,210 \\
2010 & 3,730 \\
\hline
\end{tabular}

Notes: Data are for the "traditional FX market" (spot, forward, FX swaps). Data for 2010 exclude USD250 billion of currency swaps, options, and other products.

Source: Survey data based on BIS (2010).

Galati (2001) concludes that trading activity fell in 2001 because of the introduction of the euro (which eliminated cross-trading among the legacy currencies), commercial bank consolidation (which eliminated many separate trading entities), and newly introduced electronic trading platforms (which

\footnotetext{
${ }^{21}$ The estimate rises to approximately USD3.98 trillion if currency swaps, FX options, and other derivative FX products are included. The survey is careful to exclude double counting of trades that take place between banks located in two countries.

${ }^{22} \mathrm{FX}$ swaps comprise roughly $50 \%$ of currency trading. FX swaps reflect minimal currency risk (related to a counterparty credit event), so the daily volume of trading that embodies directional currency exposure may be close to USD2 trillion per day.
} 
eliminated some of the need for active trading among interbank dealers). Galati and Melvin (2004) credit the explosive growth in FX trading after 2001, however, to a variety of sources. First, as equity markets turned downward after the dot-com bubble, investors were encouraged to look at other asset classes, which helped support the notion of FX as an asset class. ${ }^{23}$ The period also witnessed substantial growth in the number of hedge funds and commodity trading advisers searching for returns. Hedge funds' reliance on currency as a return source was, in turn, aided by the creation of prime brokerage facilities at the major banks. In essence, a prime brokerage agreement with Bank X allows an institutional fund manager to trade in the FX market under the same pricing and credit terms that other counterparties would grant to Bank X. A prime brokerage agreement, therefore, gives the institutional manager entry into the full range of interbank FX products.

The 2007 BIS survey noted an increase in the level of technical trading, some of it associated with so-called algorithmic trading. About the same time, retail investors, aided by a variety of consumer-friendly web-based trading platforms, began to take on greater activity in FX. The rise in trading activity by nonbank financial institutions - such as mutual funds, money market funds, insurance firms, pensions, hedge funds, currency funds, and even central banks—is noted in the 2010 BIS survey. Trading activity among these non-FX-dealing banks has grown so much that, for the first time in the survey's history, the share of trading volume attributed to FX dealers (about 39\%) is smaller than the share attributed to other financial institutions (about 48\%), as shown in Table 2.

Other metrics in the composition of FX trading are noteworthy. In Table 3, the data show that spot FX trading declined from a roughly $60 \%$ share of total trading in 1989 to only 33\% in 2007. Over the same period, FX

Table 2. Turnover in the Global FX Market by Counterparty, 1992-2010

\begin{tabular}{llllllll}
\hline & 1992 & 1995 & 1998 & 2001 & 2004 & 2007 & 2010 \\
\hline $\begin{array}{l}\text { With reporting dealers } \\
\begin{array}{l}\text { With other financial } \\
\text { institutions }\end{array}\end{array}$ & $69.8 \%$ & $64.1 \%$ & $63.5 \%$ & $58.7 \%$ & $52.8 \%$ & $42.8 \%$ & $38.9 \%$ \\
$\begin{array}{l}\text { With nonfinancial } \\
\text { customers }\end{array}$ & 12.5 & 20.2 & 19.5 & 28.0 & 33.0 & 40.1 & 47.7 \\
\hline
\end{tabular}

Source: Survey data based on BIS (2010).

\footnotetext{
${ }^{23}$ The notion of "currency as a separate asset class" began in the late 1980s in reference to currency overlay strategies used to hedge part of the risk in international equity portfolios. The realization that the currency component of an international portfolio might be actively hedged, and profitably so, led some managers to consider offering currency management as a separate product, one in which the positions are not dependent on the implied currency positions in an equity or fixed-income portfolio.
} 
Table 3. Percentage Share of Trading in the Global FX Market by Contract Type, 1989-2010

\begin{tabular}{lcccccccc}
\hline & 1989 & 1992 & 1995 & 1998 & 2001 & 2004 & 2007 & 2010 \\
\hline Spot & $59 \%$ & $51 \%$ & $43 \%$ & $40 \%$ & $33 \%$ & $35 \%$ & $33 \%$ & $40 \%$ \\
Outright forward & 5 & 7 & 9 & 9 & 11 & 12 & 12 & 13 \\
FX swap & 36 & 42 & 48 & 51 & 56 & 53 & 56 & 47 \\
\hline
\end{tabular}

Source: Survey data based on BIS (2010).

swaps and outright forward contracts (viewed as risk management vehicles for, respectively, banks and corporations) became a progressively larger share of FX trading. The share of FX trading by currency of denomination, shown in Table 4, is more heavily centered on the U.S. dollar than many readers might expect. Nearly $85 \%$ of all currency transactions tracked in the 2010 BIS survey included the U.S. dollar as one of the two currencies in the trade. As high as this figure may seem, it has actually gradually declined from 91\% in the 2001 survey. These data are an indication of the international role of the U.S. dollar as an intermediary currency, or so-called vehicle currency, in facilitating transactions between the currencies of, for example, two small countries for which no active and liquid market operates. ${ }^{24}$

Market Structure and Trading Conventions. Although the foreign exchange market has evolved considerably over the last 20 years, some important features of the traditional, or classic, market remain in place. ${ }^{25}$ The FX market has always been and remains a geographically dispersed broker/dealer market. The interbank FX market is not housed in any city or trading floor but, instead, is composed of individuals known as dealers, traders, or market makers who work for large banks and financial institutions. FX dealers communicate and trade with one another either through brokers, who assemble price quotations from numerous other market makers and match counterparties, or through direct dealing, whereby a dealer from Bank A contacts a dealer from Bank B. Such direct dealing is done via cable, telex, telephone, or a web-based network, depending on the available technology. On the one hand, using a voice broker — or, for the last 25 years or so, an electronic broking system—allows the bank dealers to remain anonymous until the trade is agreed upon and delivery

\footnotetext{
${ }^{24}$ For example, a trade in goods or securities between Mexican and Japanese counterparties could require an exchange of Mexican pesos and Japanese yen balances. Because no active market exists for exchange between these two currencies, a trader would construct a price based on the USD/MXN and USD/JPY rates and then execute two trades to complete the exchange of MXN and JPY balances. In practice, the two trades would involve less cost, time, and risk than attempting to execute a single MXN/JPY trade.

${ }^{25}$ See King, Osler, and Rime (2011) for a detailed discussion of FX market structure and its evolution.
} 
Table 4. Percentage Share of Trading in the Global FX Market by Currency of

Denomination, 2010

\begin{tabular}{lc}
\hline Currency & Share \\
\hline USD & $84.9 \%$ \\
EUR & 39.1 \\
JPY & 19.0 \\
GBP & 12.9 \\
AUD & 7.6 \\
CHF & 6.4 \\
CAD & 5.3 \\
HKD & 2.4 \\
SEK & 2.2 \\
NZD & 1.6 \\
KRW & 1.5 \\
SGD & 1.4 \\
NOK & 1.3 \\
MXN & 1.3 \\
Others & 13.1 \\
\hline
\end{tabular}

Notes: USD = U.S. dollar, EUR = Euro member countries euro, JPY = Japanese yen, GBP = U.K. pound, AUD = Australian dollar, $\mathrm{CHF}=$ Swiss franc, $\mathrm{CAD}=$ Canadian dollar, $\mathrm{HKD}=$ Hong Kong dollar, SEK = Swedish krona, NZD = New Zealand dollar, KRW = South Korean won, SGD = Singapore dollar, NOK = Norwegian krone, $\mathrm{MXN}=$ Mexican peso. Because two currencies are involved in each transaction, the sum of the percentage shares of individual currencies totals $200 \%$ instead of $100 \%$. Source: Survey data based on BIS (2010).

and settlement information is exchanged. Direct dealing, on the other hand, puts dealers and Bank A and Bank B in direct contact with one another, which eliminates the broker's fee but exposes the dealers to the risk of revealing information about their inventory positions or their views on market conditions.

The corporate, or retail, sector of the FX market is another market segment serviced by the core interbank market. Traditionally, corporate FX transactions were executed on the basis of communication between a corporate treasury manager and a bank corporate FX trading desk. Corporate treasurers were free to shop among their relationship banks, but shopping can be time-consuming 
and costly (in terms of lost opportunities). Since 2000, newly introduced webbased platforms have given corporations the option to conduct their FX trades in a reverse-auction setting, whereby banks bid for the corporate trade. ${ }^{26}$

For equity investors, banks and custodians have typically bundled the FX trade into the execution of a foreign securities transaction. For example, when a U.S. pension fund manager buys or sells shares of Nestlé in the Swiss market, the broker or custodian handling the equity trade also handles the attendant currency transaction. ${ }^{27}$ As mentioned previously, the development of prime brokerage agreements has greatly facilitated the entry of many smaller banks, mutual funds, hedge funds, and specialized money managers into the FX market. These entities would have appeared as retail clients in the past, but they now trade on far more favorable, essentially interbank, terms.

The structure of FX trading differs in some important respects from equity market trading, especially equity trades executed on an organized exchange. As noted, the FX market is a geographically dispersed market with no centralized trading floor. Trading in the major currency pairs (EUR/USD, USD/JPY, and GBP/USD) is essentially continuous throughout the 24-hour day, although trading is more active during the time when the major trading centers (Tokyo, followed by Europe and then the United States) have their sequential normal business hours. Unlike the situation in most equity markets, no national regulatory authority oversees FX trading. ${ }^{28}$ Also, unlike equity trades funneled through an exchange, no public record is maintained of the price and volume of FX transactions as they occur through the day. The terms of a trade between Bank A and Bank B or between Bank A and its client remain private information. No ticker tape reports actual transaction prices of FX trades. Prices that are circulated via Bloomberg and other web-based systems are usually indicative only, meaning that actual transaction prices could be different. ${ }^{29}$

\footnotetext{
${ }^{26}$ Companies offering this service include Currenex, founded in 2000 and acquired by State Street Bank in 2007, FX Alliance, and FX Connect.

${ }^{27}$ Linking the equity and FX pieces of the transaction may be desirable in order to take account of timing differences in clearing and settlement between equity and FX. Litigation is now pending between several U.S. pension funds and custodian banks regarding alleged irregularities in FX trades that were bundled with equity transactions (see Dash 2009 and Dash and Lattman 2011).

${ }^{28}$ In many of the major trading centers, industry groups strive to develop guidelines for FX trading and best practices for operational risk management. The website of New York's Foreign Exchange Committee (see www.newyorkfed.org/fxc/links.html) provides further information and links to other sites.

${ }^{29}$ Some studies suggest that it is the opaque nature of the FX market that enables market makers to profit. Banks may take an incoming order to buy or sell at a small deviation from market prices and then cover their position quickly without much impact on prices (see Yao 1997 and Lyons 2001). The fact that some corporate clients and equity investors are somewhat price insensitive, because they view foreign exchange as a cost rather than their mainline business, may further support profitable market making (see Hafeez and Brehon 2010).
} 
The bilateral nature of FX transactions (e.g., Bank A trades with Bank B or Bank A trades with its client) suggests the heterogeneous nature of prices and trading risks that accompany seemingly similar trades between the same pair of currencies. Because the FX market is not centralized and many visible quotations are not necessarily indicative of future transaction prices, some heterogeneity can exist in transaction prices between Banks $\mathrm{A}$ and $\mathrm{B}$ versus prices between Banks $\mathrm{C}$ and $\mathrm{D}$ at any moment. Perhaps more importantly, because banks in this example each have a distinct credit risk, the risk profiles of the two trades (e.g., a EUR/USD trade involving Banks $\mathrm{A}$ and $\mathrm{B}$ versus a similarly sized EUR/USD trade involving Banks C and D) can also differ. In contrast, the ultimate counterparties to all trades on organized futures and option exchanges, as well as trades on U.S. equity exchanges, are anonymous to one another. This anonymous trading system functions for futures and options because their exchange clearinghouse acts as the legal counterparty to all trades and all transactions in U.S. equity exchanges pass through the Depository Trust \& Clearing Corporation, who at the end of day $T+1$ inserts the National Securities Clearing Corporation as the counterparty to all trades. ${ }^{30}$

As an example of a type of trading risk that affects FX transactions, consider a transaction whereby Bank A sells JPY80 million to Bank B in exchange for USD1 million for delivery on day T. Bank A would deliver its JPY to Bank B's account in Tokyo on the morning of day $T$. The problem is that when it is 10:00 a.m. in Tokyo, it is usually 9:00 p.m. in New York on the evening of day $T-1$, a time when New York banks are closed for business. If Bank B were unable to deliver its USD in New York 10-12 hours later (because of bankruptcy or some other reason), then Bank A would have suffered a total loss by paying out its leg of the transaction in Tokyo (the JPY) but not receiving the other leg of the transaction (the USD) in New York.

This example might seem a remote possibility, or simply extremely bad luck, but such events have occurred in the past. On the morning of 26 June 1974, various banks paid out millions of German marks (DEM) to the Herstatt Bank in Cologne, Germany. Later that day, but before it could make U.S. dollar payments to its counterparties in New York, Herstatt Bank filed for bankruptcy, thus leaving its counterparties with a total loss.

The possibility of a total loss coupled with the hard reality that banking hours around the world do not sufficiently overlap led policymakers and bankers to develop a new institution. The CLS Bank was launched in 2002 to help

\footnotetext{
${ }^{30}$ See Morris and Goldstein (2009) for an overview of clearing and settlement in U.S. equity markets.
} 
standardize and reduce the settlement risk that affects FX transactions. ${ }^{31}$ In brief, the CLS (an acronym for "continuous linked settlement") Bank operates a payment-versus-payment system for settling transactions. In our example, Bank A would transfer its JPY to the CLS Bank, which would hold them until Bank B had transferred its USD to the CLS Bank as the matching leg of the transaction. After the CLS Bank verified that both legs of the transaction had been paid in, the bank would pay out the USD and JPY balances. In the event that the CLS Bank did not receive one leg of the transaction, any funds that were received would be returned to the one performing counterparty. ${ }^{32}$

As this example of a busted trade demonstrates, the CLS Bank removes the possibility of Bank A transferring, say, JPY80 million to Tokyo and getting nothing in return. In a busted trade in which Bank A was left holding JPY80 million, however, Bank A could find that, because of changes in market prices, it required more than JPY80 million to purchase USD1 million as it originally intended. In that case, Bank B's default on its leg of the original transaction would inflict a partial loss on Bank A but not the total loss it would have suffered if it had decided to settle bilaterally rather than by using the CLS Bank. ${ }^{33}$

Surprisingly, a modern example of Herstatt risk occurred as recently as 15 September 2008. The KfW Bank in Germany had arranged for bilateral settlement of a EUR/USD transaction with Lehman Brothers as its counterparty. Without using the CLS Bank, KfW delivered approximately EUR300 million to a Lehman Brothers European bank account. When Lehman declared bankruptcy, however, it did not produce its USD leg of the transaction.

Important Parity Conditions and Pricing Principles. The exchange rate often plays a balancing, or equilibrating, role between economies. When economies are open to trade in goods and services - and to trade in financial assets-the exchange rate tilts purchases of goods and services-and

\footnotetext{
${ }^{31}$ The CLS Bank is a U.S.-based Edge Act corporation regulated and supervised by the U.S. Federal Reserve Bank. Its parent organization, CLS Group Holdings AG, is an industry-owned consortium of 71 shareholders from 22 countries. In July 2012, the CLS Bank announced it had been designated a systemically important Financial Market Utility institution by the Financial Stability Oversight Council, a body created by the Dodd-Frank Wall Street Reform and Consumer Protection Act.

${ }^{32}$ The U.S. Department of the Treasury (2011) points to a well-functioning settlement process, the fact that FX swaps and forwards require a physical exchange of currency on fixed terms set at the outset of the contract, and other factors as reasons to exempt FX swaps and forwards from the requirement in the Dodd-Frank Act for a central clearinghouse for derivative securities. The Treasury proposal was offered in April 2011 and adopted in November 2012.

${ }^{33}$ The price risk associated with default may be more important for forward contracts, in which the period between trade booking and delivery is longer and, therefore, there is more time for one counterparty to fail prior to the settlement date.
} 
purchases of bonds or risk-bearing assets—-toward one market or the other. It is useful to measure what values of the exchange rate cause this tilt to operate in one direction or the other.

Stated another way, when economies offer us alternative currencies in which goods and services can be purchased-and alternative assets that are denominated in different currencies-a set of parity conditions can be useful for understanding when conditions favor purchases or investments in one market versus the other. A parity condition is a no-arbitrage condition that specifies the value for the exchange rate between two currencies at which investors (or consumers or producers) are indifferent between transacting in the two markets.

At some times and under some conditions, parity conditions hold quite closely, and at other times and under other conditions, they do not. Either circumstance - a tendency for exchange rates to move toward their parity values or to remain out of parity - can be the basis for a currency investment strategy or rule. Whether any trading rule has the possibility to produce profits more than commensurate with risk is an important issue we take up later in this section.

We consider three parity conditions: covered interest parity, uncovered interest parity, and purchasing power parity. When short-run or long-run deviations from parity are suspected, these parity conditions can form the basis for potentially profitable currency-trading strategies.

Covered interest parity. Covered interest parity (CIP) relies on the principle that two investments exposed to the same risks must have the same expected returns. When the parity relationship holds, covered yields (i.e., yields hedged against exchange risk) are identical on assets that are similar in all important respects (e.g., maturity, default risk, exposure to capital controls, and liquidity) except for their currency of denomination.

Consider an example with two currencies, the U.S. dollar and the British pound. One-period interest rates in the two currencies are given by $i(\mathrm{USD}, 1)$ and $i(\mathrm{GBP}, 1)$, respectively, and spot and one-period-forward rates in USD/GBP are defined by $S_{t}$ and $F_{t, 1}$, respectively. On the one hand, the forward contract obligates the buyer to deliver $F_{t, 1}$ units of the USD in one period in exchange for GBP1. On the other hand, an agent could borrow $S_{t} /[1+i(\mathrm{GBP}, 1)]$ units of USD today at a cost of $i$ (USD, 1), exchange the USD for GBP in the spot market, and invest those GBP at the rate $i(\mathrm{GBP}, 1)$ for one period, which would also result in net proceeds of GBP1 one period hence. Both strategies-(1) buying one British pound at a cost $F_{t, 1}$ and (2) borrowing U.S. dollars today at a cost of $i(\mathrm{USD}, 1)$, converting the USD to GBP in the spot market, and investing those $\mathrm{GBP}$ at the rate $i(\mathrm{GBP}, 1)$-result in the same cash flows in one period. As a result, if we ignore the impact of transaction costs, taxes, and any risks associated 
with execution or default, the two alternatives must have the same price or cost. This equality of prices is summarized as follows:

$$
F_{t, 1}=S_{t} \frac{1+i(\mathrm{USD}, 1)}{1+i(\mathrm{GBP}, 1)} .
$$

Equation 1 demonstrates that, in equilibrium, the forward rate will equal the spot rate plus the interest rate differential (where the differential is expressed in ratio form, as shown in Equation 1). Equation 1 also implies that the forward rate is a redundant instrument. The cash flows of a forward contract can be fully replicated by a spot contract combined with borrowing and lending in the two currencies (what we referred to earlier as an FX swap).

It is a simple matter, but still useful, to rearrange the terms in Equation 1 to inspect the following relationships:

$$
\begin{aligned}
& 1+i(\mathrm{USD}, 1)=[1+i(\mathrm{GBP}, 1)] \frac{F_{t, 1}}{S_{t}} ; \\
& 1+i(\mathrm{GBP}, 1)=[1+i(\mathrm{USD}, 1)] \frac{S_{t}}{F_{t, 1}} .
\end{aligned}
$$

Equation 2 reveals that investing in U.S. dollars is equivalent to first converting the dollars to British pounds in the spot market, then investing the pounds at the market interest rate and covering (hedging) the currency exposure by selling principal and expected interest earnings in pounds at the forward rate, $F_{t, 1}$. Equation 3 demonstrates the analogous concept, that the yield on a GBP position is equivalent to the yield on a USD position teamed with a forward contract to hedge against exchange risk.

Equations 2 and 3 clarify that, in equilibrium, markets should establish parity (i.e., interest rate parity) between interest rates in foreign and domestic currencies. Because the replicating transaction involves covering (hedging or eliminating) foreign currency exposure, interest rate parity is also referred to as the CIP relationship.

Equations 2 and 3 also suggest that if borrowing in one market-say, U.S. dollars—is impeded, one can compensate by borrowing in another-say, British pounds - and simultaneously entering into offsetting spot and forward currency contracts. Or if investing in pounds seems subject to unusual costs or risks, one can create a synthetic GBP position by investing in a USD security and simultaneously entering into offsetting spot and forward currency contracts. Creating synthetic positions is straightforward, and they can produce considerable value when financial markets are constrained or under stress. Precisely at these times, investors may willingly choose a synthetic position that yields less or borrowers may choose a synthetic that costs more in order to overcome a market dislocation. 
Taking Equation 1 and subtracting 1.0 from both the left and right sides produces

$$
\frac{F_{t, 1}-S_{t}}{S_{t}}=\frac{i(\mathrm{USD}, 1)-i(\mathrm{GBP}, 1)}{1+i(\mathrm{GBP}, 1)},
$$

which shows that the percentage forward premium is (approximately) equal to the interest differential. In equilibrium, the currency with the higher interest rate should trade at a forward discount to reflect the fact that a lower return is available in the second currency. ${ }^{34}$

The CIP equilibrium condition described in Equations 1-4 is facilitated by arbitrage. In Equation 1, if $F_{t, 1}$ were less than the synthetic price given by $S_{t}[1+i(\mathrm{USD}, 1)] /[1+i(\mathrm{GBP}, 1)]$, arbitrageurs would buy the forward contract and sell the synthetic, helping to restore a balance. "Selling the synthetic" GBP forward would entail borrowing GBP, buying USD in the spot market, and investing in USD for one period. In Equation 2, if USD interest rates exceeded GBP rates on a covered basis, arbitrageurs would borrow in GBP, hedge themselves with spot and forward contracts, and lend the synthetic USD at a higher rate. At the margin, arbitrage purchases tend to raise prices (of currency and money market instruments) whereas sales tend to lower prices (of currency and money market instruments) and thus tend to reduce any measured deviations from parity. Arbitrage transactions, however, entail costs (in currency markets and money markets) and risks (of default on investment positions or forward contracts or of possible controls on capital movements). These costs and risks limit the amount of arbitrage and retard the speed of, or even preclude, the convergence of rates toward parity.

Many empirical studies have attempted to measure the costs and risks associated with covered interest arbitrage in order to gauge how efficient the market is at eliminating low-risk covered interest differentials. ${ }^{35}$ Overall, throughout most of the floating exchange rate period until the recent global financial crisis, the empirical evidence shows that, when based on short-term offshore interest rates for the currencies of major developed countries, deviations from CIP

\footnotetext{
${ }^{34}$ For example, given $S=\mathrm{USD} 1.50 / \mathrm{GBP}, i(\mathrm{USD})=4 \%$, and $i(\mathrm{GBP})=8 \%$, we expect $F_{t, 1}=$ USD1.444/GBP, where $F_{t, 1}$ is the forward rate today for delivery one period hence (one year hence because interest rates are stated in annualized terms). The British pound has the higher interest rate, and it is at a discount (i.e., cheaper) in the forward market.

${ }^{35}$ See Levich (forthcoming 2013) for a review of the literature on interest rate parity and covered interest arbitrage.
} 
have tended to be quite small- and smaller than the cost of conducting arbitrage. ${ }^{36}$ Thus, during normal market conditions, Equation 1 offers a good guide to the way forward currency prices are likely to be set as a function of the spot exchange rate and short-term offshore money market interest rates.

Deviations from CIP provide a useful guide to conditions in the foreign exchange market. Figure 1 shows three-month CIP deviations for the EUR/ USD daily rate from the beginning of 2000 until the end of September 2010. The period through July 2007 appears tranquil, with essentially all deviations less than 25 bps away from parity and upward of $95 \%$ of all deviations less than 10 bps away from parity. This period strongly conveys the notion of a highly liquid market with virtually perfect capital mobility between short-term EUR and USD instruments. By the summer of 2007, however, after the bank Northern Rock had been nationalized by the Bank of England and Bear Stearns had been sold to JPMorgan Chase, deviations from CIP increased to the 40-50 bp range.

Figure 1. Deviations from CIP in the EUR/USD Relationship, 1 January 2000-30 September 2010

(three-month maturity, daily data)

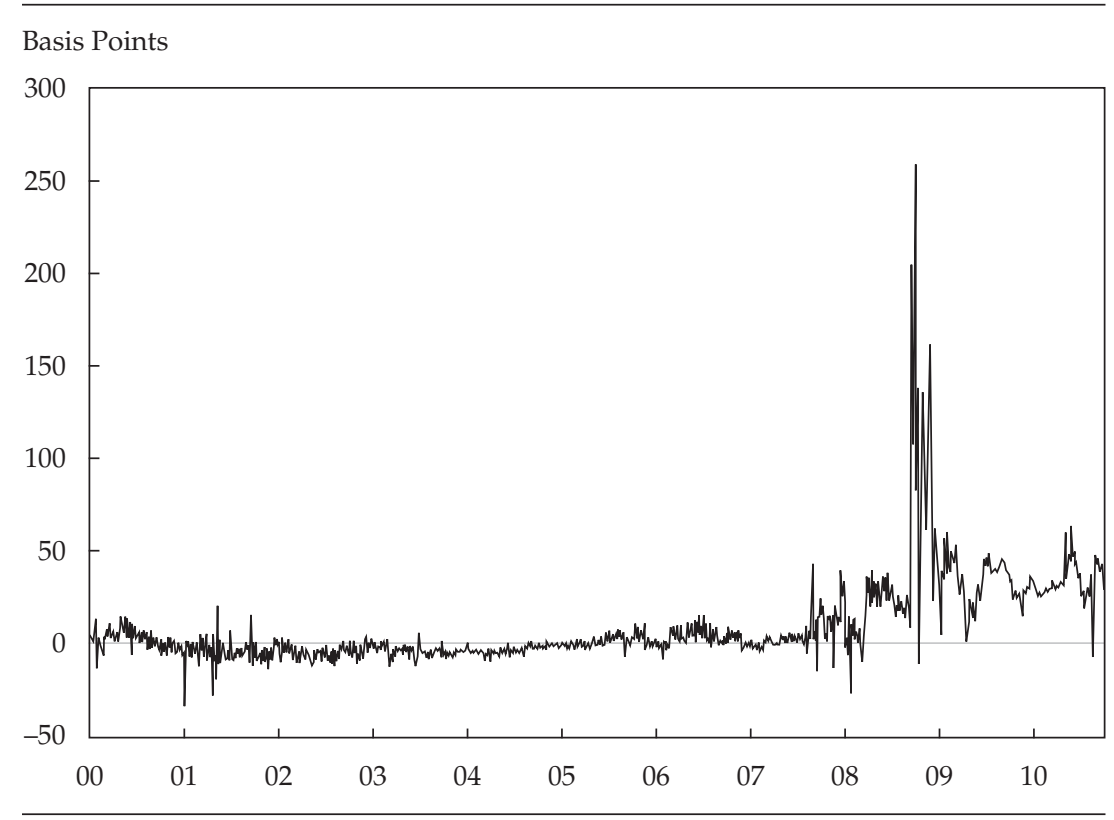

Sources: Bloomberg and author calculations.

\footnotetext{
${ }^{36}$ In this context, "offshore" refers to transactions entered into under a regulatory regime different from the regulations applied to deposits used to execute domestic transactions. For example, USD deposits in London and GBP deposits in Singapore are considered offshore deposits. Many countries have established so-called international banking facilities that create an offshore banking environment located physically within domestic borders but open only to nonresidents.
} 
After Lehman Brothers failed on 15 September 2008, deviations from CIP in the market's most liquid currency pairing spiked to more than 200 bps and, for the most part, remained above 100 bps for the next three months. Even though CIP deviations had subsided to the 25-50 bp range by spring 2009 , this range is clearly far higher than in the tranquil period of nearly perfect capital mobility in the first few years of the millennium.

Studies by Baba and Packer (2009) and Coffey, Hrung, and Sarkar (2009) find that the combination of funding shortages in the U.S. financial markets and a heightened sense of counterparty risk even among large banks active in the FX market led to deterioration in liquidity and the observed deviations from CIP in the USD/EUR pair. During the crisis period, banks outside the United States had particular difficulty accessing USD facilities through their traditional U.S. commercial bank counterparties (who were subject to heightened default risk). To meet their various USD funding obligations, these banks turned to the synthetic approach suggested by Equation 2. By borrowing in their home currencies, perhaps through access to the home central bank, and then executing an FX swap, non-U.S. banks could synthetically create a USD position-but only at a premium to a direct position in USD. The synthetic approach explains one policy response to this aspect of the global financial crisis.

In the spring of 2009, the U.S. Federal Reserve, together with other central banks, opened up substantial official swap facilities. These official swaps increased the supply of U.S. dollars offshore, and non-U.S. banks could access U.S. dollars through their home central banks rather than their commercial bank counterparties. Despite these policy initiatives, Figure 1 suggests that deviations from CIP are experiencing a "new normal" in 2012, with deviations in the range of 25-50 bps for the EUR/USD pair (instead of the 10-25 bps observed a decade previously).

Uncovered interest parity. Uncovered interest parity (UIP) considers the breakeven relationship between an investor facing a domestic currency return of $i(\mathrm{USD}, 1)$ and a foreign currency-denominated return of $i(\mathrm{GBP}, 1)$ when the future spot exchange rate, $\tilde{S}_{t+1}$, is unknown:

$$
1+i(\mathrm{USD}, 1)=[1+i(\mathrm{GBP}, 1)] \frac{E\left(\tilde{S}_{t+1}\right)}{S_{t}},
$$

where $E\left(\tilde{S}_{t+1}\right)$ is the expectation of the future spot rate. The situation appears similar mathematically to the CIP example just discussed, but there are some crucial economic differences. Because the investor has not used a forward contract to hedge the foreign currency investment, the USD value of the investment at time $t+1$ is not known with certainty. In Equation 5, the expectation of the future spot rate is used to estimate the USD value of the GBP investment. 
Consider these numerical examples. Suppose investors expect the British pound to depreciate by $1 \%$ over the next period-from, say, USD1.5000/GBP to USD1.4850/GBP. For UIP to hold, the one-period interest rate on the GBP needs to be $1 \%$ higher than the USD interest rate for the investor to be indifferent, on an expected value basis, between these USD and GBP investments. But suppose the expectation is for the British pound to appreciate by $2 \%$ over the next period-from, say, USD1.5000/GBP to USD1.5300/GBP. In that case, UIP would require that the one-period GBP interest rate be $2 \%$ lower than the one-period USD interest rate.

The logic of UIP is straightforward and compelling. Investors typically require a high interest rate to compensate for a currency that is expected to lose value (i.e., depreciate) over a holding period, and investors are willing to accept a low interest rate when a currency is expected to gain value (i.e., appreciate) versus their benchmark alternative.

The logic of UIP is analogous to situations in equity and fixed-income markets. In the case of equity, consider two companies that are identical and, therefore, have the same expected return over time but Company A pays a higher dividend than Company B. In that case, we would expect the price of the shares of Company B to appreciate more over time to reflect the lower dividend (and higher retained earnings) of Company B. In equilibrium, the difference between the dividend yields on the two firms would exactly offset the greater price appreciation of $B$ shares versus that of $A$ shares.

In fixed income, consider a case of the bonds of Company A having greater risk and a higher yield to maturity than bonds issued by Company B. Under a pure expectations pricing model, the expected return on bonds from $\mathrm{A}$ and $\mathrm{B}$ would be identical if the higher prospect of default (and percentage loss in case of default) on Company A bonds versus those of Company B matched the yield differential between the bonds. Note that in both cases, the higher dividend for the equity in Company $\mathrm{A}$ and the higher quoted yield to maturity on Company A bonds are not signals of a free lunch. They are, instead, indicators that the market expects less performance of the stock price of Company $\mathrm{A}$ and a lower chance of a full return on principal on the bonds issued by Company A. In the same way, according to UIP, a higher interest rate on Currency A relative to Currency B reflects the market's expectation that Currency A is likely to depreciate relative to Currency B so as to offset the interest differential.

Rearranging Equation 5 and subtracting 1.0 from both the left and right sides results in

$$
\frac{E\left(\tilde{S}_{t, 1}\right)-S_{t}}{S_{t}}=\frac{i(\mathrm{USD}, 1)-i(\mathrm{GBP}, 1)}{1+i(\mathrm{GBP}, 1)} .
$$


Because the right-side terms of Equations 4 and 6 are identical, these equations imply that the forward premium equals the expected exchange rate change or that the forward rate itself is an unbiased estimate of the future expected spot rate: $F_{t, 1}=E\left(\tilde{S}_{t, 1}\right)$.

Extensive empirical evidence, sometimes presented under the guise of testing the forward rate unbiased proposition, rejects UIP. The empirical tests are often based on regressions of the actual change in the exchange rate over a short interval, such as one or three months, against the interest rate differential over a matching time interval, as in the following:

$$
\Delta S_{t, t+k}=\alpha+\beta\left[i_{t}(\mathrm{USD}, k)-i_{t}(\mathrm{GBP}, k)\right]+\varepsilon_{t},
$$

where $\Delta S_{t, t+k}$ represents the exchange rate change over the interval $(t, t+k)$.

Equation 7 shows the interest rate differential as the independent variable in the regression, but some studies substitute the forward exchange rate premium. If UIP or the forward rate unbiased proposition are true characterizations of market prices, we would expect to find that $\alpha=0$ and $\beta=1$ and that a high $R^{2}$ statistic measures the overall fit of the regression. The data overwhelmingly reject this result, however, for short-term maturities (maturities of less than one year).

Froot and Thaler (1990) surveyed 75 published studies of UIP and conclude that the average $\beta$ was -0.88 rather than 1.0. In other words, the data support the notion that, contrary to UIP, currencies with high short-term interest rates tend to appreciate rather than depreciate. Surveys of the forward rate unbiased literature by Hodrick (1987) and Engel (1996) reach a similar conclusion-namely, that the $\beta$ coefficient in regressions such as Equation 7 are almost always negative. These findings not only reject UIP and the forward rate unbiased proposition, but they also suggest that a carry trade strategy based on borrowing the low-interest-rate currency and investing in the highinterest-rate currency could be profitable, albeit subject to risk.

Two further strands of research on UIP remain active. One is whether UIP also has a tendency to fail when longer maturity instruments are studied. Pursuing this line of investigation is difficult because few countries have long time series-5-year-maturity and 10-year-maturity bonds. Moreover, other empirical issues, such as coupon-paying bonds and overlapping sample periods, present many challenges. Chinn and Meredith (2004) find that the data are more supportive of UIP at longer horizons. The $\beta$ coefficients tend to be positive and closer to 1.0 than to zero for the interest differential based on 5 -year and 10-year government bonds.

The second empirical issue is whether the generally high returns associated with the carry trade represent (1) compensation for exposure to risk or (2) an excess return (pure profit) resulting from a market inefficiency. Brunnermeier, Nagel, and Pedersen (2009) show that returns on carry trades are negatively skewed and subject to a "crash risk" - that is, a sudden drying up of liquidity 
when large numbers of speculators try to exit the trade. Lustig, Roussanov, and Verdelhan (2010) suggest that carry trade returns represent compensation to U.S. investors who are exposed to various risks, such as an upward spike in the U.S. business cycle that would raise U.S. rates and draw capital back from overseas. Menkhoff, Sarno, Schmeling, and Schrimpf (2012a) posit that exposure to spikes in FX volatility could drive investors back toward safer, lowinterest-rate currencies and threaten carry trade profits.

Burnside (2011), however, concludes that these risk measures are insufficient to explain the time variation in carry trade returns and suggests that old-fashioned "peso problems"-meaning the large probability of small gains (from the interest differential) and the small probability of a large loss (from a substantial exchange rate depreciation) - might help explain carry trade returns. In this interpretation, carry traders might be seen as picking up nickels (the small interest differential) in front of a steamroller (the small chance of a substantial depreciation). Despite these caveats (that carry trade returns could be a form of compensation for risk incurred), many currency market professionals point out that other, favorable market metrics (e.g., high Sharpe ratios and low correlations with many other investment strategies) make carry trading a popular investment strategy despite the risk.

Purchasing power parity. Purchasing power parity (PPP) is a staple in the toolkit of every international financial strategist and currency economist. Although prices of individual goods may differ considerably among countries, PPP relies on the tendency of exchange rate movements to reflect the difference in rates of inflation across countries, as summarized in the following expression:

$$
\Delta S_{t, t+k}=p(h, k)-p(f, k),
$$

where $p(h, k)$ and $p(f, k)$ represent the rate of inflation in the home and foreign countries, respectively, over the period $t$ through $t+k$ and $S$ is the home currency price of foreign currency. The economic logic of Equation 8, the socalled relative version of PPP, is simple and straightforward. Suppose that the price of foreign goods, $S P_{f}$, is unusually high relative to the price of domestic goods, $P_{b}$. To get this ratio back to a more "normal" level, either $S P_{f}$ needs to decline or $P_{b}$ needs to rise, or both. (In practice, prices of local goods tend to be sticky whereas the exchange rate is highly flexible.) A decline in $S$ is equivalent to a depreciation of foreign currency. The logic is symmetrical when the price of foreign goods is unusually low relative to domestic goods. To get the ratio back to a more normal level, either $S P_{f}$ needs to rise or $P_{b}$ needs to fall, 
or both. A rise in $S$ is equivalent to an appreciation of foreign currency. ${ }^{37}$ The same point stated somewhat differently is that over a sufficiently long period, countries with high (low) inflation relative to their trading partners tend to experience currency depreciation (appreciation). PPP describes an equilibrium relationship between goods prices and exchange rates with no implications about causality.

To make relative PPP operational, two things are needed. The first is a benchmark for the "normal" relationship between home and foreign prices. Various international agencies, such as the Organisation for Economic Co-operation and Development (OECD) and the International Monetary Fund, as well as many private banks and financial institutions, compute PPP indices for most countries. These indices typically take a multilateral perspective-calculating the weighted average of a country's PPP rates against a broad group of trading partners- to develop an overall PPP index for each country. The design of these alternative indices may vary (e.g., as to what date or range of dates is taken as a benchmark or in the selection and weighting of goods included in the price index, the weights assigned to trading partners, and how frequently the indices are rebased in light of changes in local consumption or trade patterns), but for the most part, alternative measures of PPP for a single country are highly correlated (see Isard, Faruqee, Kincaid, and Fetherston 2001).

The second requirement is to give operational meaning to the "tendency" for exchange rates and prices to satisfy the condition in Equation 8. Empirical evidence shows that the contemporaneous relationship between relative price changes and exchange rate changes is weak at best. The EUR/USD exchange rate could change by $0.5-1.0 \%$ in a day, or $5-10 \%$ or more in a year, even though the differential between U.S. and eurozone inflation is nowhere close to the exchange rate change over the same time period. When we examine the movement deviations from PPP over a long period of time, however, the tendency for PPP to reassert itself, a property referred to as "mean reversion," becomes more evident.

To illustrate mean reversion, Figure 2 shows a plot of the spot EUR/USD rate versus its PPP value (a ratio also referred to as the "real exchange rate") over a period of nearly 40 years. Values above the PPP line correspond to

\footnotetext{
${ }^{37}$ Note that the idea of a so-called normal relationship between the price of home and foreign goods need not imply that the prices of each good, or even all goods on average, are identical across countries. For example, in the Economist magazine survey of $\mathrm{McD}$ onald's Big Mac prices, the price of a Big Mac stated in U.S. dollar terms is often higher in such countries as Switzerland and Sweden and lower in such countries as China and the Philippines compared with the price in the United States. The price differences may reflect many factors, such as land and labor costs, market competition among restaurants, and the target income levels of prospective customers. Once these relatively sticky factors are accounted for, relative prices of Big Macs in various countries show a tendency to oscillate around a historical normal ratio (see Cumby 1996 and articles referenced in Clements, Lan, and Seah 2012). The Economist article is focused on Big Mac prices because it is a relatively homogeneous good and most people are familiar with it.
} 
Figure 2. Cumulative Deviations from Relative PPP: Germany and the United States, 1973-2011

(153 quarters)

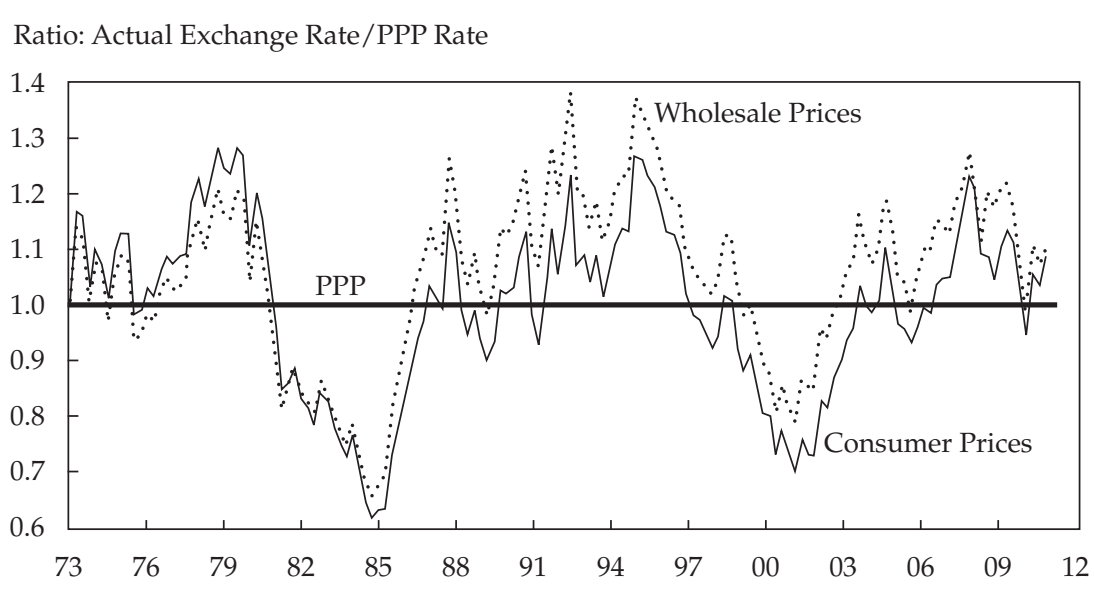

Note: The calculation uses the German mark until the introduction of the euro in 1999.

times when the German mark (later, euro) is overvalued and the U.S. dollar is undervalued, while below the PPP line, the situation is reversed. The real exchange rate based on consumer prices crosses the PPP line about 20 times in 38 years, indicating a return to PPP. The graph also suggests that large deviations from PPP can be reversed more quickly and by larger changes compared with small deviations from PPP. While the figure shows a visible tendency for PPP to be restored periodically, it also shows the risk that large deviations can get larger, rather than smaller.

Figure 3 offers another way to visualize the tendency for exchange rates to gravitate back toward PPP over the longer run. Figure 3 shows the combination of spot exchange rate changes versus the U.S. dollar and the corresponding consumer price changes for the 21 OECD member countries for a 32-year period. When PPP holds and the exchange rate change for a currency matches the difference in relative price movements between that country and the United States, the data points plot along the $45^{\circ}$ line (i.e., the PPP line). In Panel A, the 672 dots (representing 32 yearly observations for 21 countries) are scattered widely about the line. In Panel B, representing 8-year intervals (84 points), and Panel C, 16-year intervals (42 points), the tendency for spot rate changes and relative price movements to gravitate back toward the PPP line is more apparent than in Panel A. And in Panel D, representing the entire 32-year interval (with only the 21 points), the correspondence between spot rate changes and relative price movements is emphatic. The message is that 
Figure 3. Exchange Rate Changes vs. Inflation Differentials for Different Time Intervals, 1974-2006

\section{A. 1-Year Intervals}

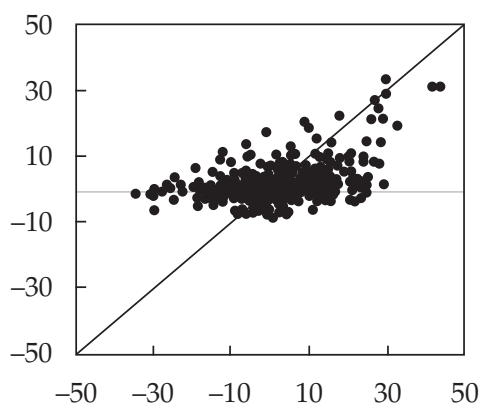

C. 16-Year Intervals

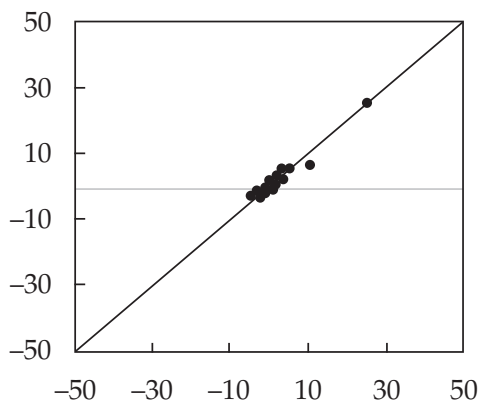

B. 8-Year Interoals

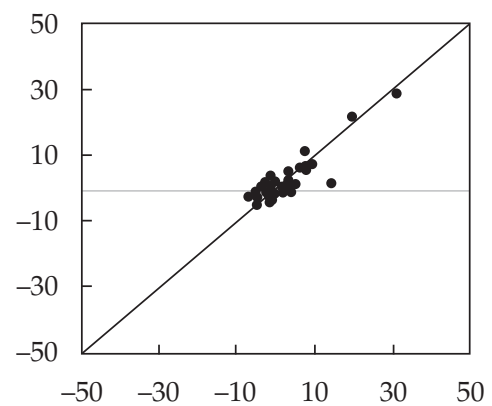

D. 32-Year Intervals

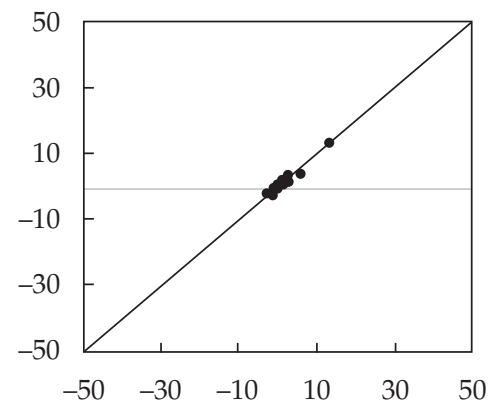

Notes: The plots were constructed from annual average data on the nominal exchange rates of 21 industrial countries' currencies versus the U.S. dollar, together with corresponding ratios of consumer price indices. Panel A plots 672 one-year changes (32 for each country); Panel B plots 84 non-overlapping eight-year changes (at annual rates) corresponding to the periods 1974-1982, 1982-1990, 1990-1998, 1998-2006, and so forth. The $x$ axes show changes in exchange rates; the $y$ axes, changes in CPIs (relative to the U.S. CPI).

Sources: Isard (2007, p.7); based on Flood and Taylor (1996).

over time, both positive and negative deviations from PPP tend to fade out for these OECD countries, who (and this point is important) share similar income levels and have experienced sustained open trading relationships.

A number of rigorous economic studies have documented that the tendency for deviations from PPP to fade out over time is statistically significant. Estimates by Abuaf and Jorion (1990) place the half-life of deviations (i.e., the time needed to shrink a deviation of $\mathrm{X} \%$ by one-half) at three to 
five years. Estimates by Flood and Taylor (1996) and Isard et al. (2001) suggest a shorter half-life, as do researchers in more recent studies, such as Imbs, Mumtaz, Ravn, and Rey (2005).

Statistically significant support also exists for the notion that the larger the deviation from PPP, the greater the speed of adjustment toward PPP. ${ }^{38}$ In other words, when deviations are small, importers and exporters can achieve only a small benefit by changing their shopping patterns or business plans to take advantage of small international price discrepancies. The potential benefit shrinks even more if one considers that any benefit could be wiped out once the extra costs of international trade, the time for contracting, and uncertainty in future price movements are taken into account. When deviations from PPP are large, however, the incentives for importers and exporters to act increase, as do the incentives for government officials to react with policy changes that could directly or indirectly reduce the adverse incentives associated with deviations from PPP.

The tendency for PPP to hold over the long run leads immediately to a value-oriented trading strategy predicated on mean reversion: Buy undervalued currencies or sell overvalued currencies. Given the nature of FX markets, where buying one currency requires shorting another, a natural value strategy in FX would be to sell overvalued currencies and use the proceeds to purchase undervalued currencies.

As compelling as the evidence just reviewed may seem, however, significant caveats must be noted for investment strategies based on PPP. First, as in the case of equities, price dynamics may lead an overvalued (or undervalued) currency to become even more overvalued (or undervalued) in the short to medium run. More fundamentally, the notion of mean reversion about a relatively stable real exchange rate assumes that no permanent real economic shocks will hit one country that do not also hit the country's trading partners equally. Just as such real economic factors as real wages, real income, and real productivity may vary over time, however (in many instances drifting upwards), so too can real exchange rates vary because real economic disturbances affect countries differently. An economic principle known as the Balassa-Samuelson hypothesis predicts that the countries that have experienced high productivity gains and higher real income growth are likely to have appreciating currencies. For countries in this category, deviations from PPP measured against an old benchmark would not disappear over time. Rather, the real exchange rate

\footnotetext{
${ }^{38}$ See Taylor and Peel (2000) for an empirical study of USD/GBP and USD/DEM rates over the 1973-96 period. Their study supports the notion of nonlinear adjustment toward PPPthat is, a faster adjustment when deviations are large and slower when deviations are small. Norman (2010) updates these results and offers evidence that with nonlinear adjustment, the half-life of PPP deviations may be shorter than the three- to five-year consensus estimate held by some economists.
} 
would evolve toward some new level, and only when the impact of the real shock had subsided would the real exchange rate level off and provide a new benchmark for the future.

East European countries that have moved from socialist or communist systems toward free market, capitalist systems are the classic modern examples of this phenomenon. Figure $\mathbf{4}$ contains charts of the real exchange rates for the Czech Republic, Poland, Hungary, and Russia. These four countries have gradually shifted their economies toward greater economic flexibility, which, in general, has led to higher labor productivity, higher real wages, higher real incomes, and higher real exchange rates - as one would have predicted from the Balassa-Samuelson theory. We offer no formal statistical analysis, but the visual impression from these charts is of four real exchange rates that generally have drifted upward over the past 20 years. Some analysts may see Poland gravitating toward the real exchange rate reached around the start of the century and, perhaps, a slowing of real appreciation for Hungary over the last five

Figure 4. Real Effective Exchange Rates for Four East European Countries, 1993-2011

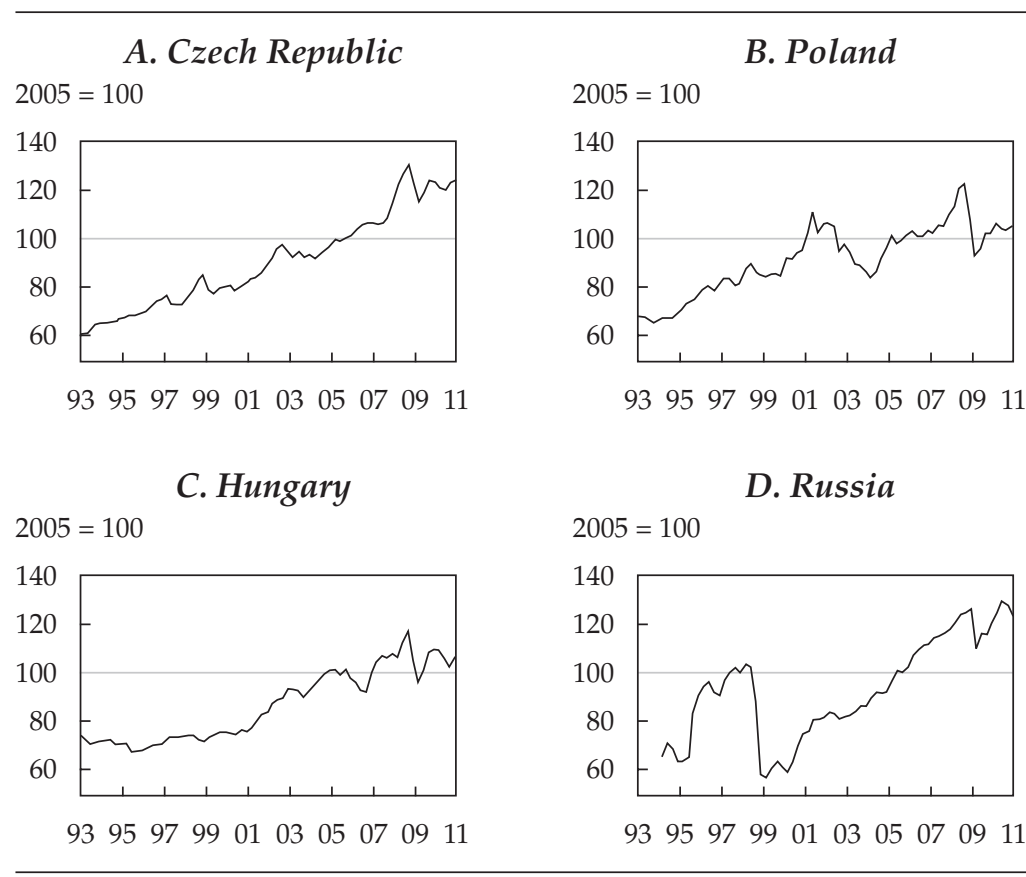

Note: Data are from International Financial Statistics, IMF, code RECZF. 
years. Nevertheless, Figure 4 raises a cautionary flag when relying on PPP to assess over- or undervaluation for emerging market countries in the throes of economic liberalization. ${ }^{39}$

Each of the parity conditions (CIP, UIP, and PPP) lead naturally to a currency-trading strategy, which we discuss further in the last section of this chapter. The next section discusses the characteristics of the currency investment mandate.

\section{The Currency Management Mandate}

The landscape of active currency management has changed dramatically over the last 25 years. $^{40}$ In the 1980s, although a small number of professionals engaged in speculative currency trading, an investment manager acquired currency exposure primarily as a by-product of investing in foreign currencydenominated stocks or bonds. In a 1991 Financial Times article on the growing appeal of overseas assets for U.K. fund managers, Dickson notes the following:

Since 1987 overseas bonds have also begun to attract interest-accounting for 2 per cent of average assets by the end of 1989. In the view of many observers—-though by no means all-they are set to become a permanent asset class in their own right in the 1990s. (Dickson 1991, p. IV)

Not surprisingly, a few boutique firms that specialized in currency viewed things differently. In a 1988 article in Pensions and Investment Age addressing the issue of whether foreign currency holdings ought to be hedged, Givant notes:

Some [pension executives] also might overlay currency management onto existing international portfolios, thereby treating currency as a separate asset class. (Givant 1988, p. 2; italics added)

The realization that the currency component of an international portfolio might be actively hedged, and profitably so, led some managers to consider offering currency management as a separate product. Freeman, in a 1989 Financial Times article, puts it this way:

Fund managers can engage in more active hedging programmes on a tactical basis, but this is where the line between genuine hedging and active currency management becomes blurred. For example, many fund managers which accumulated a good in-house track record in hedging decided a few years

\footnotetext{
${ }^{39}$ Although this caveat may undermine recommending a PPP strategy for emerging market countries, it could support a carry trading strategy. For example, when EM interest rates exceed rates in developed country markets, some of the differential may be the result of a real interest rate differential that supports capital flows into the emerging market and an appreciation of the EM currency.

${ }^{40}$ This section draws substantially on Levich and Pojarliev (2012).
} 
ago to develop their experience and launch managed currency funds, which concentrate entirely on forecasting exchange rate movements. (Freeman 1989, p. VI; italics added)

A LexisNexis search of newspapers and periodicals for the keywords "currency" and "asset class" used in the same article results in only a handful of articles each year in the years prior to $1990 .{ }^{41}$ By 2007 , the annual number of mentions for this pair of keywords exceeds 1,100. Although not all of these articles refer to currency as an asset class, the notion of taking currency formally into account and having it separately managed by a currency professional has become part of the international investment manager's and plan sponsor's basic toolkit.

Each agreement between an institutional investor and its currency manager is unique. For discussion purposes, however, it is useful to consider, first, the types of mandates that are in common use and their key features and, second, other structural and operational choices that differentiate mandates. By varying these contractual parameters, institutional investors influence their expected alpha (what we call the "alpha continuum") and their exposure to risk.

Features of a Currency Mandate. There are two basic types of currency mandates. In an absolute return mandate, the investor seeks to earn a positive return, usually in excess of some benchmark and subject to acceptable risk levels. With a currency overlay mandate, the investor already owns a portfolio of foreign debt or equity and the objective is either to entirely eliminate currency risk from the portfolio or partially reduce currency risk while opportunistically going after return. ${ }^{42}$

In both absolute return and currency overlay mandates, the agreement specifies how much latitude the manager has to operate, identifies provisions that constrain the manager, and of course, spells out how the manager's performance will be determined as well as the formula for setting compensation. The main considerations stipulated in a currency mandate will include the following:

Passive vs. active management. A passive manager is constrained to simply track a predefined benchmark and does not seek to generate excess returns. Because most benchmarks are constructed on the basis of a clearly defined investment rule, a passive manager simply executes the trading rule to

\footnotetext{
${ }^{41}$ For the period 1975 until 1982, we find no articles including mentions of both "currency" and "asset class." The first mention in a single article appears in 1983.

${ }^{42}$ Hedging within a currency overlay strategy often takes the fairly simple objective of establishing a predictable home currency value for assets denominated in a foreign currency. For example, consider a U.S. plan sponsor whose financial statements and returns are prepared in U.S. dollars. If the plan sponsor owns shares in Volkswagen valued at EUR100, selling 100 euros for U.S. dollars establishes a known USD value for the foreign assets. The hedge will probably be imperfect because the euro share price of Volkswagen itself will probably be sensitive to the EUR/USD exchange rate. The size of the hedge also needs to be adjusted, over time, for fluctuations in the euro share price of Volkswagen.
} 
track the benchmark. ${ }^{43}$ For example, if the AFX Currency Management Index (based on three moving-average trading rules and seven currency pairs) is used as a benchmark, a passive manager can use those same moving-average rules and currency pairs to govern trading. ${ }^{44}$ For an absolute return mandate, trading designed to mimic benchmarks based on carry trading, trend following, value trading, or volatility are all examples of passive strategies ${ }^{45}$ For a currency overlay mandate, always fully hedging the currency position in a fixedincome portfolio or always hedging $50 \%$ of the foreign currency value of the position are typical examples of passive strategies.

An active manager, however, has discretion to implement a variety of trades based on different ideas. For an absolute return mandate, the active manager seeks to add value beyond the return of the benchmark and to do so by entering into positions that deviate from those in the benchmark. For example, an active currency overlay manager who believes that foreign currency has a strong chance of appreciating might, in an attempt to add extra return, hedge only $25 \%$ of the foreign currency exposure in a fixed-income portfolio instead of $100 \%$. Whether operating under an absolute return or currency overlay mandate, an active manager might adopt a systematic or rule-based investment process, a discretionary investment process, or a combination of the two.

Allowed currencies. A currency mandate agreement will typically constrain the manager to operate within a set menu of currencies, perhaps restricted to the $\mathrm{G}-3$ or $\mathrm{G}-10$ currencies, where financial markets offer greatest depth, or emerging market currencies, where markets are less liquid but where greater profit opportunities may be present. ${ }^{46} \mathrm{~A}$ wider range of currencies may be more valuable in the case of an absolute return mandate, although some managers may prefer to limit themselves to only those currency pairs

\footnotetext{
${ }^{43}$ Some market professionals have taken issue with this definition. Melvin and Shand (2011) note that tracking any currency trading index involves some degree of active management because positions must be bought and sold as underlying market conditions change.

${ }^{44}$ The AFX Currency Management Index is based on trading in seven currency pairs weighted by their volume of turnover in the spot market, with returns for each pair based on an equally weighted portfolio of three moving-average rules (32, 61, and 117 days). The seven currency pairs are EUR/USD, USD/JPY, USD/CHF, GBP/USD, EUR/JPY, EUR/GBP, and EUR/CHF. More information about the index is available at http://web.archive.org/web/20100527043718/ http://www.ljmu.ac.uk/LBS/102316.htm.

${ }^{45}$ Passive absolute return mandates are still rather rare. Most absolute return mandates are characterized as active.

${ }^{46}$ The G-3 is an unofficial designation for the world's three largest developed economies: the United States, the European Union, and Japan. In this context, the G-10 refers to 10 actively traded currencies: the USD, EUR, JPY, GBP, AUD, CHF, CAD, SEK, NZD, and NOK (see Table 4 for correspondence between currency symbols and countries) and not the countries in the official Group of Ten (see https://www.imf.org/external/np/exr/facts/groups.htm\#G10).
} 
in which they have the greatest expertise. In a currency overlay, the allowed currencies are often, although not always, limited to those currencies in the underlying portfolio; at times, cross-hedging can be a useful tool.

Permitted instruments. A currency mandate agreement may also specify which instruments the manager is permitted to use. The manager may be constrained to trade spot and forward contracts only, or the manager may be allowed discretion to use plain-vanilla currency options or other derivative instruments, such as exotic currency options (e.g., barrier or basket options). In the case of a currency overlay agreement, derivatives may offer an efficient way of hedging particular risks in the underlying portfolio. Derivatives also provide a way to make asymmetrical trades that leave the underlying portfolio unharmed if the currency moves in one direction but allow the manager to benefit if the currency moves in a way that the manager has forecast. In the case of an absolute return mandate, derivative instruments are often a more efficient way to obtain leverage, so whether or not they are permitted may be linked to how much leverage is allowed by the mandate.

Leverage. The degree of leverage allowed is an important consideration for absolute return mandate agreements and also for currency overlays that have some return-seeking objective. A manager could be constrained to use leverage or allowed discretion to vary leverage up to some limit, depending on market conditions. For an absolute return mandate, leverage up to a factor of 10 is typical, but greater leverage is feasible and sometimes observed in hedge funds or managed trading accounts. Rather than specify leverage, a currency mandate could specify target volatility, expected return, or worst permitted drawdown.

Performance benchmark and compensation. Last but certainly not least, a currency mandate will specify how performance will be measured, how it will be compared with that of a passive benchmark, and how outperformance will be compensated. For an absolute return mandate, when a manager is given trading authority over a pool of funds, the benchmark for performance of those funds could be LIBID (the London Interbank Bid Rate), LIBID $+x$, or some other index denominated in the investor's base currency. Investing the assigned assets at LIBID is essentially risk free, whereas benchmarks greater than LIBID entail risk. When the manager receives only a line of credit against funds that are invested elsewhere, then the benchmark for performance can be zero, an amount $x$ that is greater than zero, or another measure of performance. A manager who never draws on the credit line, and never takes a currency position, will earn zero return and incur zero risk. Active use of the credit line in the pursuit of positive returns entails risk. Performance benchmarks for a currency overlay manager are usually designed to reflect the returns from a continuum of hedging choices - from no hedging through continuous hedging of the entire 
underlying position. The returns from a strategy of a continuous $50 \%$ hedge are often taken as a naive benchmark for a currency overlay manager. We discuss the economic rationale for these benchmarks in Chapter 3.

Manager compensation itself often has several parameters, including, almost always, an annual management fee (a "flat" fee) and a performance incentive fee based on annual returns. ${ }^{47}$ For high-net-worth individuals and funds of funds that invest in currency hedge funds, the most common fee structure is a $2 \%$ a year management fee (based on assets under management $[A U M])^{48}$ and $20 \%$ share of profits earned over the year. Institutional clients are likely to negotiate management fees that are far lower than those for retail investors while still being subject to the $20 \%$ performance fee. Management fees are often related to the expected or targeted volatility of the mandate; for example, high management fees are difficult to justify for low-volatility mandates. In addition, compensation is usually governed by a high-water mark rule such that performance fees, which are usually calculated daily and paid quarterly, ${ }^{49}$ are paid only to the extent that the returns push the manager's cumulative returns above the previous high-water mark. ${ }^{50}$

Structural and Operational Choices. The agreement between an institutional investor and the manager is also likely to lay out various structural or operating principles for the relationship. Perhaps the most fundamental

\footnotetext{
${ }^{47} \mathrm{~A}$ review of the fee structure for currency funds that report through the TASS and CISDM databases shows that the $2 \%$ management fee and $20 \%$ performance fee are the modal charges. Some managers assess fees that are higher than 2 and 20, however, and some charge less.

${ }^{48}$ For fully funded absolute return mandates, AUM is typically measured as simply the cash under management; in other words, a USD200 million fully funded mandate means AUM of USD200 million. For unfunded absolute return mandates, AUM is reported as the agreed notional value, independent of the specific margin requirements. For example, a client might have to fund only 10\% of the USD200 million; the AUM will still be reported as USD200 million and not as USD20 million, and the USD200 million will be the base for calculating returns and management fees. For currency overlay mandates, the AUM is typically defined as the reporting currency amount of the international holdings in the underlying portfolio; that is, assuming a USD/JPY exchange rate of 80, a JPY80 billion investment in the Nikkei 225 Index equals USD100 million of AUM in currency overlay exposure. For mandates that specifically have a volatility target, some managers report AUM adjusted for volatility; for example, a USD200 million mandate with a target volatility of 4\% could be counted as a USD100 million mandate with a target volatility of $8 \%$.

${ }^{49}$ Performance fees are usually subject to lifetime or rolling high-water marks.

${ }^{50}$ For example, consider an absolute return mandate in which the initial AUM is USD100 and the first year's returns are 25\%, which pushes the AUM to USD125. The manager is paid a performance fee of $20 \%$ on the USD25 profit, so AUM at the start of Year 2 is USD120. If the manager loses 10\% in Year 2, AUM declines to USD108 and no performance fee is paid. If the manager gains 20\% in Year 3, AUM rises by USD21.6 to reach USD129.6. The manager is paid the performance fee only on the portion of annual profits, USD9.6 in this case, that pushed the fund's AUM above the earlier high-water mark of USD120.
} 
choice is whether, or to what degree, the account is funded or unfunded. In a funded program, the investor designates specific funds that are placed in custody accounts for which the manager is permitted to trade. For example, a pension fund sponsor might allocate USD10 million to a currency fund manager. If the mandate allowed for 10 times leverage, the currency manager would have up to USD100 million AUM to invest. These funds would be placed on deposit earning LIBID unless otherwise committed to a foreign currencytrading strategy. If the pension fund sponsor began with USD100 million in global equity holdings, carving off USD10 million for currency (by selling that amount of equities) would change the sponsor's exposure to USD90 million in global equity and to between USD10 million and USD100 million in currency, depending on the degree of leverage devoted to currency.

In an unfunded program, the plan sponsor retains custody of the underlying assets but earmarks some of those assets to collateralize a trading account for use by the currency manager. ${ }^{51}$ In this case, the currency manager initially has no assets and, therefore, faces a zero return unless trading positions are established. In such a structure, the sponsor can keep the USD100 million global equity position and also manage the resulting currency exposures through a currency overlay.

In principle, an absolute return mandate could be executed through either a funded or unfunded structure. A currency overlay mandate is more commonly implemented through an unfunded structure because the plan sponsor wishes to retain the ability to trade the underlying foreign currency assets that require the overlay.

Other operational choices may be covered in a currency mandate. An example is which banks and exchanges may be used for trading. The introduction of prime brokerage services by investment banks has allowed hedge fund managers to source liquidity from a variety of market makers while maintaining a credit relationship, placing collateral, and settling with a single entitythe prime broker. Thus, prime brokerage allows hedge funds, despite having a possibly limited credit history or high risk profile, to use the prime broker's credit rating to gain access to new counterparties. Typical services offered by the prime broker are leverage, access to market liquidity, and consolidated settlement, clearing, and reporting. The availability of prime brokerage services allows experienced currency traders and strategists to set up as currency managers who can secure sponsor mandates and operate efficiently.

Alpha Continuum of the Mandate. Some of the numerous features of an agreement between an institutional plan sponsor and a currency manager allow the manager great latitude in pursuing excess returns and managing risks,

\footnotetext{
${ }^{51}$ The plan sponsor may have to provide cash rather than securities as collateral. Typically, a currency overlay program for a USD100 million foreign currency portfolio can be supported by USD10 million in cash collateral.
} 
and others constrain the manager. Through the mandate, the sponsor and currency manager target a combination of expected return and risk. At one extreme, the sponsor may design a currency overlay mandate intended to provide only currency risk reduction with no expected return. At the other extreme, the sponsor may design an absolute return mandate to authorize the currency manager to hunt for the maximum alpha conditional on a particular level of risk. Between these two extremes lies the alpha continuum of target alpha levels and risks. ${ }^{52}$

\section{Currency Investment Strategies}

Previous research (see P-L 2008, 2010) has shown that three basic trading strategies - carry, trend following, and value-plus the volatility of the FX market explain the bulk of the returns generated by professional currency managers. This section provides a brief overview of these FX trading strategies.

Carry Strategy. The empirical evidence against UIP provides the fundamental underpinning for the carry trade. Indeed, as discussed earlier in this chapter, the empirical evidence runs opposite to the predictions of UIP: Currencies with high interest rates tend to appreciate against currencies with low interest rates. This phenomenon is often called the "forward rate puzzle." Hence, the carry strategy involves buying currencies with high interest rates (target currencies) and selling currencies with low interest rates (funding currencies). If the target currency appreciates or does not depreciate more than the interest rate differential against the funding currency, the carry trade is profitable.

When applied to a single currency pair, a carry strategy may be based on borrowing one currency at a cost of, say, $0.25 \%$ and using the proceeds to buy another currency at, say, $4.0 \%$. An example of a carry portfolio is a short $100 \%$ position in Japanese yen at a low interest rate with the proceeds used to go long 50\% in Australian dollars and long 50\% in New Zealand dollars, both of which pay much higher interest rates than the yen. The weights in this example were chosen arbitrarily but are subject to the constraint that the weights sum to zero. Positions would be changed periodically as interest rate relationships change.

Trend-Following Strategy. Unlike the carry and the value strategies, which are closely related to parity conditions that are, in turn, based on fundamental determinants of currency value, trend-following, or momentum, strategies are based purely on the assumption that currency movements exhibit some degree of persistence or predictability that is shown in recognizable patterns. Empirical evidence on the profitability of trend-following rules, not

\footnotetext{
${ }^{52} \mathrm{By}$ definition, alpha is the risk-adjusted difference between the absolute return earned and the return on the benchmark - that is, the residual from a regression on the benchmark, usually with both the absolute return earned (dependent variable) and benchmark return (independent variable) in excess of the risk-free rate. Later, we propose alternative benchmarks and alpha measures.
} 
only in currencies but also in equities and fixed income, supports the adoption of trend-following strategies. ${ }^{53}$ The most common principle of trend-following strategies is to buy currencies that have been appreciating and sell currencies that have been depreciating.

When applied to a single currency pair-for example, the euro and the U.S. dollar-a short-term rise in the EUR might lead a manager to go long the EUR and short the USD. The trading position would be maintained until an opposite signal appeared. In a multicurrency setting, the manager might take long positions in several of the $\mathrm{G}-10$ currencies with the greatest recent positive momentum and finance them with short positions in several G-10 currencies with the greatest recent negative momentum. Again, positions would be changed periodically as the momentum estimates for the G-10 currencies changed.

Value Strategy. The tendency for PPP to hold over the long term, as discussed in the section titled "Important Parity Conditions and Pricing Principles," provides the economic underpinning for the value strategy. Similar to value investing in other asset classes, the value strategy involves buying undervalued currencies with funds obtained by selling overvalued currencies. Valuation traders commonly use an estimate of a currency's long-term fair value given by PPP or another macroeconomic model to identify "overvalued" and "undervalued" currencies.

When applied to a single currency pair, a large undervaluation of, say, the euro against the U.S. dollar might lead a manager to go long the euro and short the U.S. dollar. The trading position would be maintained until the undervaluation became insignificant. In a multicurrency setting, the manager might take long positions in several G-10 currencies with the greatest measured undervaluation and finance them with short positions in several G-10 currencies with the greatest measured overvaluation. Again, positions would be changed periodically as the valuation estimates for the G-10 currencies changed.

Variations on the Strategies. Many tactical variations are possible for each of the generic strategies. A carry strategy, for example, could be based on the entire yield curve and a family of interest differentials (see Gyntelberg and Schrimpf 2011). The carry strategy could incorporate volatility to scale expected returns and act as a filter to exit and reenter carry trade positions (see Pojarliev 2009). Trend-following strategies could also be varied considerably by adopting different techniques for identifying trends, using periods of different lengths to measure trends, and including the possibility of reversals

\footnotetext{
${ }^{53} \mathrm{~A}$ substantial body of research has examined the returns for trend-following or technical analysis strategies in which individual currencies are bought and sold over time; see Menkhoff and Taylor (2007) for a survey. More recent empirical work examines the profitability of momentum strategies in a cross section of currencies; see Menkhoff, Sarno, Schmeling, and Schrimpf (2012b).
} 
after a prolonged trend. In much the same way, value strategies will depend on the specific price index and methodology used to define the PPP rate and to decide what magnitude of deviation from PPP will trigger taking positions in over- and undervalued currencies.

Although changes in the tactics for implementing the generic strategies will have an impact on the timing and choice of positions, these variations are likely in many instances to result in fairly similar risk-adjusted returns. ${ }^{54}$ Later, when we make use of these generic strategies to measure the performance of currency managers, our objective will be to use simple and transparent versions of each strategy that could be easily (and cheaply) replicated.

Risk-Return Profiles of Common FX Strategies. Gyntelberg and Schrimpf (2011) simulated the returns of some common FX investment strategies and measured their risk-return characteristics. In addition, the authors compared the performance of the common FX strategies with the performance of the U.S. equity market. Specifically, they constructed portfolios that reflected the returns of (1) the carry strategy, (2) a trend-following strategy based on the previous one month's performance, (3) a trend-following strategy based on the past three months' performance, and (4) a term spread strategy that is a variation of the carry strategy. They analyzed the performance of these strategies for the period January 1985 through September 2011 for 25 currencies measured against the U.S. dollar. Although the simulated returns varied on the basis of the specific implementation of the trading strategy, time horizon, and number of currencies, they found that several conclusions are valid regardless of the specific implementation:

- Returns for the common FX strategies have been larger than or equal to the excess returns generated by the equity market. ${ }^{55}$

- Sharpe ratios for the common FX strategies are clearly higher than those for equities. Downside risks are smaller than for the equity market. ${ }^{56}$

- During periods of extreme market stress, the common FX strategies provide diversification. For example, during the recent global financial crisis, the carry strategy suffered large losses, but by April 2009, the initial losses had been recouped. FX trend-following strategies performed well over this crisis period.

In Chapter 4, we provide further evidence regarding the risk-return characteristics of the common FX strategies by reporting the empirical statistics for indices designed to mimic the return of these strategies.

\footnotetext{
${ }^{54}$ See Pojarliev (2009) for a comparison of three variations of the carry strategy.

${ }^{55}$ Because FX strategies require minimal funding, comparing FX returns with equity returns requires subtracting the risk-free rate (one-month U.S. Treasury bill rate) from the equity returns. ${ }^{56}$ Gyntelberg and Schrimpf (2011) define downside risk as $1 \%$ value at risk (VaR) and 1\% expected shortfall (the expected loss given that the loss exceeds the $1 \% \mathrm{VaR}$ ).
} 


\section{Currency Investment Processes}

The primary way of characterizing an investment process is to gauge how systematic, versus how discretionary, the investment decisions are. When the investment decisions are based purely on quantitative models or a clearly articulated set of rules, the manager is said to be "systematic." One example of a systematic investment process would be when trades are undertaken entirely on the basis of the signals of a trend-following model. Other examples would be a carry strategy based on owning the three highest-yielding currencies financed by short positions in the three lowest-yielding currencies or a value strategy based on owning the three most undervalued currencies financed by short positions in the three most overvalued currencies.

In contrast, a discretionary investment process suggests that investment decisions are based on investment experience; that is, they are "judgmental." A discretionary process may rely on political and economic analysis related to current trends and events but in a way that is not easily quantified. An example of a judgmental trade would be when in the summer of 1992, George Soros famously profited handsomely at the expense of the Bank of England and the Bank of Italy by shorting the British pound and the Italian lira against the German mark. ${ }^{57}$ A hypothetical example for a discretionary currency trade would be a bet that the Swiss National Bank (SNB) is about to raise the floor in EUR/CHF at an upcoming SNB policy meeting. ${ }^{58}$ If a discretionary currency manager expected such an event to happen, the manager would buy euro versus the Swiss franc ahead of the meeting and exit the trade if the expectations were not met.

In reality, the investment process of the vast majority of managers uses both systematic and judgmental elements. For example, a systematic manager might override the signals of a trading model from time to time to incorporate additional market information..$^{59}$ Even more basic would be the decision to use a particular quantitative model (thereby excluding other quantitative models and modes of implementation) but to implement the model in a particular way. Even systematic managers must make this judgment.

A second way of delineating managers is to describe them as either "fundamental" or "technical." Fundamental managers base their decisions on macro data. For example, systematic managers who use trading models based on macroeconomic variables could be classified as fundamental. Technical managers base their investment decisions entirely on the price action. An example would

\footnotetext{
${ }^{57}$ Britain and Italy succumbed to economic and political pressure and devalued their currencies versus the German mark despite a European Union agreement to hold to a pegged rate. Notably, this trade was contrary to a carry trade. Soros borrowed the high-yielding currencies and owned the low-yielding currency. Thus, he paid the cost of carry while waiting for an exchange rate change.

${ }^{58}$ In August 2011, the SNB set a floor of EUR1.20/CHF, which was still in place as of late 2012.

${ }^{59}$ The policy decision described in footnote 58 is one such example.
} 
be a trend-following model with trading signals based on short-run and longrun moving averages. Again, in reality, an investment process is likely to use both macro and technical elements.

Finally, managers can be classified as beta grazers or alpha hunters. ${ }^{60}$ Although both alpha hunters and beta grazers endeavor to earn investment returns, a considerable philosophical divide separates the two groups. Beta grazers aim to earn returns by harvesting the risk premium associated with style factors (e.g., carry). Beta grazers do not need to formulate a view on the future direction of the market. Alpha hunters seek to exploit market inefficiency and behavioral biases through timing, expertise in selecting profitable trading strategies, or advantages in information access, trading execution, or other factors that give them a competitive edge. Put differently, alpha hunters will generate profits only when their specific view on the future direction of the market turns out to be right. Conceptually, at least, all beta grazers could be right, but alpha hunters can earn their alphas only at the expense of other alpha hunters.

${ }^{60}$ Leibowitz (2005) introduced the terms "alpha hunter" and "beta grazer." 


\section{A Model of Alpha and Beta Returns from Currency Management}

In Chapter 2, we described two alternative currency management mandates: a currency overlay mandate and an absolute return mandate. Because a currency overlay mandate is often primarily concerned with risk reduction whereas an absolute return mandate is more focused on generating additional returns, the methodology for benchmarking these mandates differs considerably.

In the case of a currency overlay, the objective is always to hedge some portion of the preexisting currency risk in an asset portfolio. The mandate may also include the option for the overlay manager to capture some additional return via selective hedging. The currency overlay manager may be evaluated against a benchmark of performance calculated as if $0 \%$ of the underlying exposure were hedged, as if $100 \%$ of the exposure were hedged, or at a point somewhere in between. ${ }^{61}$ Strange (1998) argues that, ultimately, the performance of managers evaluated against these benchmarks depends on whether the base currency for measuring performance appreciated or depreciated over the cycle. For this reason, Strange suggests, the $50 \%$ hedge ratio became the most popular benchmark. A currency manager is deemed to add value if the manager outperforms a naive strategy of hedging half the exposure, which is the position a manager would take if the manager had no expertise to determine whether a currency was rising or falling relative to its forward premium. Strange reports that in his sample of 152 overlay programs managed by 11 firms, on average, $80 \%$ outperformed their individually specified benchmarks. ${ }^{62}$

Our primary interest concerns the benchmarking and performance of fund managers with absolute return mandates. We identify three benchmarks: a traditional benchmark in widespread use among currency management professionals, an alternative benchmark based on the returns of various investment style factors, and another alternative benchmark based on the expected return for bearing foreign exchange risk.

According to the traditional benchmark, the expected rate of return associated with holding currency risk is zero. This conventional benchmark gained credence from macroeconomic models of the 1970s plus financial theory, according to which currency risk is diversifiable and, therefore, not a risk compensated by a risk premium. Another way of expressing this idea is that FX trading is a

\footnotetext{
${ }^{61}$ Strange (1998) refers to the $0 \%$ and $100 \%$ as polar benchmarks.

${ }^{62}$ Strange also notes, in his 1998 study, that the earliest mandates had been given out only 10 years earlier, or about the year the financial press first began reporting on currency as an asset class.
} 
zero-sum game in which every profitable position is matched by an opposite losing position. ${ }^{63}$ According to this argument, currency, unlike equities or real estate, does not generate a net profit to reward all holders of currency risk. ${ }^{64}$

Moreover, to the extent that nonzero realized currency returns were shown to exist, empirical studies showed that these returns were uncorrelated with a general market index. Currency was thus seen as a zero-beta asset that, in equilibrium, was not associated with a positive expected rate of return.

Finally, numerous studies argued that short-run exchange rate changes were largely unpredictable and that the most consistent currency forecast was one based on the random walk assuming no drift. ${ }^{65}$ In that setting, speculators have no special ability to outforecast the market, so the expected return from currency speculation would be zero. ${ }^{66}$

Arbitrage pricing theory (APT) offers an alternative approach for modeling the expected rate of return on financial assets. ${ }^{67}$ APT posits that the expected return on a financial asset can be expressed as a linear function of certain macroeconomic factors or market indices. APT was developed in the context of pricing stocks. ${ }^{6}{ }^{8}$ Recently, Fung and Hsieh (2002) used an APT framework to model hedge fund returns. The model specification takes the form

$$
R_{t}=\alpha+\sum_{i} \beta_{i} F_{i, t}+\varepsilon_{t},
$$

where

$$
\begin{aligned}
R_{t}= & \text { the fund's return at time } t \\
\alpha= & \text { a measure of active manager skill } \\
F= & \text { a style factor } \\
\beta= & \text { a coefficient or factor loading that measures the sensitivity of the } \\
& \text { manager's returns to the factor } \\
\varepsilon= & \text { a random error term }
\end{aligned}
$$

Fung and Hsieh (2002) note that asset-based style factors can be interpreted in the same way as traditional market indices if two conditions are satisfied. First, there must be complete transparency in how factor returns are

\footnotetext{
${ }^{63}$ The author of an article in the Financial Times (15 December 2010) Lex column also makes these points. See also McCrum (2012).

${ }^{64}$ Currency overlay firms often use this "zero return, high risk" argument to sell their hedging services. ${ }^{65}$ Meese and Rogoff (1983) are responsible for this famous result. Returning to the topic years later, Rogoff (2002) wrote, "To make a long story short not only have a subsequent twenty years of data and research failed to overturn the Meese-Rogoff result, they have cemented it...."

${ }^{66}$ If the random walk with no drift model is taken seriously, then the carry trade in which speculators borrow a low-interest-rate currency and invest in a high-interest-rate currency ought to earn an expected profit (subject to risk).

${ }^{67}$ The original formulation of the APT is in Ross (1976).

${ }^{68}$ For example, see Roll and Ross (1980) and Chen, Roll, and Ross (1986) for empirical tests relating macroeconomic variables to stock prices. See Huberman and Wang (2005) for a review article.
} 
derived. Second, the return series must be sufficiently long to produce reliable statistical results. In principle, arbitrage pricing theory can be used for modeling currency returns if suitable factors can be identified. In the APT context, currency expected returns are not necessarily nonzero nor are they necessarily best modeled as a random walk without drift.

Finally, a variation on the APT approach makes explicit allowance for currency risk factors not captured in Equation 9. Nucera and Valente (2010) argue that excess performance is the component of returns that is higher than what can be explained by the manager's exposure to a set of currency risk factors. For example, performance in excess of a carry trading index represents excess performance only to the extent that the extra return is unrelated to other, identifiable currency-related risks.

To build a basic factor model for currency market returns, we rely on financial market theory, which informs us that the return of any portfolio can be decomposed into beta and alpha components. The beta component captures the systematic relationship between returns and the common factors driving returns (common among securities or asset classes). The beta component for currency might stem from exposures to risk factors or trading styles in a spirit similar to the way APT models have been used to relate equity returns to such factors as company size, book-to-market ratio, price-to-earnings ratio, and so on.

For currencies to qualify as an asset class, factors must be identified that correlate with or explain patterns of currency fund manager returns. Building on earlier research on hedge funds and on several well-known currencytrading strategies, we have previously proposed (P-L 2008) four possible factors that could explain currency returns earned by professional managers-in generic terms, carry, trend following, value, and volatility.

- Carry. The carry factor reflects the returns on the well-known strategy of borrowing in one or more low-interest-rate currencies and investing in one or more higher-interest-rate currencies. A carry strategy entails risk because the high-interest-rate currency may depreciate-possibly by more than the interest differential, which would result in a loss.

- Trend following. This factor reflects the returns from investing in currencies with upside momentum financed by borrowing in currencies with downside momentum. Trend-following strategies entail many risks, such as false trends, sudden reversals of trends or patterns, excessive trading costs, and so on.

- Value. The value factor reflects the returns of borrowing in an overvalued currency and investing in an undervalued currency. A value strategy is exposed to the risk that currency values may become still more misaligned, that rates will be slow to revert toward the equilibrium (e.g., purchasing 
power parity) value, and that the currency's long-run real exchange rate (or estimated PPP exchange rate) has changed-in other words, the risk that the investor's estimate of the currency's over- or undervaluation is wrong.

- Volatility. This factor reflects the impact of currency volatility on trading returns. Unlike the other three factors, this factor does not represent the return of a trading strategy but, rather, the risk from a change in foreign exchange volatility. ${ }^{69}$ Currency managers incur exposure to volatility risk simply by taking open currency positions but also by using options and other derivatives whose prices are sensitive to volatility.

These four factors $\left(F_{i}\right)$ can be proxied by well-defined trading strategies that are easily replicated and transparent within the currency domain. As Melvin and Shand (2011) stress, the four proposed trading styles can be implemented in many ways. For example, currency managers using a value strategy may use alternative specifications of PPP and various indicators of misalignment to trigger their buy and sell orders. Managers might also vary the menu of currencies they monitor.

But even though our style factors are dynamic and require some measure of skill to mimic, they do not involve active management in the traditional sense and the methodology summarized in Equation 9 is not invalidated. ${ }^{70}$ Nor do the characteristics affect the usefulness of the style factors in gauging a currency fund manager's style or relative performance. ${ }^{71}$ Indeed, this approach has become fairly commonplace in the hedge fund industry apart from currency funds. The novelty in our approach is to apply an established methodology to

\footnotetext{
${ }^{69}$ Although some currency managers trade volatility as an asset class, anecdotal evidence suggests that they represent a small subsample of the currency management industry. Indeed, option transaction costs are much higher than spot transaction costs, suggesting that directional volatility trades are not feasible for those who are not market makers. For example, at-themoney three-month AUD/USD options (AUD are Australian dollars) are usually quoted 0.5 volatility wide (e.g., 10/10.5); volatility has to increase by $5 \%$ just to cover transaction costs. In comparison, the AUD/USD exchange rate is quoted only 3 pips wide (e.g., 1.00/1.0003); only a $0.03 \%$ move in spot is necessary to cover the transaction costs. We are unaware of a generic, clearly defined volatility index (investable exchange-traded fund) that is designed to capture the return of trading currency volatility as an asset class. The Royal Bank of Scotland produced a volatility index that was designed to represent the return from selling volatility, but the bank discontinued this index in 2011.

${ }^{70}$ Traditionally, active management implies that the manager makes specific investments based on his or her investment expertise, with the goal of outperforming an investment benchmark. The style factors for currency returns, in contrast, are rule-based dynamic strategies, which managers could track by simply following the respective investment rule.

${ }^{71}$ Tracking the S\&P 500 Index could also be characterized as a "dynamic" strategy because companies are dropped and added to the index. Although beta grazing is by no means trivial and requires professional expertise, the required skills are quite different from those that promote successful active portfolio management.
} 
a subset of the hedge fund industry (currency funds). Although the alpha estimates might vary, depending on the particular choice of risk factors, investors will benefit by looking at a range of possible estimates rather than assuming that all returns represent alpha returns. Assuming a zero-beta benchmark is not rational when a significant part of the excess return can be replicated with simple trading strategies.

To be a credible and useful benchmark, the factor model should rely on trading strategies that are purposely naive and transparent. If so structured, a factor model then offers a reasonable benchmark that professionals can attain-and surpass, if they have skills beyond these naive strategies. In Chapter 4, we present empirical evidence supporting our four-factor model. 


\section{Empirical Evidence}

Investigating the relationship between currency trader returns and the four factors requires data on currency managers' returns and on proxies for the risk factors.

\section{Proxies for Currency Investment Returns and Risk Factors}

The Barclay Currency Traders Index (BCTI) is an equally weighted composite of managed programs that trade currency futures and/or cash forwards in the interbank market. Subject to certain caveats about biases common in many hedge fund data sources (which we address later), the BCTI offers a reasonable proxy for the returns generated by the currency management industry.

Over the index's life, the number of programs included in the BCTI has varied and, as Figure 5 shows, has trended upward over the past 10 years. By 2011, the index included 117 currency programs. Assets under management in currency funds declined during the global financial crisis, but having bounced back since then, AUM reached a new high of USD28 billion in 2011. In contrast, Figure 5 shows that the number of funds remains below the peak reached in 2008, suggesting that some funds did not survive the market turbulence in 2008.

Figure 5. BCTI: Number of Programs and AUM at Year-End (in USD billions)

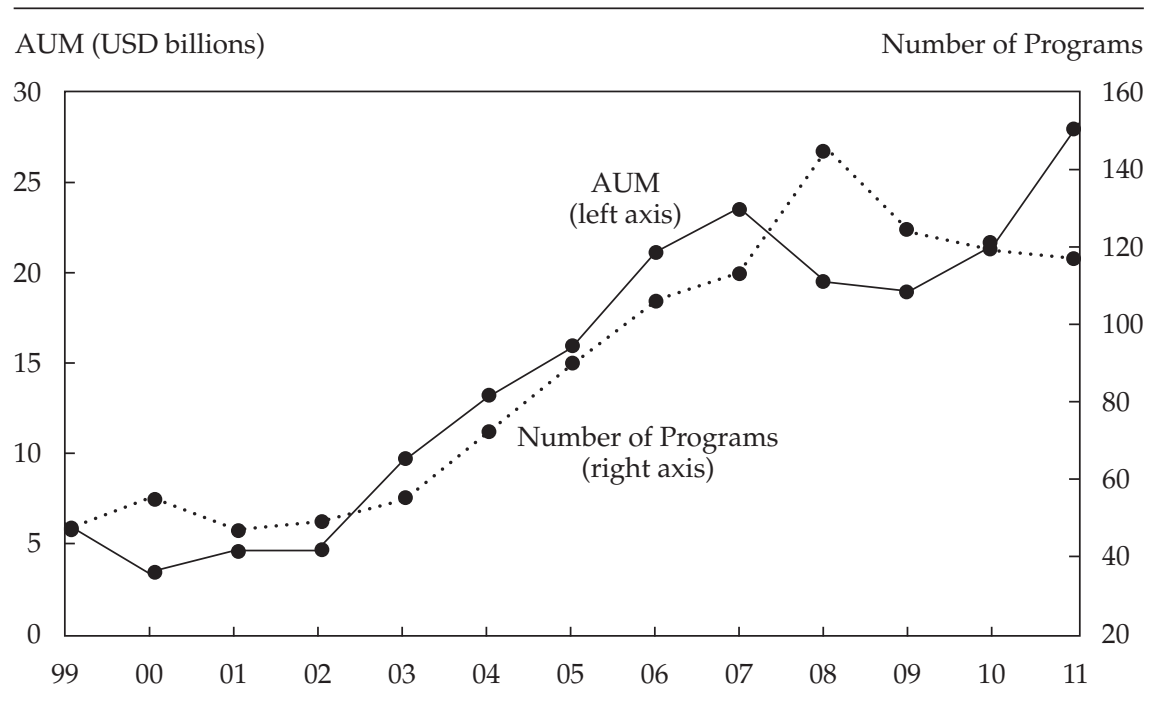

Source: AUM and numbers of funds are provided courtesy of BarclayHedge; annual returns are available at www.barclayhedge.com. 
The USD28 billion invested in currency funds represents only a tiny fraction of the assets invested in hedge funds. Estimates suggest that total hedge fund assets are about USD2 trillion (Strasburg and Eder 2011). Thus, despite the depth of the foreign exchange market, professional currency investors represent only a small proportion of the hedge fund industry. ${ }^{72}$ Whether currency is an underused asset class is a theme we explore further in Chapter 5.

As Melvin and Shand (2011) point out, there are many definitions for generic currency strategies and "inferences drawn from empirical work will differ according to which concepts are employed by the researcher" (p. 13). To address this concern, and as robustness checks, we used various proxies for the risk factors. We collected data for three proxies for the trend factor and two proxies for each of the other three factors.

Selecting appropriate factors is a matter of empirical analysis. If an investor discovers that the return generated by the investor's managers can be replicated cheaply through a naive trading strategy, then such return could be classified as a beta return and would not deserve active management fees. Complete transparency is required, however, in how the factor returns are derived. In addition, the return series must be sufficiently long out-of-sample to produce reliable statistical results. Most of the available factor proxies have been introduced only recently, which effectively means comparing real currency managers' returns with those from back-tested strategies.

A number of banks have recently introduced indices designed to proxy the return from currency management. The majority of these indices have been introduced only recently, however, and are not transparent enough. For example, Credit Suisse produces six factor indices (carry, momentum, value, terms of trade, growth, and emerging markets), collectively known as the FX Factor Index. A Credit Suisse press release from 27 April 2009 states:

The FX Factor Index is based on six strategies [as listed above]... These are strategies that have performed in a diverse set of market environments. By gaining exposure to these six strategies, the FX Factor Portfolio can outperform more narrowly-based foreign exchange indices. (www.credit-suisse. com/news/en/media_release.jsp?ns=41154)

The methodology to construct these factors, however, is not well articulated in available documents. Furthermore, because the factors were introduced only in 2009, we decided against using them to gauge currency managers' performance prior to 2009. Similarly, although Citibank has produced both alpha and beta FX indices since 2007, it appears to have revised its beta indices in 2010

\footnotetext{
${ }^{72}$ Note that currency investment strategies are also applied by market participants other than FX-only managers. For example, global macro hedge funds also invest in the FX market. Therefore, total assets exposed to currency strategies are much larger than the USD28 billion invested in FX-only funds.
} 
to generate alpha. According to an FX Week article from November 2010, "The indexes include more currency pairs than previous versions and feature five core investment styles: G10 Trend, G10 Carry, Emerging Market Trend, EM Carry, and G10 Purchasing Power Parity (PPP)" (Ali 2010). Because the Citibank indices have been revised and some are intended to generate alpha returns rather than function as naive benchmarks, they are less suitable for our purposes here.

Fortunately, both the Royal Bank of Scotland (RBS) and Deutsche Bank (DB) produce indices of currency strategies that are transparent and easily available on Bloomberg. RBS produces four indices designed to proxy the returns from carry, trend, value, and a short volatility strategy. ${ }^{73}$ Anecdotal evidence suggests that these indices have been known across the FX management community for quite a while. The calculations underlying the RBS indices were originally described in an article by Binny (2005) in the Journal of Alternative Investments. $\mathrm{DB}$ also produces carry, trend, and value indices designed to represent the returns from naive currency strategies. The DB Currency Volatility Index is simply a measure of the implied volatility and does not represent returns from a trading strategy. Deutsche Bank launched these indices in March 2007 and, in 2010, prepared a detailed report on their performance and statistical properties for a 30-year period (see Hafeez and Brehon 2010).

Another well-established proxy for the return generated by a trend-following strategy is the AFX Currency Management Index. Research by Lequeux and Acar (1998) shows that this measure has been a good proxy for a trend-following style among professional managers. It has been used for a number of years in various research papers and, therefore, is known to researchers in this field.

We collected monthly data on the BCTI, the four RBS indices, the four DB indices, and the AFX for the period January 1990 through December $2010 .{ }^{74}$ Appendix A contains a more detailed description of the indices. Descriptive statistics for these variables for the entire sample and for two subperiods are presented in Table 5.

The mean monthly return on the Barclay Currency Traders Index, at $0.55 \%$, is roughly $6.6 \%$ a year over the 21 -year period reported in Panel A. The excess return on the BCTI is its monthly return minus the one-month

\footnotetext{
${ }^{73}$ As a short (long) volatility strategy, we refer to an investment strategy that will benefit by a decline (increase) in volatility. Such a strategy is usually implemented by selling (buying) straddles, a combination of a put and a call options.

${ }^{74}$ The DB Currency Volatility Index has been available on Bloomberg only since August 2001. As a proxy for the implied volatility prior to 2001, we used the average of the one-month implied volatility for the EUR/USD exchange rate (DM/USD prior to the introduction of the euro) and for the USD/JPY exchange rate. These two currency pairs, which have the mostliquid options in the FX market, account for roughly $54 \%$ of currency option trading in the BIS surveys for 1995-2004. The correlation of our measure for implied volatility and the DB Currency Volatility Index is 96\% between August 2001 and May 2011.
} 


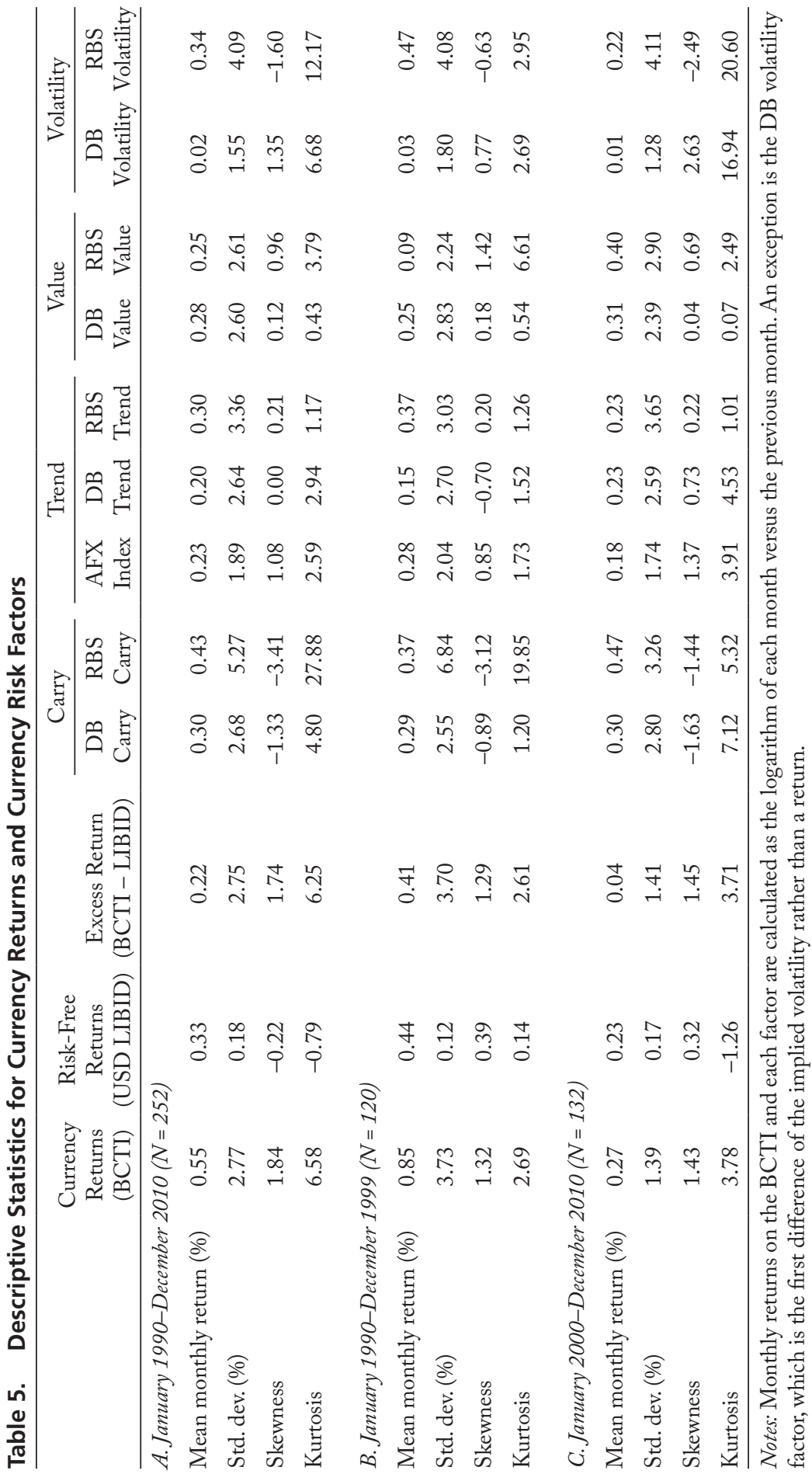


USD LIBID rate. ${ }^{75}$ As a result, the mean monthly excess return on the BCTI is only $0.22 \%$, similar to the returns on the trend factor $(0.23 \%$ for the AFX and $0.20 \%$ for the DB trend) and the value factor $(0.28 \%$ for the DB value and $0.25 \%$ for the RBS value). The carry strategy and a short volatility strategy would have generated a slightly higher return. The highest of the factor returns for the full period is the mean monthly return on the RBS carry, at $0.43 \%$; the DB carry generated $0.30 \%$, and the RBS volatility, $0.34 \%$.

As expected, the trend factors reflect positive skewness and the carry factors exhibit negative skewness. These results can be explained in two ways. First, although trend following behaves like a long volatility strategy, carry trading functions like a short volatility strategy. Second, a more fundamental explanation is that a trend-following strategy allows a right tail of profits when trends are prolonged, but reversals end the trend, close positions, and limit left-tail losses. ${ }^{76} \mathrm{~A}$ carry strategy may produce many small returns from a positive interest differential (i.e., the carry) but be prone to large left-tail losses if the target currency depreciates sharply against the funding currency. ${ }^{77}$

The value factors show positive skewness and kurtosis. Kurtosis for the RBS carry is more pronounced than for any other factors. Naturally, the RBS volatility factor (a short volatility strategy) exhibits a negative skewness. The DB volatility factor (representing difference in the implied volatility rather than a return) has a slightly positive mean monthly return, indicating that volatility was, on average, increasing over the sample period. ${ }^{78}$

In the two subperiods shown in Panels B and $\mathrm{C}$ of Table 5, mean excess returns on the BCTI were far higher- $0.41 \%$ per month - in the first period (only $0.04 \%$ per month in the second period). This very large difference cannot be explained by declining equilibrium returns on currency beta. Rosenberg (2010) suggests that the decline in return generated by currency managers in recent years is the result of a tendency of currency managers to place greater emphasis on downside risk management in this period.

Mean monthly returns on the factors were similar or higher in the second period with the exception of the short volatility strategy, which generated $0.47 \%$ in the first period but only $0.22 \%$ in the second. The short volatility strategy suffered in the second period because of the spike in volatility during the global financial crisis of 2008.

\footnotetext{
${ }^{75} \mathrm{All}$ funds represented in the BCTI are absolute return programs. We used the one-month USD LIBID rate to proxy the risk-free return on the AUM in these programs. All funds in the BCTI report their data on a net basis after deducting all management fees.

${ }^{76}$ See Schulmeister (2005) for a statistical analysis of the distribution of returns from technical trading models in currency, which confirms this general pattern.

${ }^{77}$ Brunnermeier, Nagel, and Pedersen (2009) review the empirical evidence on the skewed lefttail nature of carry trade returns.

${ }^{78}$ Substantial correlation is found between this currency volatility measure and both the VIX (the Chicago Board Options Exchange Market Volatility Index, a proxy for the volatility in the equity market) and the MOVE Index (Merrill Lynch Option Volatility Estimate Index, a proxy for volatility in the bond market).
} 
Figures 6-8 show the performance of the factors for the 21 years between January 1990 and December 2010. Figure 6 plots the performance of the short volatility strategy as well as that of the two carry strategies. As expected, both carry strategies earned almost identical carry premiums over the period. The cumulative return is essentially the same regardless of the difference in index definitions. Interestingly, the short volatility strategy earned a similar cumulative return. Evidently, the yield received by writing options (selling volatility) is similar to the yield received by being long high-yielding currencies and short low-yielding currencies.

Figure 7 shows that, in contrast to the results for carry strategy, the cumulative returns for the three trend-following indices are not very similar. The RBS trend returned over $20 \%$ more than the DB trend during our sample period, and the performance of the AFX is in between. These results suggest that the size of the available trend beta could depend substantially on the specific trend-following model.

Figure 8 indicates that the size of the value premium is similar regardless of the exact methodology of value index construction. Although uncorrelated in some periods, $\mathrm{DB}$ value and $\mathrm{RBS}$ value produced similar cumulative returns over the 21-year sample.

Figure 6. Carry and Volatility Factors: Cumulative Returns, January 1990December 2010

( $N=252$ months)

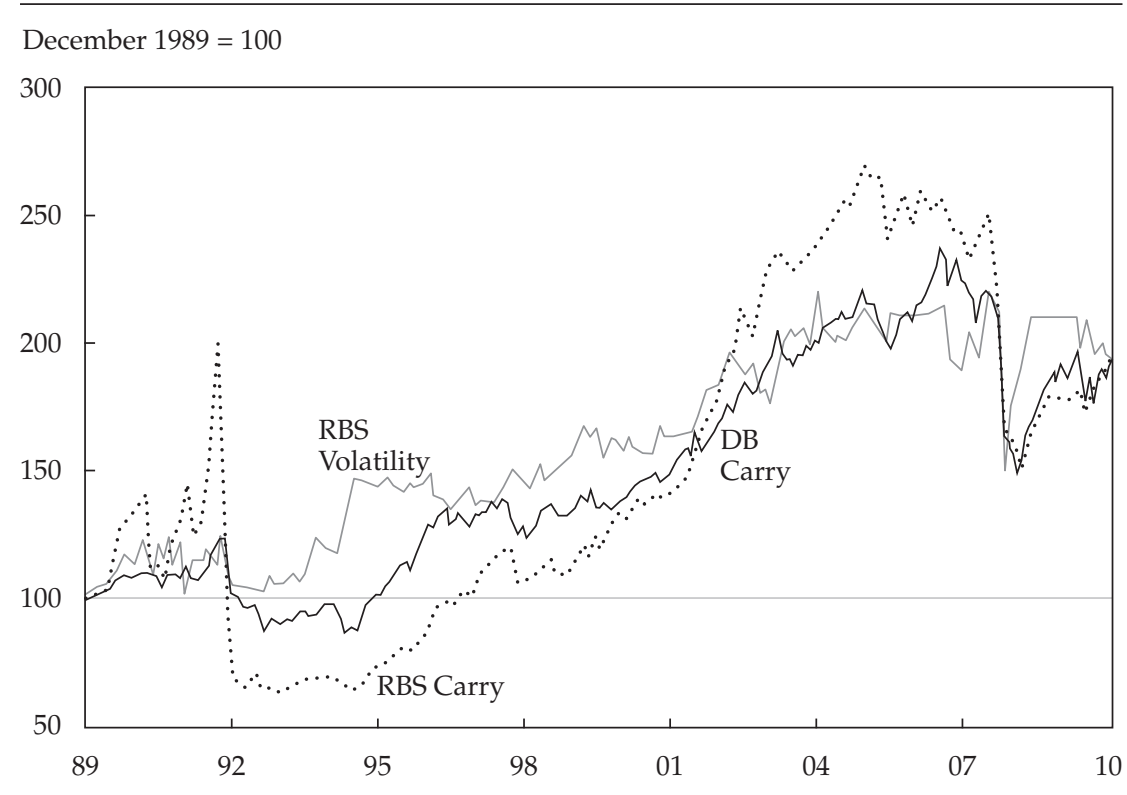


Figure 7. Trend Factors: Cumulative Returns, January 1990-December 2010 ( $\mathrm{N}=252$ months)

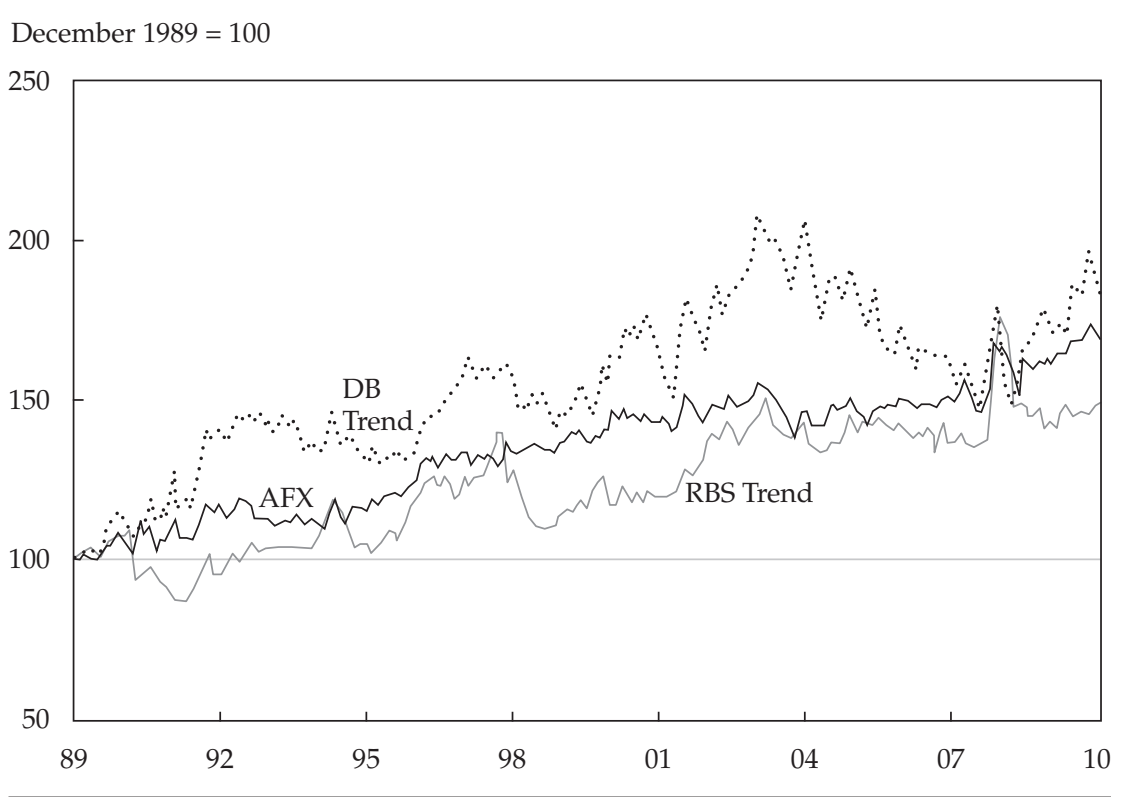

Figure 8. Value Factors: Cumulative Returns, January 1990-December 2010

( $\mathrm{N}=252$ months)

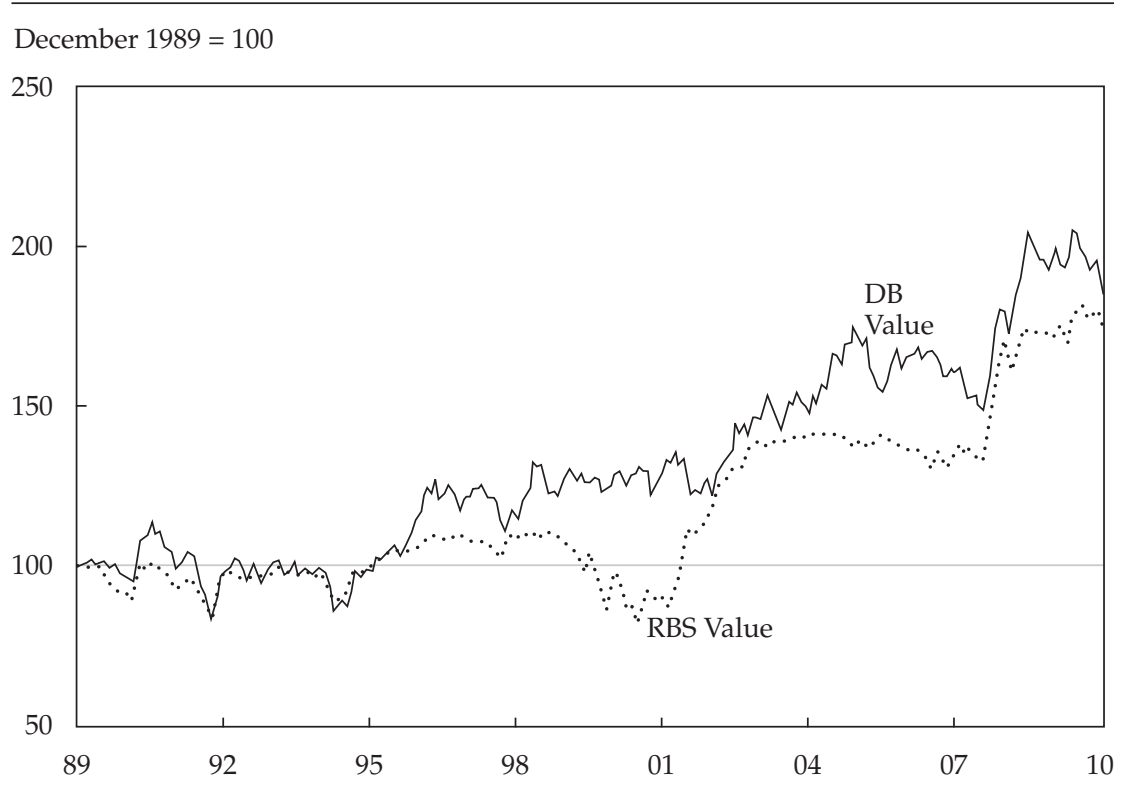


Figures 6-8 confirm the results reported by Gyntelberg and Schrimpf (2011) - namely, that common FX strategies have generated economically significant returns over the past 20 years.

Table 6 shows the simple correlations between the proxies for the four factors over the entire sample. The correlation between the proxies for each factor is reasonably high: $67 \%$ for carry, $45 \%$ for value, and $71 \%$ for trend. An interesting exception is the DB trend. The correlation between the RBS trend and the AFX trend is high at 71\%, but the DB trend has essentially no correlation with either one of them. This difference could be because both the RBS and AFX trend-following results are based on moving-average rules that generate positions in all the major currencies whereas the DB trend strategy is based on long positions in the top three momentum currencies financed by short positions in the bottom three momentum currencies (where momentum is calculated over a single 12-month period).

$\mathrm{DB}$ volatility and RBS volatility are not correlated, but this result is to be expected because the DB volatility factor is simply the difference in the level of implied volatility between period $t$ and period $t-1$ and does not represent the return from a volatility trading strategy. ${ }^{79}$ The RBS volatility, however, captures the return from systematically selling volatility.

Table 6. Correlations of Returns for Carry, Trend, Value, and Volatility Style Factors: January 1990-December 2010 (252 monthly observations)

\begin{tabular}{l|ccccccccc}
\hline & DB & RBS & AFX & DB & RBS & DB & RBS & DB & RBS \\
& Carry & Carry & Index & Trend & Trend & Value & Value & Volatility & Volatility \\
\hline DB carry & 1.000 & 0.671 & -0.081 & -0.114 & -0.011 & 0.098 & -0.220 & -0.421 & 0.068 \\
RBS carry & & 1.000 & 0.052 & 0.118 & 0.133 & -0.280 & -0.430 & -0.132 & 0.091 \\
AFX index & & & 1.000 & 0.161 & 0.707 & 0.077 & 0.131 & 0.443 & -0.368 \\
DB trend & & & & 1.000 & 0.104 & -0.193 & -0.303 & 0.209 & -0.022 \\
RBS trend & & & & & 1.000 & -0.040 & 0.037 & 0.253 & -0.203 \\
DB value & & & & & & 1.000 & 0.448 & -0.146 & -0.203 \\
RBS value & & & & & & & 1.000 & 0.090 & -0.186 \\
DB volatility & & & & & & & & 1.000 & -0.086 \\
RBS volatility & & & & & & & & & 1.000 \\
\hline
\end{tabular}

Note: The DB volatility factor does not represent the return of a trading strategy but measures changes in the FX implied volatility.

\footnotetext{
${ }^{79}$ The DB Currency Volatility Index measures the level of implied volatility for the G-10 currencies (see Appendix A for more details). In our analysis, we use the first difference- that is, the change in the level of implied volatility.
} 
Table 6 reveals essentially no correlation between the trend and carry factors or between trend and value. The DB trend is, again, an exception; it is somewhat negatively correlated with $\mathrm{DB}$ value $(-19 \%)$ and with $\mathrm{RBS}$ value $(-30 \%)$. Carry has been a more profitable trading strategy than value, but there is a somewhat negative correlation between these two factors. The correlation between RBS value and RBS carry is $-43 \%$. Volatility (DB volatility) appears weakly positively correlated with trend and somewhat negatively correlated with carry. Volatility thus appears to be a "friend of the trend" but may work to undermine carry trades that seek to collect interest in a steady FX environment. Surprisingly, the short volatility strategy is not correlated with carry, although they seem to earn almost identical cumulative returns. In general, finding only a small correlation between the factors is important because they play the role of independent, right-hand variables in our regression estimates of Equation 9.

\section{Results for the Barclay Currency Traders Index, 1990-2010}

To examine the relationship between the overall currency returns and explanatory factors, we regressed the excess monthly returns on the BCTI against various combinations of the four factors.

The results for the full sample period are shown in Table 7 and are consistent with results reported in P-L $(2008,2010)$ and Nasypbek and Rehman (2011). First, managers included in the BCTI, as a group, were not able to generate alpha returns. After accounting for our four systematic risk factorscarry, trend, value, and volatility - alpha estimates range from -6 to +8 bps per month, or about $-0.72 \%$ to $0.96 \%$ per year over the 252 -month period. Thus, alpha estimates are statistically and economically not significantly different from zero. The implication of this result is that, although the overall excess return on the BCTI was 22 bps per month (Table 5), this return can be attributed to the four explanatory factors. In other words, the returns represent beta returns. Second, the $R^{2}$ s for the regression are relatively high, indicating that these factors (carry, trend, value, and volatility) account for roughly $40-60 \%$ of the variability in monthly excess returns over the entire sample period.

Trend and carry appear to be the most significant factors. The trend and carry beta coefficients are highly significant in each of the specifications. The $\mathrm{DB}$ trend is the notable exception; it is not statistically significant. The $R^{2}$ in Specification 3, which used the DB trend as the proxy for the trend factor, is only 0.152 - notably lower than the $R^{2}$ s in the other specifications. This finding indicates that currency managers, on average, are collecting different trend-following premiums from those represented by this index. This result does not invalidate the usefulness of the four-factor model. Finding the right 


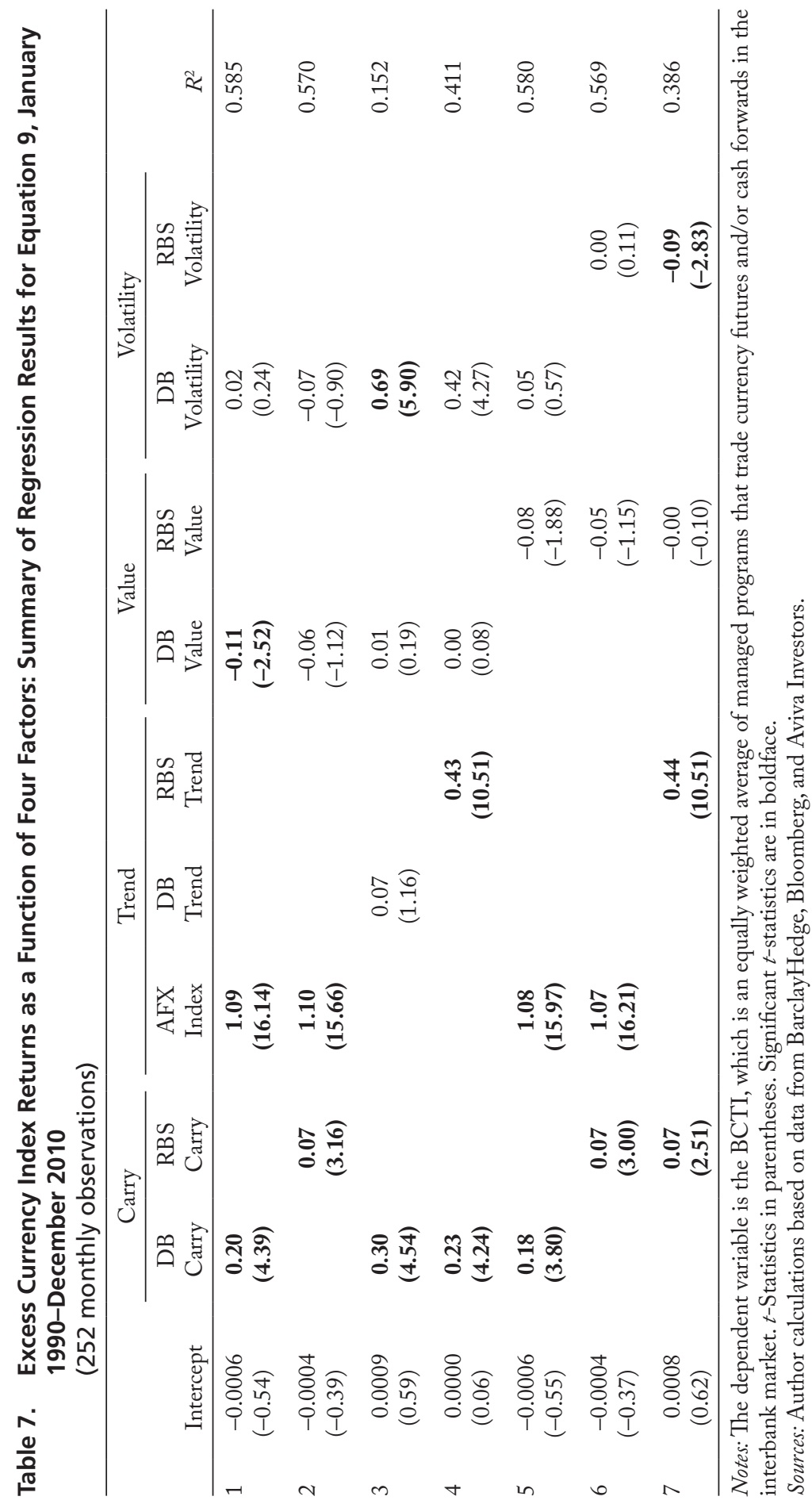


factor is, after all, a matter of empirical analysis. If managers generate return by following a simple, naive strategy that is easily and cheaply replicable, then such return could be considered beta return.

The value coefficient in Table 7 is significant only in Specification 1, and the volatility coefficient is significant in Specifications 3 and 7.

To test for stability of these relationships over time, we divided the sample into four subperiods: January 1990 through December 1994, January 1995 through December 1999, January 2000 through December 2004, and January 2005 through December 2010. The regression results for these four subperiods are shown in Table 8. The results are similar to the results reported by P-L (2008).

Trend is the most significant factor; the coefficients for the AFX trend and the RBS trend are highly significant in all subperiods but substantially higher in the 1990-94 subperiod than in the 2005-10 subperiod. In the first subperiod (Panel A), the trend beta as measured by exposure to the AFX is 1.80 , compared with only $0.31-0.34$ in the $2005-10$ subperiod (Panel D). Results for the RBS trend index instead of the AFX are similar. The trend beta is above 1.0 in the first subperiod and declines to $0.12-0.13$ in the last subperiod.

In contrast, exposure to carry is barely significant in the first two subperiods but becomes highly significant after 2000. These results confirm those reported by P-L (2008). On average, over the 20-year period, managers included in the BCTI increased their exposure to the carry factor and reduced their exposure to the trend factor in the post-2000 period. The results are also consistent with other evidence that returns on simple currency trend-following strategies declined in the late 1990s and beyond, leading currency managers to shift away from trend-following rules (see Pukthuanthong-Le, Levich, and Thomas 2007 and Pukthuanthong-Le and Thomas 2008). Table 9 highlights these results by reporting the estimates for two subperiods-January 1990 through December 1999 and January 2000 through December 2010, respectively. On the one hand, exposure to trend clearly declined by $60-75 \%$ in the post-2000 period. On the other hand, exposure to carry is rarely significant prior to 2000 but highly significant after 2000, regardless of the specification.

Panels C and D in Table 8 highlight the impact of the global financial crisis on exposure to carry. The carry beta (as measured by exposure to the DB carry index) is highly significant and ranges from 0.18 (Specification 5) to 0.36 (Specification 4) in the subperiod January 2000 through December 2004, but it declines to $0.06-0.08$ for the subperiod January 2005 to December 2010. This outcome suggests that liquidation of the carry trades during the global financial crisis was substantial and that, as a group, currency managers reduced their exposure to carry. 


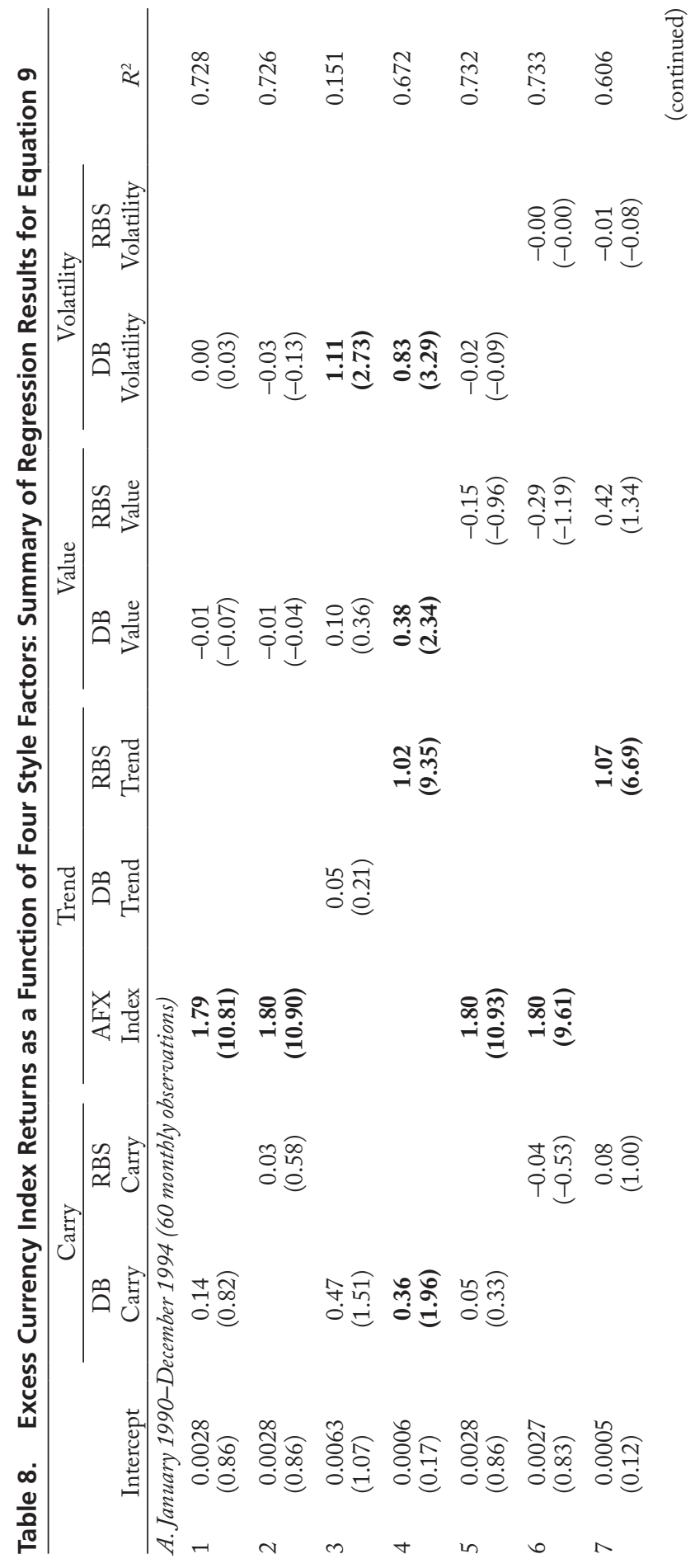




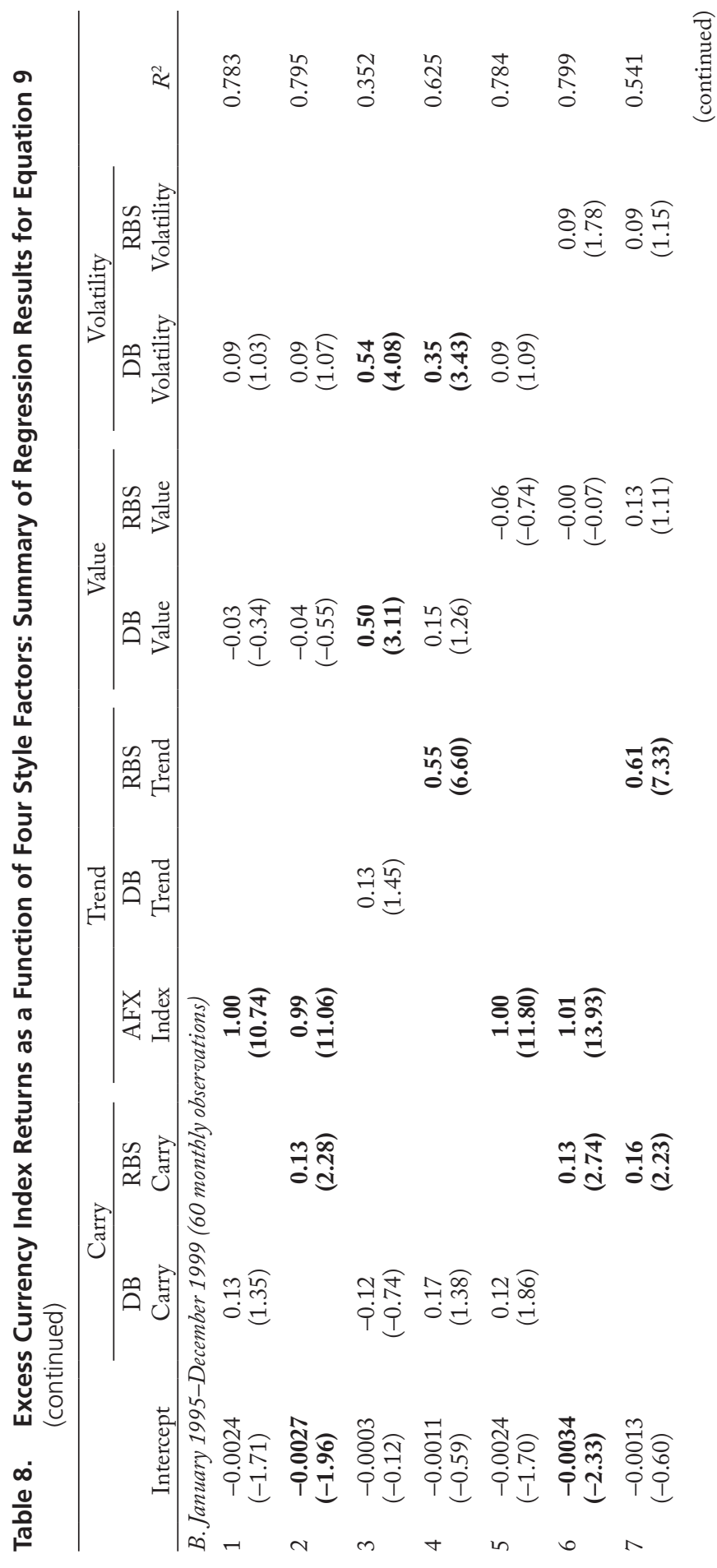




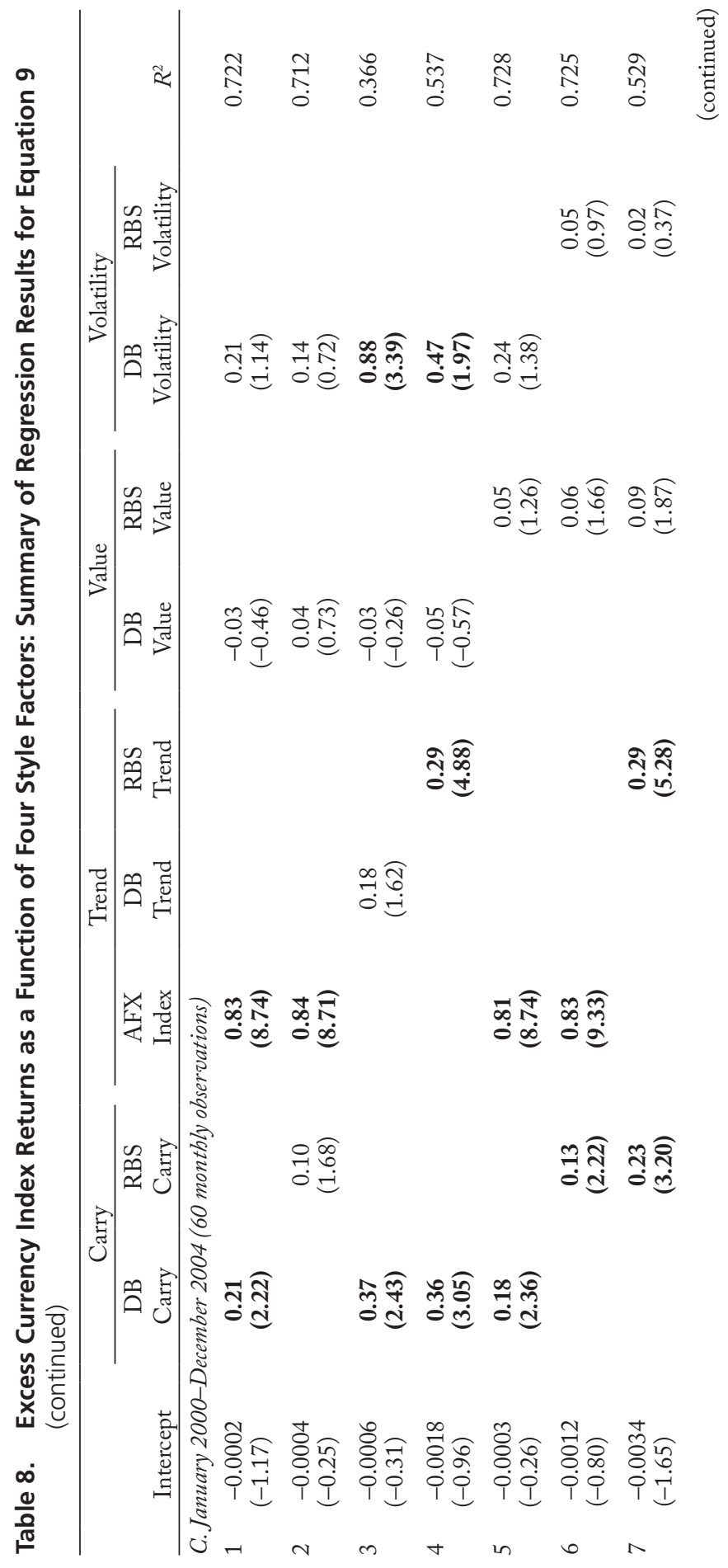




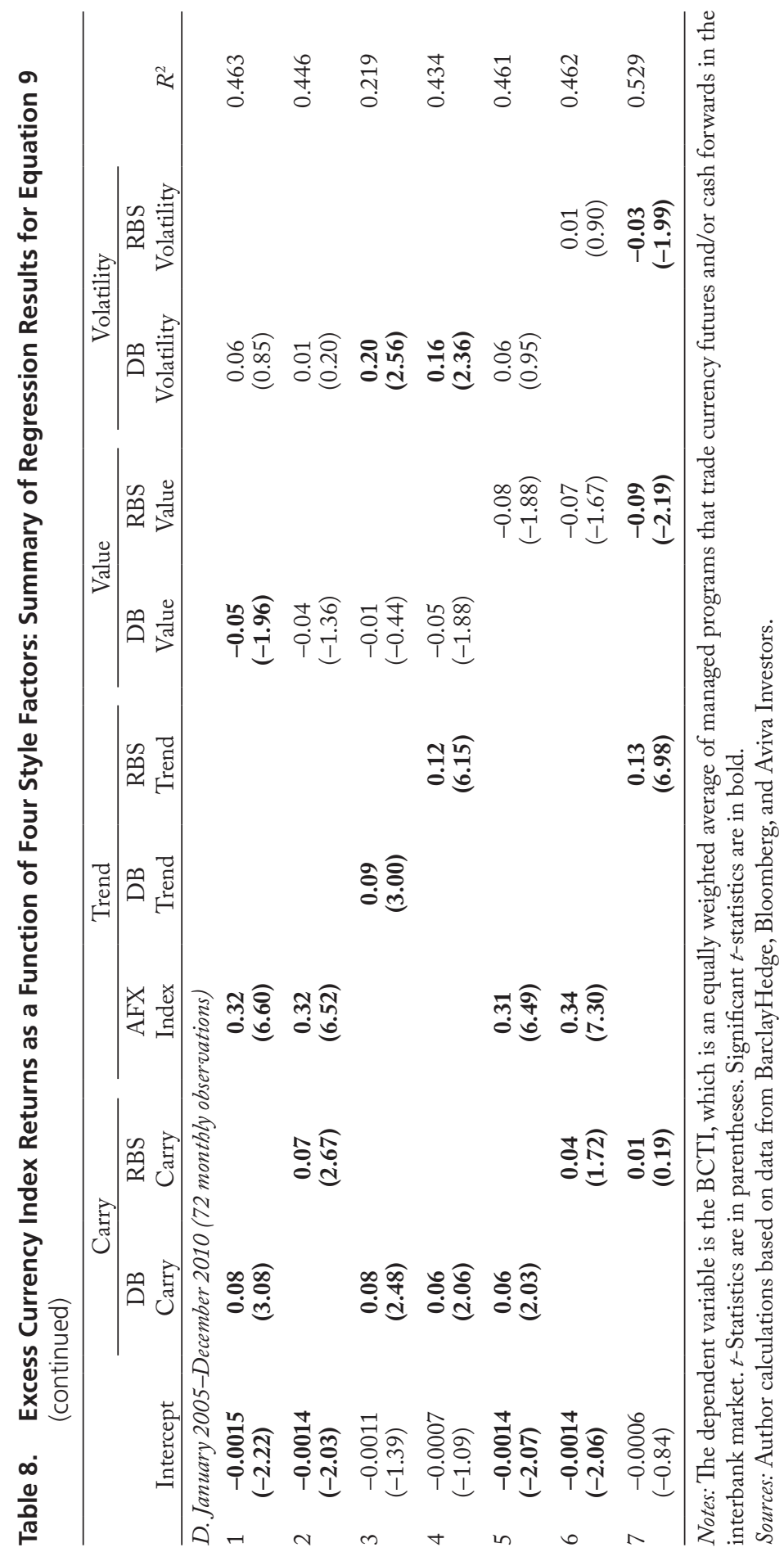




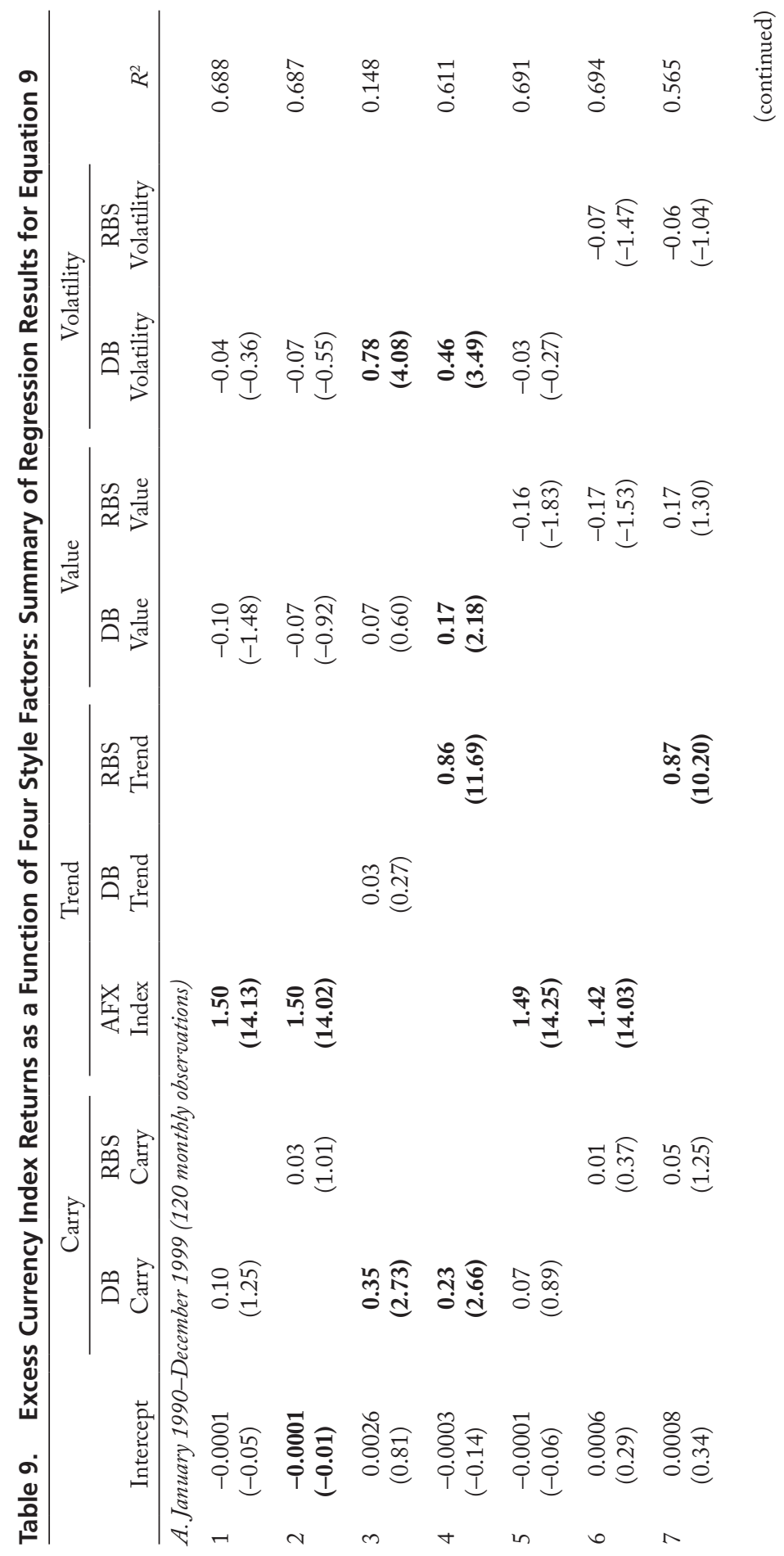




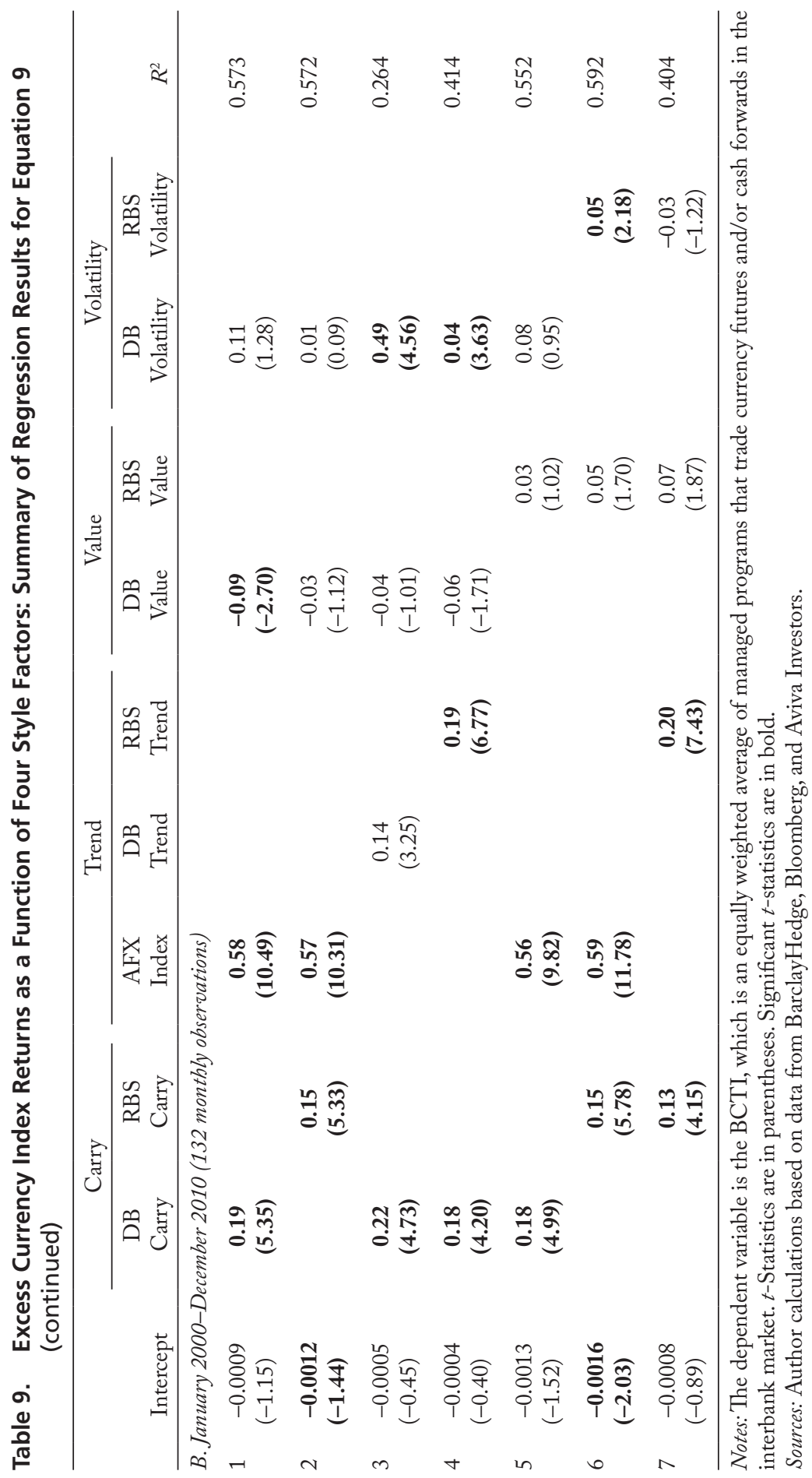


Interestingly, the intercept (alpha) is negative and significant for most specifications in Table 8, Panel D, the period from January 2005 until December 2010. Currency managers, on average, not only failed to deliver positive alpha, but they actually subtracted value from their clients during the last six years of the sample. This result highlights that the period of the global financial crisis has been quite challenging for currency investment managers and may explain why the number of funds as reported in Figure 5 is still below the peak reached in 2008.

Emerging Markets. The risk factors used in the previous section represent returns from generic trading strategies in only the major currencies. To investigate whether currency managers, as a group, have taken a significant degree of exposure to EM currencies, we collected data on two generic factors that measure exposure to EM currencies.

In addition to a G-10 carry index, Deutsche Bank also calculates two additional carry indices, which provide exposure to EM currencies: ${ }^{80}$

- the Global Currency Harvest Index, based on the 10 major currencies and $10 \mathrm{EM}$ currencies (shorting the 5 currencies with the lowest interest rates to purchase the 5 currencies with the highest interest rates) and

- the Balanced Currency Harvest Index, based on the 10 major currencies and $10 \mathrm{EM}$ currencies but with a minimum of $2 \mathrm{G}-10$ currencies on the funding (short) side and 2 on the investment (long) side.

A more detailed description of these indices is given in Appendix A.

In Table 10, we report regression results for Equation 9, in which these two indices were used to test for exposure to EM currencies. Because data on the Harvest Global have been available only since October 2000 and on the Harvest Balanced only since January 2000, our results cover only the 10 years from January 2001 through December 2010.

Table 10 shows essentially no increase in $R^{2}$ when a G-10 carry index was replaced with a carry index that invests in both developed and emerging market currencies. This finding implies that currency managers, as a group, do not have significant carry exposure to EM currencies. This finding does not imply, however, that currency managers do not invest in EM currencies; rather, it implies that managers (as a group) may be seeking trend (and/or value) exposure rather than, specifically, carry exposure to EM currencies. Indeed, Pojarliev (2005) finds that trend-following strategies work better for emerging market currencies whereas carry trading strategies perform better for developed market currencies. Unfortunately, we are not aware of the existence of indices designed to proxy the returns of trend and value strategies for EM currencies.

\footnotetext{
${ }^{80}$ The exact index name is the Deutsche Bank Currency Harvest G10 Index. For more information, see Appendix A.
} 
Table 10. EM Carry Factors and Excess Currency Index Returns: Summary of Regression Results for Equation 9, January 2001-December 2010 (120 monthly observations)

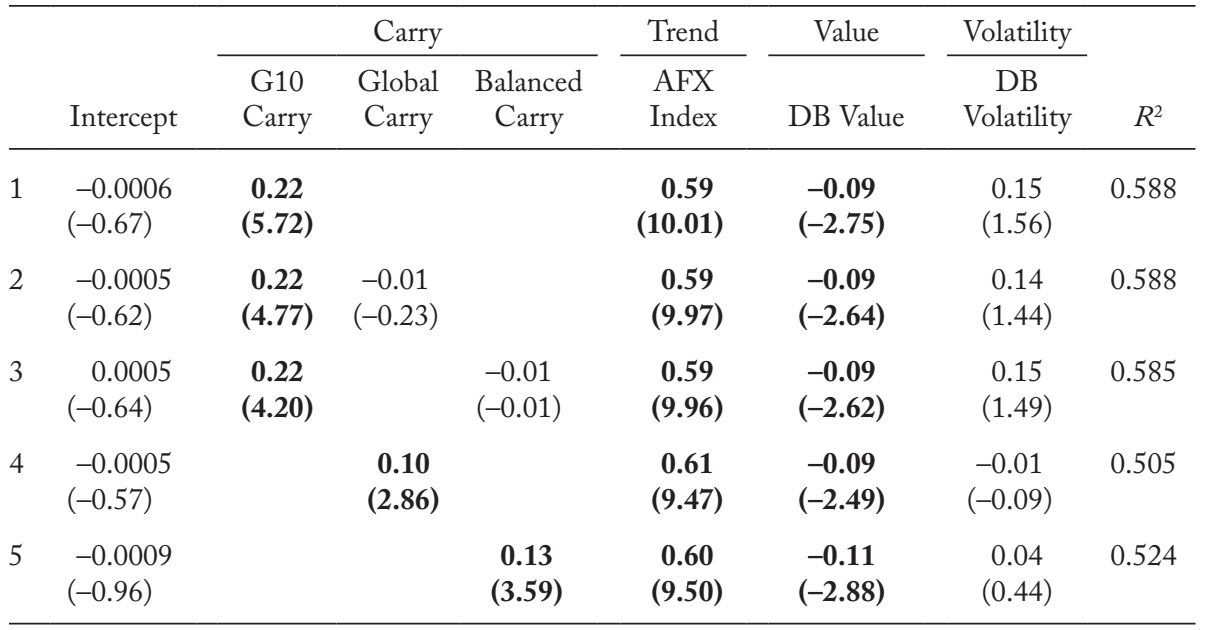

Notes: The dependent variable is the BCTI, which is an equally weighted average of managed programs that trade currency futures and/or cash forwards in the interbank market. $t$-Statistics in parentheses. Significant $t$-statistics are in boldface.

Sources: Author calculations based on data from BarclayHedge, Bloomberg, and Aviva Investors.

The limited availability of EM currency products is consistent with the 2010 survey by the Bank of International Settlements, which shows that the bulk of market turnover is conducted in the so-called major currencies. As Table 4 shows, the market share of top three currencies (U.S. dollar, euro, and Japanese yen) are, respectively, 84.9\%, 39.1\%, and 19.0\%. The market share of the emerging market currencies remained modest (at 14\%) in April 2010 compared with 12.3\% in April 2007. The U.S. dollar, euro, and Japanese yen were involved in $99 \%$ of the trading with EM currencies; the dollar was involved in $85 \%$ of the trading. In other words, pure EM currency trading, with an EM currency on both the bid side and the offer side, is negligible.

Single-Index Factor Model. Estimating Equation 9 allows insights about a manager's investment style, but the beta coefficients are not known ex ante, so the alpha estimates may be biased downward. Put differently, without knowledge of the betas, Equation 9 is not an investable strategy that managers can mimic even if they want to. One intuitive solution to this dilemma is to consider a single-index model, based on an equally weighted combination of possible currency investment strategies, to be representative of a naive investment strategy. This single index with fixed weights then becomes an investable currency strategy. If a manager outperforms this index, perhaps simply 
by varying the allocation across styles, then the outperformance constitutes alpha. To address this possibility, we estimated a single-index model in which the index, $F$, is an equally weighted average of the available currency strategies.

We constructed three single-factor indexes. $F^{*}$ is an equally weighted combination of the $\mathrm{DB}$ carry, $\mathrm{AFX}$, and $\mathrm{DB}$ value indices; $F^{* *}$ is an equally weighted combination of the $\mathrm{DB}$ carry, $\mathrm{DB}$ trend, and $\mathrm{DB}$ value indices; and $F^{* * *}$ is an equally weighted combination of the RBS carry, RBS trend, RBS value, and RBS volatility indices. Note that $F^{*}$ and $F^{* *}$ omit the volatility factor because the DB volatility index does not represent an investable strategy.

Table 11 reports the regression results of the three single-factor models for all subperiods and the full 21-year period. As an empirical matter, our estimates of alpha and inferences about excess performance are essentially unchanged when based on the single-factor index model. As expected, the $R^{2}$

Table 11. Single-Factor Model

( $t$-statistics in parentheses)

\begin{tabular}{ccccc}
\hline Intercept & $F^{*}$ & $F^{* *}$ & $F^{* * *}$ & $R^{2}$ \\
\hline
\end{tabular}

\begin{tabular}{|c|c|c|c|c|c|}
\hline \multicolumn{6}{|c|}{ A. January 1990-December $2010(N=252)$} \\
\hline Specification 1 & $\begin{array}{c}0.0002 \\
(0.15)\end{array}$ & $\begin{array}{c}0.71 \\
\mathbf{( 6 . 4 5 )}\end{array}$ & & & 0.142 \\
\hline Specification 2 & $\begin{array}{l}0.0015 \\
(0.86)\end{array}$ & & $\begin{array}{c}0.25 \\
\mathbf{( 2 . 1 0 )}\end{array}$ & & 0.017 \\
\hline Specification 3 & $\begin{array}{c}0.0007 \\
(0.42)\end{array}$ & & & $\begin{array}{c}0.43 \\
\mathbf{( 4 . 6 7 )}\end{array}$ & 0.080 \\
\hline \multicolumn{6}{|c|}{ B. January 1990-December $1994(N=60)$} \\
\hline Specification 1 & $\begin{array}{l}0.0045 \\
(0.89)\end{array}$ & $\begin{array}{c}2.49 \\
(5.33)\end{array}$ & & & 0.329 \\
\hline Specification 2 & $\begin{array}{l}0.0062 \\
(0.99)\end{array}$ & & $\begin{array}{c}0.13 \\
(0.19)\end{array}$ & & 0.000 \\
\hline Specification 3 & $\begin{array}{c}0.0054 \\
(0.89)\end{array}$ & & & $\begin{array}{c}0.36 \\
(1.40)\end{array}$ & 0.032 \\
\hline \multicolumn{6}{|c|}{ C. January 1995-December $1999(N=60)$} \\
\hline Specification 1 & $\begin{array}{l}-0.0007 \\
(-0.26)\end{array}$ & $\begin{array}{c}0.54 \\
\mathbf{( 4 . 0 5 )}\end{array}$ & & & 0.220 \\
\hline Specification 2 & $\begin{array}{l}0.0006 \\
(0.21)\end{array}$ & & $\begin{array}{c}0.31 \\
\mathbf{( 1 . 9 7 )}\end{array}$ & & 0.063 \\
\hline Specification 3 & $\begin{array}{l}-0.0033 \\
(-1.35)\end{array}$ & & & $\begin{array}{c}1.18 \\
\mathbf{( 5 . 8 7 )}\end{array}$ & 0.373 \\
\hline
\end{tabular}


Table 11. Single-Factor Model (continued)

(t-statistics in parentheses)

\begin{tabular}{ccccc}
\hline Intercept & $F^{*}$ & $F^{* *}$ & $F^{* * *}$ & $R^{2}$ \\
\hline D. January $2000-D e c e m b e r 2004(N-60)$ &
\end{tabular}

D. January 2000-December $2004(N=60)$

Specification 1

$-0.0001$

0.61

0.196

$(-0.03)$

(3.75)

Specification 2

$$
0.0004
$$

(0.15)

0.40

0.089

(2.39)

Specification 3

$-0.0033$

0.72

0.386

$(-1.56)$

(6.04)

E. January 2005-December $2010(N=72)$

$\begin{array}{llc}\text { Specification } 1 & -0.0013 & 0.15 \\ & (-1.49) & \mathbf{( 2 . 4 0}\end{array}$

0.076

Specification 2

$-0.0012$

$(-1.39)$

0.13

0.065

(2.21)

Specification 3

$-0.0009$

$(-1.12)$

0.09

0.045

F. January 1990-December $1999(N=120)$

Specification 1 0.0013

$$
\text { (0.44) }
$$

(5.02)

Specification 2

$$
0.0035
$$

0.25

0.009

Specification 3

(1.04)

$\begin{array}{cc}0.51 & 0.065 \\ \mathbf{( 2 . 8 6 )} & \end{array}$

G. January 2000-December $2010(N=132)$

Specification 1

$-0.0005$

0.37

$(-0.49)$

(4.43)

Specification 2

$$
-0.0003
$$

0.26

$(-0.27)$

(3.17)

0.072

Specification 3

$-0.0007$

$(-0.69)$

0.36

(5.67)

Notes: In Specification $1, F^{*}$ is an equally weighted combination of DB carry, AFX, and DB value. In Specification $2, F^{* *}$ is an equally weighted combination of DB carry, DB trend, and DB value. In Specification $3, F^{* * *}$ is an equally weighted combination of RBS carry, RBS trend, RBS value, and RBS volatility. 
is considerably lower than when the four-factor model was used (see Tables 7-9). The estimated alphas are somewhat larger for the single-factor model but, again, not significantly different from zero. Whereas the four-factor model might underestimate alpha, the single-factor model might, in some cases, overestimate alpha. For example, suppose a manager has publicized the intention of mimicking a single strategy (e.g., carry), for which the manager then earns a positive return. Evaluating this manager's return against a single index combining many strategies would leave some returns unexplained and labeled "alpha" when, in fact, they are beta returns wholly related to a single strategy.

\section{Results for the Deutsche Bank dbSelect Platform, 2005-2010}

Empirical analysis of returns earned by professional investment managers should take into account the possible impact of survivorship and reporting bias. The number of funds in the BCTI grew from 44 in 1993 to 117 in 2011. By design, however, the index includes only those managers who entered the currency management business, survived, and offered to supply their data to BarclayHedge.

In self-reported data of this sort, backfill and survivorship bias can be severe. Malkiel and Saha (2005) report that for a generic sample of hedge funds, backfill bias averages $7.3 \%$ per year and survivorship bias averages $4.4 \%$ per year. To address backfill and survivorship biases, we used the same database as in P-L (2011b) — namely, daily return data for currency managers listed on the dbSelect trading platform. ${ }^{81}$ The dbSelect dataset is unique relative to other hedge fund databases because it provides actual return data, made possible because gains and losses are computed by Deutsche Bank on the basis of real trades processed through the bank's prime brokerage. The return data are audited by an independent third party. In contrast, hedge fund databases simply collect return data submitted by managers and are affected

\footnotetext{
${ }^{81}$ Launched in March 2005 under the name FXSelect, dbSelect is an open platform of managed accounts held by Deutsche Bank, which allows investors to allocate investments to a variety of currency managers. According to information posted on its website, dbSelect had attracted USD3.7 billion in AUM from pension funds, funds of funds, private banks, insurance companies, and other investors as of August 2010. Any currency manager can apply for registration on the platform and be accepted by satisfying the following criteria: (1) Managers must be able to provide a daily track record for at least the last 18 months verified by a third party, (2) managers cannot have had more than a $20 \%$ performance drawdown over the preceding 12 months, (3) AUM must be at least USD15 million, and (4) criminal and regulatory searches on key individuals must be satisfactory. We are grateful to Neville Bulgin and Rashid Hoosenally from Deutsche Bank for supplying the data.
} 
by numerous biases. ${ }^{82}$ Thus, our dataset is especially useful for studying the currency management industry. Our data cover slightly more than five years, from 6 April 2005 through 30 June 2010. We obtained daily data, but to correct for accounting errors and eliminate data outliers, we transformed the daily returns into 274 weekly returns by using Wednesday observations. ${ }^{83}$

During our sample period, 107 currency funds were active on the platform at some point. ${ }^{84}$ Of these, only 67 funds were active as of 30 June 2010. Another 40 managers joined the platform and exited prior to the end of the sample period. Figure 9 plots the number of funds on the platform, together with the funds that joined the platform and those that delisted in the period 2005-2010. At the beginning of our sample, 22 funds were available on the platform, but only 10 of these funds (or fewer than 50\%) survived until the end of the sample. This information highlights the fact that our sample covers a challenging investment period. It encompasses the global financial crisis in 2008-2009 and the European debt crises in 2010. So, survivorship bias could be severe. Using the performance of the listed and delisted funds, we computed the survivorship bias to be $5.30 \%$, similar to the results reported by Malkiel and Saha (2005). ${ }^{85}$

As noted in the previous paragraph, 10 funds in our dbSelect sample had a complete 63-month track record. Analysis of these funds' performance allowed us to examine individual currency manager returns. Annualized returns, standard deviations of returns, and other performance measures for these 10 managers are shown in Table 12. The average annual return ranges from a low of $-1.96 \%$ to a high of $12.96 \% .{ }^{86}$

\footnotetext{
${ }^{82}$ In addition to Fung and Hsieh's (2000) examination of various biases that affect the estimate of average hedge fund returns, Aggarwal and Jorion (2010) have investigated bias that resulted from the merger of the Tremont database into the TASS database. Aiken, Clifford, and Ellis (2010) measured the self-reporting bias attributable to funds that choose to report versus those that do not.

${ }^{83}$ We used Wednesday because fewer bank holidays fall on Wednesday than on other days. Managers were based in various locations (Australia, Canada, Germany, Ireland, Monaco, Spain, Sweden, Switzerland, the United Kingdom, and the United States).

${ }^{84} \mathrm{We}$ use the terms "manager" and "fund" interchangeably here. Note that one currency management firm may have multiple funds or programs on the platform. Although we may use the term "fund," currency programs do not have to be funded. In fact, many currency management firms offer currency programs via managed accounts that require only minimal funding (about $10 \%$ of the notional). Indeed, the nonfunded nature of currency investments is one of its advantages as a portable alpha strategy.

${ }^{85}$ The mean annual return of all 107 funds (live and dead), while listed on the platform, is 4 bps for the period. The mean annual return of only the live funds is $534 \mathrm{bps}$.

${ }^{86}$ Note that these returns are gross of fees. Returns to investors would be lower after deducting managers' fees and fees collected by Deutsche Bank.
} 
Figure 9. Funds on dbSelect Platform: Total Number, Newly Listed, and Delisted, 6 April 2005-30 June 2010

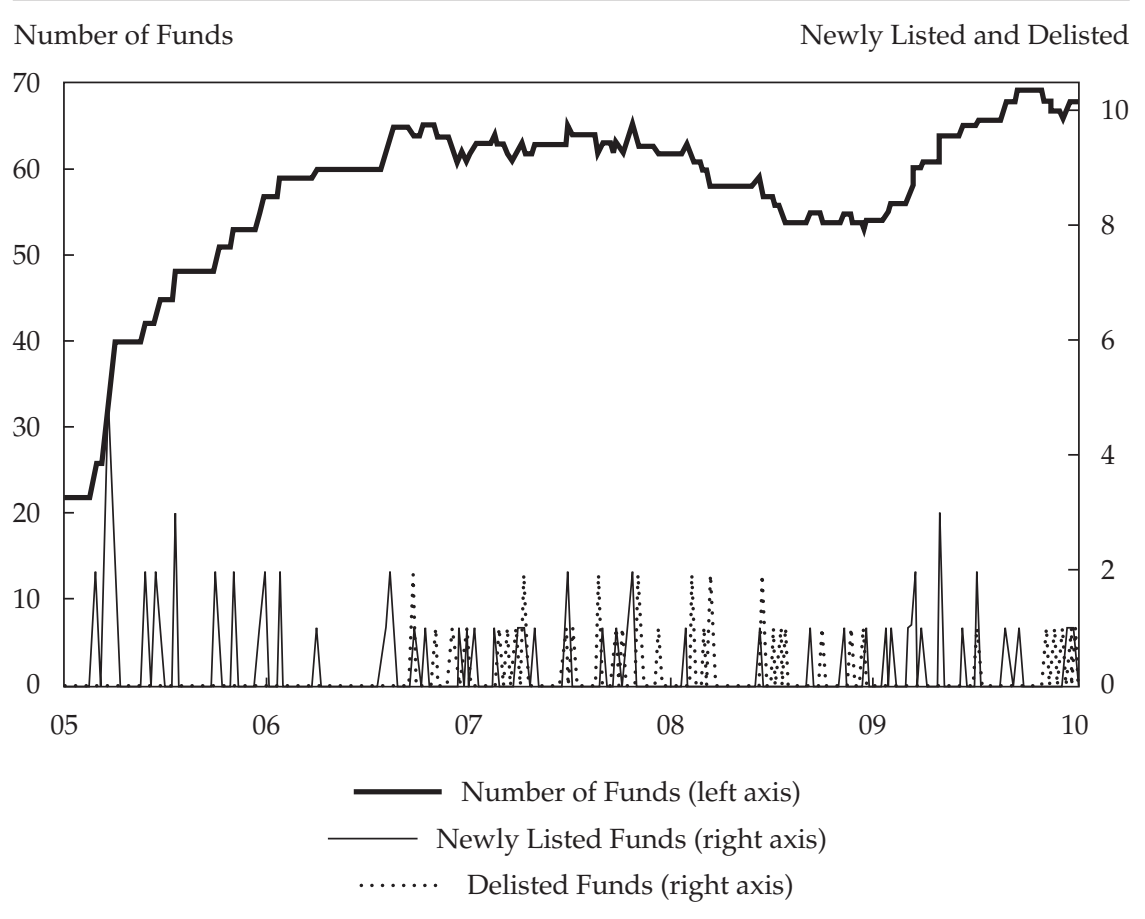

Source: Pojarliev and Levich (2011b).

Table 12. Performance of Selected Currency Managers on the dbSelect Platform, 6 April 2005-30 June 2010

\begin{tabular}{lcccccc}
\hline Manager & $\begin{array}{c}\text { Annual } \\
\text { Return }\end{array}$ & Std. Dev. & IR & $\begin{array}{c}\text { Annual } \\
\text { Alpha }\end{array}$ & $\begin{array}{c}\text { Tracking } \\
\text { Error }\end{array}$ & IR* $^{*}$ \\
\hline L10 & $2.02 \%$ & $3.91 \%$ & 0.52 & $1.45 \%$ & $3.70 \%$ & 0.39 \\
L15 & -1.96 & 13.48 & -0.15 & 0.50 & 11.80 & 0.04 \\
L28 & 7.58 & 4.99 & 1.52 & 7.59 & 4.89 & 1.55 \\
L29 & 12.96 & 17.78 & 0.73 & 12.69 & 16.91 & 0.75 \\
L35 & 3.02 & 13.07 & 0.23 & 3.34 & 12.76 & 0.26 \\
L42 & 9.72 & 14.18 & 0.69 & 7.65 & 11.63 & 0.66 \\
L47 & 2.15 & 3.94 & 0.54 & 2.57 & 3.88 & 0.66 \\
L49 & 4.70 & 5.46 & 0.86 & 4.08 & 5.16 & 0.79 \\
L50 & 1.31 & 16.67 & 0.08 & -3.36 & 13.51 & -0.25 \\
L53 & 2.53 & 12.23 & 0.21 & 3.13 & 11.12 & 0.28 \\
\hline
\end{tabular}

Notes: Includes only managers with 274 weekly observations. IR is an information ratio, equal to the ratio of average annual returns to standard deviation of returns. IR* is an alternative information ratio that is equal to the ratio of estimated alpha, $\hat{\alpha}_{j}$, to its standard deviation $\sigma\left(\hat{\alpha}_{j}\right)$. 
Because currency-trading programs can be initiated with interest-earning assets serving as collateral, the annualized return has traditionally been interpreted as an excess return and the standard deviation as the tracking error. The information ratio (IR) is then simply the annualized return divided by the annualized standard deviation. The results in Table 12 show that these 10 currency managers have been performing well since 2005; the average IR, which ranges from a disappointing -0.15 to an impressive 1.52 , is 0.52 . Note that these results overstate the performance achieved by the currency management industry because of the severe survivorship bias.

Our goal is to illustrate how the four-factor model could be applied to individual managers to differentiate between alpha hunters and beta grazers. In our framework as presented in Equation 9, excess returns for fund manager $j$ would be only that portion of returns, $\alpha_{j}$, that are not explained by the four factors, or

$$
\hat{\alpha}_{j}=R_{j, t}-\sum_{i} \hat{\beta}_{i, j} F_{i, t}+\varepsilon_{j, t} .
$$

We can thus define an alternative information ratio

$$
I R_{j}^{*}=\frac{\hat{\alpha}_{j}}{\sigma\left(\hat{\alpha}_{j}\right)}
$$

that reflects estimated alpha divided by its standard deviation. Calculations shown in Table 12 illustrate that IR* is quite different from the traditional IR for some of the managers. For example, on the one hand, L50 has an IR* that is considerably lower than the traditional IR ${ }^{87}$ On the other hand, L15 has an IR* that is markedly higher than the traditional IR. This outcome occurs because some funds are earning beta returns while other funds are generating pure alpha returns.

When data analysis reveals that currency returns could be replicated cheaply with naive trading strategies, then investors may be less willing to pay active management fees. To investigate how much of these returns is pure alpha and how much is because of exposure to risk factors (beta), we regressed the monthly returns of the 10 currency managers against the same four explanatory factors as in Specification 1 in Table 7. (We chose Specification 1 because it yielded the highest $R^{2}$ in Table 7.)

Table 13 summarizes the regression results. Several observations stand out. First, only one manager, L28, exhibits positive and significant alpha (intercept). This result shows that the performance statistics from Table 12 may be misleading in that a substantial part of the returns stems from exposure to our trading factors. In the context of our factor model (Equation 9), returns generated by currency managers may include both alpha and beta

\footnotetext{
${ }^{87} \mathrm{~L} 50$ stands for manager \#50 in the database. We are using the same notation for managers as in P-L (2010) and P-L (2011b).
} 
Table 13. Regression Results for Equation 10 for Individual Currency Managers: Managers $j=1, \ldots, 10,6$ April 2005-30 June 2010

(based on 274 weekly observations)

\begin{tabular}{lccccccccccc}
\hline & & \multicolumn{3}{c}{ Beta } & \multicolumn{3}{c}{ Beta } & \multicolumn{3}{c}{ Beta } & \multicolumn{3}{c}{ Beta } \\
Manager & Intercept & $t$-Stat & Carry & $t$-Stat & Trend & $t$-Stat & Value & $t$-Stat & Volatility & $t$-Stat & $R^{2}$ \\
\hline L10 & 0.0003 & 0.91 & 0.01 & 0.71 & 0.14 & $\mathbf{3 . 2 4}$ & 0.01 & 0.31 & 0.13 & $\mathbf{2 . 4 1}$ & 0.102 \\
L15 & 0.0001 & 0.09 & 0.43 & $\mathbf{6 . 6 0}$ & 0.49 & $\mathbf{3 . 6 0}$ & -0.58 & $-\mathbf{6 . 7 0}$ & 0.25 & 1.50 & 0.233 \\
L28 & 0.0015 & $\mathbf{3 . 5 2}$ & -0.02 & -0.85 & 0.04 & 0.70 & -0.05 & -1.45 & 0.11 & 1.50 & 0.037 \\
L29 & 0.0024 & 1.70 & -0.30 & $-\mathbf{3 . 2 0}$ & -0.32 & -1.64 & -0.02 & -0.15 & 0.63 & $\mathbf{2 . 5 8}$ & 0.094 \\
L35 & 0.0006 & 0.59 & 0.13 & 1.77 & 0.08 & 0.54 & 0.02 & 0.23 & -0.37 & $-\mathbf{2 . 0 0}$ & 0.047 \\
L42 & 0.0015 & 1.49 & -0.60 & $-\mathbf{9 . 3 7}$ & -0.11 & -0.82 & 0.16 & 1.85 & 0.18 & 1.08 & 0.327 \\
L47 & 0.0005 & 1.49 & 0.01 & 0.24 & -0.07 & -1.57 & -0.05 & -1.69 & 0.07 & 1.23 & 0.028 \\
L49 & 0.0008 & 1.78 & -0.03 & -0.93 & 0.15 & $\mathbf{2 . 6 0}$ & -0.01 & -0.17 & 0.17 & $\mathbf{2 . 2 7}$ & 0.106 \\
L50 & -0.0007 & -0.57 & -0.03 & -0.40 & 1.42 & $\mathbf{9 . 1 5}$ & 0.06 & 0.64 & 0.16 & 0.80 & 0.343 \\
L53 & 0.0006 & 0.64 & 0.35 & $\mathbf{5 . 7 7}$ & 0.68 & $\mathbf{5 . 3 2}$ & -0.33 & $-\mathbf{4 . 0 3}$ & 0.02 & 0.10 & 0.173 \\
\hline
\end{tabular}

Note: Significant $t$-statistics are in boldface.

returns. For example, Manager L50 has significant exposure to the trendfollowing strategy. The trend coefficient is large (1.42) and highly significant ( $t$-value of 9.15), and the $R^{2}(0.343)$ is the highest of all 10 managers. Table 12 indicates that Manager L50 generated annualized returns of $1.31 \%$ over this 63-month period, but this manager's performance appears to reflect primarily beta returns. The alpha for L50 is negative ( -7 bps per week) and not statistically different from zero.

Second, the highest factor exposure is to trend following. The trend factor is significant for $50 \%$ of the managers. The carry factor is significant for four managers, but two managers have significant negative exposure to carry. Value is significant for only two managers, and five managers are significantly exposed to volatility.

Eight of the ten managers have a significant exposure to at least one factor; three of those have a significant exposure to two factors. One manager has a significant exposure to three factors, and one, to all four factors. These results imply that managers have been diversifying across styles by having exposure to more than one style factor. 


\section{Summary of Empirical Results}

Overall, these empirical results show that four factors, representing three styles of currency investing and the volatility of the FX market, explain a significant part of the returns of professional currency managers. ${ }^{88}$ The average excess return of the BCTI was positive at 22 bps per month between 1990 and 2010. Once we account for the four systematic beta factors, however, the alpha is no longer positive or significant. ${ }^{89}$ Most importantly, these results are robust to using different proxies for the risk factors, different datasets for returns of professional currency managers, and measurement over different time horizons. This result demonstrates that currencies have similarities with other asset classes whose returns can be related to risk factors.

Trend appears to be the most important factor, followed by carry; value and volatility appear to be less important. Interestingly, the value beta in most cases (or specifications) is negative, indicating that currency managers, as a group, were betting against PPP during the sample period. ${ }^{90}$

Note some interesting differences between the various subperiods. For example, managers reduced their exposure to trend in the post-2000 period relative to the 1990s. The highest exposure to carry (as measured by the size of the beta estimates) was recorded in the 2000-04 period; this exposure was sharply reduced between 2005 and 2010.

Note that the reported alpha estimates are probably biased toward the downside, thus underestimating the value added by active currency managers. Ideally, the performance of any active manager should be evaluated against available investable passive alternatives that incorporate the transaction costs associated with each dynamic trading strategy. The DB currency indices are investable through existing single products, but the RBS currency indices are not. And an important consideration is that, although the AFX is investable, in the sense that its dynamic strategy is transparent and readily implemented in the $\mathrm{G}-10$ currencies, no live version of the AFX exists that incorporates transaction costs and other market frictions. ${ }^{91}$ This warning could be important because the AFX appears to be the dominant factor in explaining the

\footnotetext{
${ }^{88}$ In some specifications, volatility represents the returns of a trading strategy of being short FX volatility by selling FX options; in others, volatility represents the first difference in the level of FX volatility.

${ }^{89}$ Depending on the proxies for risk factors and time horizon, the alpha is, in some instances, negative and significant.

${ }^{90}$ Betting against value has reduced the total return, on average, because value generated positive returns over the investigated time horizon.

${ }^{91}$ The problem of using style factors that omit transaction costs and other market frictions is present in related empirical studies. The standard evaluation for equity funds calculates alpha in excess of returns on the Fama-French $(1992,1993)$ and Carhart (1997) factors. Although passive indices exist that proxy the Fama-French factors, no passive investment vehicle provides exposure to the momentum factor of Carhart.
} 
returns of the currency managers. An attempt to replicate the actual return of the AFX would be likely to yield lower returns than studies report after transaction costs, management fees, and market impact costs.

Our empirical results suggest that, as with other asset classes, the currency market offers beta-like returns and some managers are able to generate significant alpha returns over and above the returns explained by the style factors. ${ }^{92}$ In the next chapter, we address the question of how institutional managers can add currency alpha and beta to their portfolios.

${ }^{92} \mathrm{P}-\mathrm{L}$ (2008) report that much of the alpha return comes from market timing, with the greatest timing ability apparent in the trend factor. Put differently, managers, as a group, have been able to increase their exposure to trend when returns of trend following rise and decrease their exposure to trend when returns of trend following fall. 


\section{Currency Alpha and Beta for Institutional Investors}

The historical starting point for a U.S. institutional investor is the classic 60/40 portfolio- $60 \%$ stocks and $40 \%$ bonds. This classic portfolio has evolved considerably over the years as institutional investors allocate less to traditional assets, such as equities and bonds, and more to alternative investments, such as hedge funds, private equity, and commodities (Anson 2011). This trend has been partly the result of conventional beliefs that hedge funds can pursue diverse goals, that diversification is the key to successful investing, and that returns on alternative assets have little or no correlation with returns on traditional investments. As the global financial crisis unfolded, however, many hedge funds delivered negative returns. Investors discovered that they were less diversified than expected. In other words, despite the fact that most institutional investors have diversified allocations to span a variety of asset classes, as Leibowitz (2011) points out, "Some level of implicit equity exposure lurks in virtually every asset." This discovery prompted investors to rethink asset allocation. The investment management industry responded by offering (yet again) a variety of new products - for example, insurance against equity tail risk (tail-hedging products) and alternative approaches to asset allocation, such as risk factor-based asset allocation and risk parity (Litterman 2011).

The advocates of risk factor-based asset allocation point out that, on average, correlations between risk factors are lower than correlations between asset classes and that risk factor correlations tend to be more robust to regime shifts than asset class correlations (Lee 2011). Risk parity, the most recent development in the evolution of asset allocation, attempts to equalize risk exposure across various asset classes. Leibowitz and Bova (2007) show that, even in a diversified institutional asset portfolio, up to $90 \%$ of the volatility can be explained by the equity market. Although the typical institutional portfolio is diversified into a variety of asset classes, these asset classes have a correlation with equity markets high enough (especially in periods of market stress) that, overall, equity risk constitutes more than $80 \%$ of the total risk of the portfolios (Anson 2011). A risk parity approach for asset allocation would, therefore, allocate a much smaller amount to equity than is held in the classic $60 / 40$ portfolio.

These new approaches to asset allocation do not invalidate the traditional core-satellite investment approach for asset allocation, in which the bulk of the assets (the core) are invested in long-only managers and a small proportion of assets are invested in satellites, such as hedge funds, real estate, and commodities. The new approaches focus on the question of how to allocate the 
core efficiently. Because the core makes up the bulk of an institution's assets, this question is, of course, extremely important. Yet, in an investment world where beta returns might be too low compared with the usual $5 \%$ spending rate of endowments and 7-8\% required annual returns of most pension funds (the yield on 30-year U.S. Treasuries fell below 3\% in September 2011), the satellites remain a crucial part of the investment portfolio. Leibowitz (2011) points out, "With so many funds in this beta-dominated camp, there will be an ample retinue of potentially motivated buyers for any asset with a reasonable alpha ratio" (p. 7). Therefore, investors should pay close attention to both who is a real alpha hunter (and a candidate for a satellite) and how to allocate assets efficiently and cheaply among various beta grazers (the core).

In this chapter, we consider the possibility that currency is an underused asset class where new beta grazers and alpha hunters can be identified and added to the traditional approach. The key questions for plan sponsors are, (1) Can diversifying at the margin into currency funds benefit their performance, and (2) if so, which currency managers might be most worthwhile to add?

To explore these questions, we considered a benchmark global equity portfolio evaluated against three alternative portfolios with some exposure to currencies. Of course, most institutional investors have diversified allocations that span a variety of asset classes. Remember Leibowitz's (2011) warning, however, about lurking equity exposure in virtually every asset. Consequently, using the MSCI World Index as the benchmark to gauge the benefit of adding currency alpha seems appropriate. Each of the three alternative portfolios allocates $2 \%$ of its assets to a cash margin account to obtain a $20 \%$ notional exposure to currencies through some of the managers listed in Tables 12 and 13. The resulting currency share in the total portfolio is $16.9 \% .{ }^{93}$

Portfolios 1, 2, and 3 all invest $98 \%$ of their assets in a fund that tracks the MSCI World, but each one differs in terms of which currency managers, selected from the dbSelect platform, are allocated the remaining $2 \%$ cash share.

- Portfolio 1: The Currency Beta Portfolio. The currency allocation is invested in an equally weighted exposure of three naive currency indices designed to capture carry, trend, and value beta. The three indices are the $\mathrm{DB}$ carry index, the AFX, and the DB value index.

- Portfolio 2: The Beta-Grazer Portfolio. The currency allocation is invested in an equally weighted exposure of the top three beta grazers (i.e., those with the highest estimated $R^{2} \mathrm{~s}$ ). These are managers L50, L42, and L15.

\footnotetext{
${ }^{93}$ Assume that an investor has USD100 million. He invests USD98 million in the MSCI World via an index fund and uses the other USD2 million as margin to obtain USD20 million notional exposure to three currency managers. He allocates USD6.66 million notional to each of the managers, so the currency share in the total portfolio is then $20 / 118$, or $16.9 \%$.
} 
- Portfolio 3: The Alpha-Generator Portfolio. The currency allocation is invested in an equally weighted exposure of the top three alpha generators (i.e., those with the highest point estimate for alpha). These are managers L29, L28, and L42.

Our empirical results are summarized in Table 14. Our sample period was a disappointing time for global equities. The annual return on the MSCI World was $-2.04 \%$, with a standard deviation of $18.30 \%$. Although currency markets also experienced a turbulent environment in this period, each of the alternative portfolios offered an economically significant improvement over the equity benchmark.

Portfolio 1, which offered exposure to currency beta by simply investing in naive trading strategies (not professionally managed), resulted in an excess return of 45 bps a year with an IR of $0.46 .{ }^{94}$ Portfolio 2 , which relied on beta grazers, achieved higher excess returns at 65 bps a year, but with a lower IR, 0.35 . This interesting result suggests that plan sponsors might be better off investing in exchange-traded funds (ETFs) that mimic the style indices rather than in managers that derive their return from exposure to risk factors. ${ }^{95}$ The

Table 14. Performance of Allocating to Currency Managers Relative to the MSCI World, 6 April 2005-30 June 2010 (274 weeks)

\begin{tabular}{|c|c|c|c|c|c|c|c|c|}
\hline \multirow[b]{2}{*}{ Portfolio } & \multicolumn{4}{|c|}{$\begin{array}{l}\text { 2\% Allocation to Currency } \\
\text { Managers }\end{array}$} & \multicolumn{4}{|c|}{$\begin{array}{l}\text { 10\% Allocation to Currency } \\
\text { Managers }\end{array}$} \\
\hline & $\begin{array}{l}\text { Excess } \\
\text { Return }\end{array}$ & $\begin{array}{l}\text { Tracking } \\
\text { Error }\end{array}$ & IR & $\begin{array}{l}\text { Standard } \\
\text { Deviation }\end{array}$ & $\begin{array}{l}\text { Excess } \\
\text { Return }\end{array}$ & $\begin{array}{l}\text { Tracking } \\
\text { Error }\end{array}$ & IR & $\begin{array}{l}\text { Standard } \\
\text { Deviation }\end{array}$ \\
\hline $\begin{array}{l}\text { Portfolio 1: } \\
\text { Equity + FX } \\
\text { beta }\end{array}$ & $45 \mathrm{bps}$ & $98 \mathrm{bps}$ & 0.46 & $18.34 \%$ & $227 \mathrm{bps}$ & 491 bps & 0.46 & $19.00 \%$ \\
\hline $\begin{array}{l}\text { Portfolio 2: } \\
\text { Equity + beta } \\
\text { grazers }\end{array}$ & 65 & 185 & 0.35 & 17.62 & 323 & 925 & 0.35 & 16.75 \\
\hline $\begin{array}{l}\text { Portfolio 3: } \\
\text { Equity + alpha } \\
\text { generator }\end{array}$ & 206 & 197 & 1.04 & 17.39 & 1029 & 985 & 1.04 & 15.77 \\
\hline
\end{tabular}

Notes: Returns were measured in U.S. dollars. The $2 \%$ share when levered up by 10 results in an effective $16.9 \%$ allocation in currency and $83.1 \%$ allocation in equity. The $10 \%$ share when levered up by 10 results in an effective $52.6 \%$ allocation in currency and $47.4 \%$ allocation in equity. Over the sample period, the MSCI produced a $-2.04 \%$ annual return with standard deviation of $18.30 \%$. The excess return here is the annual return of the portfolio less than the annual return of the MSCI World. The annual rate of return was computed as the average weekly return multiplied by 52 . The tracking error was computed as the standard deviation of the difference between the portfolio and MSCI World return. The information ratio is the excess return divided by the tracking error.

${ }^{94}$ This result is similar to results reported in Kroencke, Schindler, and Schrimpf (2011).

${ }^{95}$ For example, Deutsche Bank offers ETFs that mimic the return of the DB carry, trend, and value style indices. For more information, see www.etf.db.com. 
alpha managers, however, would offer a significant improvement over such ETFs. Portfolio 3, which invested in the alpha generators, resulted in an excess return of 206 bps a year with an impressive IR of 1.04 .

It is also striking that the standard deviations of returns for Portfolios 2 and 3 are lower than that for the benchmark portfolio. According to conventional wisdom, higher returns go hand in hand with higher risk. But Portfolios 2 and 3 generated higher returns with lower total risk relative to the benchmark. This outcome is particularly noteworthy because the currency position has been levered by a factor of 10 and currency managers rely on either dynamic trading strategies (beta grazers) or active strategies (alpha hunters). The diversification effect is even greater with the larger allocation to currency of $10 \%$. The right-hand panels of Table 14 show the impact of a $10 \%$ currency allocation to currency managers. Basically, it multiplies the excess return and tracking error figures by 5 , leaving the IR estimates unchanged. Figure 10 highlights the benefit of the greater currency allocation by plotting the

Figure 10. Performance of Global Equities and Impact of Adding Currency Managers, 6 April 2005-30 June 2010

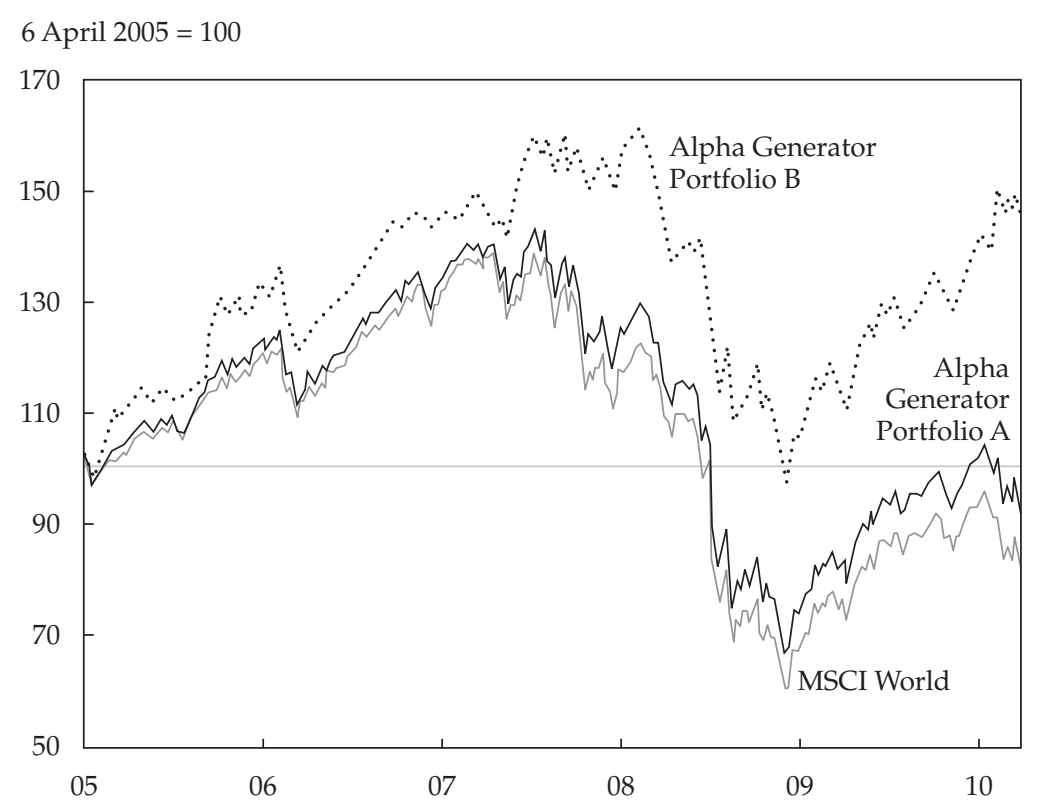

Notes: Alpha-Generator Portfolio A (2\% currency allocation) invests $98 \%$ cash in the MSCI World with the remaining 2\% cash used to obtain a $20 \%$ notional exposure in the top three alpha generators. The currency share is then $16.9 \%(20 / 118)$, and the equity share, $83.1 \%$ (98/118). In Alpha-Generator Portfolio B (10\% currency allocation), the cash share allocated to currency managers is $10 \%$. The total currency share is then $52.6 \%(100 / 190)$, and the equity share is $47.4 \%(90 / 190)$. 
cumulative performance of the Alpha-Generator Portfolio with either a $2 \%$ or a $10 \%$ cash allocation to currency managers. The MSCI World is included as the benchmark.

Portfolio 1 has a standard deviation slightly higher than the benchmark portfolio. Investing in pure currency beta (via indices) would have increased the return of the portfolio but with no diversification benefit. In our sample, only the alpha generators offer a real diversification gain.

Overall, our analysis suggests that adding a relatively small position in currency of $2 \%$ (albeit levered by 10 to boost the weight in the portfolio to $16.9 \%)$ can bring about an economically significant improvement in performance. The currency component had the undesirable effect of increasing tracking error versus the benchmark by a relatively small amount but also produced a portfolio with lower total risk.

Note that these results represent an in-sample experiment: At the beginning of the time period studied, it was not possible to distinguish between the beta grazers and the alpha generators. P-L (2011b) reports similar out-ofsample results, however, which supports the notion of alpha and beta persistence. In the earlier work, we classified managers into beta grazers and alpha generators in-sample and showed that (1) the classification tends to hold outof-sample and (2) currency managers classified as alpha generators in-sample provide the greatest benefits to equity portfolios out-of-sample.

These results imply that, although all currency managers who excel at generating returns in general add excess returns to the benchmark portfolio and provide some diversification gain, some managers offer more benefits to institutional investors than others. Consequently, applying the framework developed by P-L (2008) can be useful for differentiating between currency managers who are beta grazers and those who are alpha hunters and for selecting the managers best suited to the institutional portfolio. In particular, the following three steps could be incorporated into the fund's due diligence process to obtain exposure to currency alpha:

- Collect return data on currency managers. Although all disclaimers state that past performance is not an indication of future performance, $\mathrm{P}-\mathrm{L}$ (2011b) reports alpha and beta persistence for professional currency managers. Hence, past performance data can be used to differentiate between alpha hunters and beta grazers. ${ }^{96}$

\footnotetext{
${ }^{96} \mathrm{We}$ caution against the use of databases with self-reported returns. Fortunately, many FX-only hedge fund platforms allow potential investors to evaluate managers' track records. Deutsche Bank's dbSelect, launched in March 2005, is one. Recently, both Citibank and Morgan Stanley have also developed FX-only platforms.
} 
- Identify the alpha generators. The four-factor model proposed by P-L (2008) can next be used to group managers into alpha generators, alpha hunters, beta grazers, and underperformers. Managers with high alphas are alpha generators, and managers with low alpha are underperformers. Managers with high $R^{2}$ s are beta grazers, and managers with low $R^{2} s$ are alpha hunters. This classification would be constructed in-sample, but empirical evidence suggests that these broad categories are likely to persist out-of-sample.

- Allocate to the alpha generators. The final step involves setting up the parameters of the currency mandate and dealing with the structural and operational choices described in Chapter 2. For example, absolute currency mandates could be tailored to different levels of risk aversion. This step could involve agreeing on a maximum monthly drawdown or target volatility.

Of course, these steps are only a small part of the due diligence process required to identify suitable managers. Our empirical results suggest, however, that incorporating these ideas into an existing manager selection approach is likely to provide value in determining the currency managers most likely to benefit institutional portfolios. 


\section{Conclusions and Implications for Investment Management}

We have taken a new look at currency management by applying an established methodology to a subset of the hedge fund industry - currency funds-which is something that has not been done previously. And we addressed several fundamental questions: Do style factors offer a useful way to explain currency returns and also allow investors to differentiate between alpha and beta components? Are currency returns predictable to any extent? Is managerial performance or management style persistent? Do currency managers-whether pure index followers, discretionary beta grazers, or genuine alpha huntersadd value to otherwise well-diversified global equity portfolios? In a generic core-satellite setting, would institutional managers be well served by adding currency managers to the satellite managers they rely on? ${ }^{97}$

The answers to these questions are, in most cases, yes, and the reasons are threefold. First, the foreign exchange market offers substantial depth and liquidity for large institutional investors. As noted in Chapter 2, daily average FX market turnover reached USD4 trillion in April 2010, a 20\% increase over 2007. This liquidity was precious during the market turmoil in 2008. Second, empirical evidence shows that returns generated by most currency strategies are, to a large extent, explained by style factors that proxy for common currency investment strategies and that currency returns are generally uncorrelated with returns from other asset classes. Third, and most importantly, the empirical evidence suggests that some managers have been able to deliver statistically and economically significant alpha even when measured against a strict benchmark based on style factors.

We qualify our answer with "in most cases" because some institutional investors might lack the governing structure needed to conduct the proper due diligence for allocating to standalone currency managers. In these cases, exposure to currency alpha might be obtained through a currency fund of funds whereas exposure to currency beta might be obtained through currency ETFs. Other institutional investors might prefer to gain exposure to currency alpha through allocations to global macro funds, many of which use currency investment strategies. In most cases, however, the currency alpha generated by these macro funds cannot be separated from the total alpha generated. Therefore, it is often impossible to evaluate whether the specialists (FX-only managers) are

\footnotetext{
${ }^{97}$ Our discussion focused on standalone active currency managers as a source of return. Global institutional portfolios may have currency exposure through investing in foreign currencydenominated assets.
} 
outperforming or underperforming the generalists (global macro funds). In any case, the question of whether to invest in boutiques or supermarkets is not confined to currency management and is beyond the scope of this book.

As discussed in Chapter 1, institutional investors may harbor realistic doubts regarding the suitability of currency as an asset class. Currency markets are highly specialized, with terminology and institutional features that differ from equity trading on organized exchanges. Concerns regarding the elusive nature of currency valuation and trading relationships cause some investors to wonder whether relying on currency as an ongoing source of return makes sense-particularly because currency may seem so different from "real investments," such as stocks, bonds, or even commodities and precious metals with alternative industrial uses. That currency trading is lightly regulated and prone to central bank intervention may seem to layer on additional risks. Furthermore, the assets under management at most currency managers are relatively small compared with the size of most institutional investors. ${ }^{98}$ As a result, plan sponsors may have difficulties allocating to $\mathrm{FX}$ managers. ${ }^{99}$

Another important challenge for institutional investors is to identify appropriate benchmarks for gauging the performance of currency managers. Without appropriate benchmarks, one cannot tell whether managers have demonstrated true skill or not. Because of the heterogeneity in mandates, Melvin and Shand (2011) question whether a single benchmark can be appropriate for all currency managers. But if not, the solution would be adopting more benchmarks rather than adopting zero as the standard. Looking at a range of alpha estimates is more beneficial than treating all return as alpha return. The lack of well-established benchmarks may be one of the reasons allocations to currency strategies remain low compared with allocations to hedge funds in general. ${ }^{100}$

\footnotetext{
${ }^{98}$ Of the 115 managers who reported AUM to BarclayHedge in January 2010, 86 (or about 75\%) managed AUM less than USD100 million and only 10 (fewer than 10\%) reported AUM in excess of USD500 million.

${ }^{99} \mathrm{As}$ a rule of thumb, institutional investors avoid allocating to managers in excess of $1 / 3$ of the manager's total AUM. For example, if the manager has USD100 million total AUM, an investor would rarely allocate more than USD35 million to that manager, which could be too small of an allocation (1) to have an impact on the investor's overall portfolio return and (2) to justify the costs for initial and ongoing due diligence.

${ }^{100}$ In contrast, numerous indices track other assets-small-capitalization, value, and emerging market stocks, stocks grouped by region and industry sector, various categories within fixed income and the term structure, and commodities. Vendors abound-S\&P, MSCI, Barclays, Russell, and others. These developments have allowed institutional managers to flourish in these niche categories. For example, AUM in the SPDR Gold Shares (NYSE:GLD), which delivers the return on gold bullion, is USD69.77 billion, whereas the AUM in a currency ETF available in the United Kingdom for institutional investors that mimics the return of the carry trade was merely GBP6.38 million as of 26 March 2012 (www.etf.db.com).
} 
In many studies of currency-trading strategies, researchers have used zero as the expected return from currency speculation and interpreted all realized returns as unusual, excess returns. In the same vein, zero has often been used as a traditional benchmark to assess the performance of currency fund managers who pursue an absolute return mandate. ${ }^{101}$ In contrast to the traditional benchmark, we have proposed a four-factor regression model as an alternative technique to gauge the performance of currency managers (initially proposed in P-L 2008). The model estimates what portion of currency-trading profits is the result of exposure to these specific trading styles or risk factors (beta) and what portion is the result of skill (alpha).

In empirical tests of the four-factor model, P-L $(2008,2010)$ use different proxies for the risk factors, but the results are strikingly similar. Depending on the time period, periodicity, and model specification, four risk factors explain $50-75 \%$ of the variability of currency fund (index) returns. We have updated some of the results with more recent data and used different proxies for the risk factors as robustness checks. The general conclusions remain unchanged: A significant part of currency returns comes from exposure to a small set of factors that proxy the returns of well-known and easily implemented trading styles. As a consequence, much of what might have been labeled "alpha" against the traditional benchmark (of zero) may be beta returns when measured against the alternative benchmark. So, in some respects, currencies seem not so different from other asset classes: The average manager may deliver zero alpha, but some skilled managers are able to deliver significant alpha. ${ }^{102}$

We have reported results when using various proxies for the style factors, but using different style factors could change the results, as Melvin and Shand (2011) caution. In addition, other factors we have omitted (such as drawdown of capital) could matter to investors. Despite these caveats about our work, we suggest that it is an improvement over the alternative- to retain the traditional performance benchmark of zero and forsake the use of a limited set of style factors for benchmarking. Keeping the zero benchmark would be inconsistent not only with our results but also with the general principle of adjusting all returns for any systematic effects or factors they may be found to contain.

For several reasons, institutional investors should be concerned about how much of a currency manager's return is alpha and how much is beta. First, proper return attribution could lead to some repricing for "active" currency

\footnotetext{
${ }^{101}$ In 2011, Citibank launched a new multimanager platform, CitiFX Access. The platform offers a range of investable currency indices, and some of these indices are intended to serve as a benchmark by providing exposure to currency managers who are deemed to represent the industry. Such a group of managers may be regarded as a peer group benchmark.

${ }^{102}$ See Jones and Wermers (2011) for a recent survey of the literature on the value of active management. They show that the average manager does not outperform but that a significant minority of active managers do add value.
} 
products. Investors should not be required to pay alpha fees for exposure to currency style betas that could be earned more cheaply. Second, currency beta might be less suitable for institutional investors than currency alpha when the goal is to diversify global equity exposure. In Chapter 5, we showed that a global equity portfolio that diversified by using alpha generators would have outperformed a portfolio invested in beta grazers by $141 \mathrm{bps}$ a year between 6 April 2005 and 30 June 2010. Diversifying with beta grazers is beneficial, as indicated by a positive IR of 0.35 , but much less beneficial than investing in alpha generators, which yielded an IR of 1.04. Indeed, investors would have been better off simply investing in currency beta via ETFs, as highlighted by the IR of 0.46 , than investing in the beta grazers.

This last result could lead institutional investors to pay close attention to the return attribution of their currency managers. Over the periods for which measurements are available, all of the currency style factors generated positive average returns. Given the relatively long history of these factors, we expect this pattern of positive currency returns to continue. With that assumption, we consider that all currency expected returns will make an incremental contribution to overall portfolio returns but that some managers will be more likely to have persistently good performance with greater diversification benefits. Choosing the "right" currency managers could increase the diversification benefits considerably for global equity portfolios. Finding these managers is challenging, but the benefits to a portfolio might be considerable. In an investment world where the beta return might be too low to cover future liabilities, investors cannot afford to ignore potential alpha providers. 


\section{Appendix A: Currency Indices and Style Factors}

\begin{tabular}{|c|c|c|c|}
\hline $\begin{array}{l}\text { Currency Index } \\
\text { or Style Factor }\end{array}$ & Description & Provider & Source \\
\hline BCTI & $\begin{array}{l}\text { The Barclay Currency Traders Index } \\
\text { is an equally weighted composite } \\
\text { of managed programs that trade } \\
\text { currency futures and/or cash forwards } \\
\text { in the interbank market. In } 2011,117 \\
\text { currency programs were included in } \\
\text { the index. }\end{array}$ & BarclayHedge & $\begin{array}{l}\text { Monthly data } \\
\text { available on } \\
\text { Bloomberg (code } \\
\text { FXTP) }\end{array}$ \\
\hline DB Carry & $\begin{array}{l}\text { The Deutsche Bank Currency } \\
\text { Harvest G10 Index systematically } \\
\text { invests in the three highest yielding } \\
\text { G-10 currencies through funding in } \\
\text { the three lowest yielding currencies; } \\
\text { it rebalances quarterly. }\end{array}$ & Deutsche Bank & $\begin{array}{l}\text { Monthly data } \\
\text { available on } \\
\text { Bloomberg (code } \\
\text { DBHVG10U } \\
\text { Index) }\end{array}$ \\
\hline $\begin{array}{l}\text { RBS Carry } \\
\text { (see Notes) }\end{array}$ & $\begin{array}{l}\text { The Royal Bank of Scotland Carry } \\
\text { Index reflects the return of being } \\
\text { long the higher yielding currencies } \\
\text { against being short the lower } \\
\text { yielding currencies (position size is } \\
\text { proportional to yield relative to U.S. } \\
\text { rate). }\end{array}$ & $\begin{array}{l}\text { Royal Bank of } \\
\text { Scotland }\end{array}$ & $\begin{array}{l}\text { Monthly data } \\
\text { available on } \\
\text { Bloomberg (code } \\
\text { FXTP) }\end{array}$ \\
\hline $\begin{array}{l}\text { AFX Index } \\
\text { (see Notes) }\end{array}$ & $\begin{array}{l}\text { The AFX Currency Management } \\
\text { Index is based on trading in seven } \\
\text { currency pairs weighted by their } \\
\text { volume of turnover in the spot } \\
\text { market, with returns for each pair } \\
\text { based on an equally weighted } \\
\text { portfolio of three moving-average } \\
\text { rules (32, } 61 \text {, and } 117 \text { days); the seven } \\
\text { currency pairs are EUR/USD, USD/ } \\
\text { JPY, USD/CHF, GBP/USD, EUR/ } \\
\text { JPY, EUR/GBP, and EUR/CHF. }\end{array}$ & $\begin{array}{l}\text { Liverpool } \\
\text { John Moores } \\
\text { University }\end{array}$ & $\begin{array}{l}\text { Monthly data } \\
\text { for this index are } \\
\text { available at the } \\
\text { AFX web site } \\
\text { (www.jmu.ac.uk/ } \\
\text { LBS/102316.htm); } \\
\text { we are grateful to } \\
\text { Pierre Lequeux of } \\
\text { Aviva Investors for } \\
\text { providing daily data }\end{array}$ \\
\hline DB Trend & $\begin{array}{l}\text { The Deutsche Bank Momentum } \\
\text { Index invests in the three best } \\
\text { performing, highest momentum } \\
\text { G-10 currencies over the previous } \\
12 \text { months (spot returns against the } \\
\text { USD) and borrows in the three worst } \\
\text { performing currencies; rebalancing is } \\
\text { monthly. }\end{array}$ & Deutsche Bank & $\begin{array}{l}\text { Monthly data } \\
\text { available on } \\
\text { Bloomberg (code } \\
\text { DBMOMUSF) }\end{array}$ \\
\hline
\end{tabular}




\begin{tabular}{cl}
$\begin{array}{c}\text { Currency Index } \\
\text { or Style Factor }\end{array}$ & \multicolumn{1}{c}{ Description } \\
\hline $\begin{array}{c}\text { RBS Trend } \\
\text { (see Notes) }\end{array}$ & $\begin{array}{l}\text { The Royal Bank of Scotland Value } \\
\text { Index reflects the return of a simple } \\
\text { moving-average strategy combined } \\
\text { with a simple rule to reduce whipsaw. }\end{array}$ \\
DB Value & $\begin{array}{l}\text { The Deutsche Bank Valuation Index } \\
\text { goes long the three most undervalued }\end{array}$ \\
& $\begin{array}{l}\text { G-10 currencies relative to OECD } \\
\text { PPP values and goes short the } \\
\text { three most overvalued currencies; } \\
\text { rebalancing is quarterly. }\end{array}$ \\
& $\begin{array}{l}\text { The Royal Bank of Scotland Value } \\
\text { RBS Value } \\
\text { (see Notes) }\end{array}$ \\
& $\begin{array}{l}\text { long undervalued currencies against } \\
\text { overvalued currencies with position } \\
\text { size proportional to the amount of } \\
\text { over- and undervaluation. }\end{array}$
\end{tabular}

DB Volatility The Deutsche Bank Currency Volatility Index is calculated based on the three-month implied volatilities of nine major currency pairs. The currency pairs and their index weights are as follows: EUR/ USD (37.84\%), USD/JPY (18.92\%), GBP/USD (12.16\%), USD/CHF (5.41\%), USD/CAD (6.76\%), AUD/ USD (8.11\%), EUR/JPY (4.05\%), EUR/GBP (4.05\%), and EUR/CHF (2.70\%).
RBS Volatility The Royal Bank of Scotland (see Notes) Volatility Index reflects the return of being short volatility; the strategy sells an at-the-money forward straddle for each currency against the USD at the start of each month if implied volatility is above its one-year average for that currency.

Provider

Royal Bank of

Scotland

Royal Bank of

Scotland

Deutsche Bank

Royal Bank of

Scotland

(continued)

\section{Monthly data available on Bloomberg (code FXTP)}

\author{
Monthly data \\ available on \\ Bloomberg (code \\ CVIX Index)
}

Monthly data

Bloomberg (code

FXTP)

available on

Bloomberg (code

DBPPPUSF)

\author{
Monthly data \\ available on \\ Bloomberg (code \\ FXTP)
}




\begin{tabular}{|c|c|c|c|}
\hline $\begin{array}{l}\text { Currency Index } \\
\text { or Style Factor }\end{array}$ & Description & Provider & Source \\
\hline Carry Global & $\begin{array}{l}\text { The Global Harvest Index invests in } \\
\text { the five highest yielding currencies } \\
\text { while shorting the five lowest } \\
\text { yielding currencies, regardless of } \\
\text { geographic region; the currency } \\
\text { universe consists of the G-10 } \\
\text { currencies and the following } \\
\text { currencies: South Korean won } \\
\text { (KRW), Singapore dollar (SGD), } \\
\text { New Taiwan dollar (TWD), Mexican } \\
\text { peso (MXN), Brazilian real (BRL), } \\
\text { Turkish new lira (TRY), Polish zloty } \\
\text { (PLN), Hungarian forint (HUF), } \\
\text { Czech koruna (CZK), and South } \\
\text { African rand (ZAR). }\end{array}$ & Deutsche Bank & $\begin{array}{l}\text { Monthly data } \\
\text { available on } \\
\text { Bloomberg (code } \\
\text { DBHVGUSI } \\
\text { Index) }\end{array}$ \\
\hline Carry Balanced & $\begin{array}{l}\text { The Balanced Harvest Index invests } \\
\text { in the two highest yielding G-10 } \\
\text { currencies plus three currencies } \\
\text { chosen from the whole currency } \\
\text { universe and shorts the two lowest } \\
\text { yielding G-10 currencies and the } \\
\text { three lowest yielding currencies } \\
\text { from the entire currency pool; the } \\
\text { non-G-10 pool consists of the KRW, } \\
\text { SGD, TWD, MXN, BRL, TRY, } \\
\text { PLN, HUF, CZK, and ZAR. }\end{array}$ & Deutsche Bank & $\begin{array}{l}\text { Monthly data } \\
\text { available on } \\
\text { Bloomberg (code } \\
\text { DBHVBUSI } \\
\text { Index) }\end{array}$ \\
\hline
\end{tabular}

Notes: At the time of our writing, the RBS indices were available on Bloomberg, code FXTP. The RBS discontinued publishing the data, however, at the beginning of 2012. Also at the time of our writing, the AFX was available at and maintained by Liverpool John Moores University. Although this website is no longer available, a cached version is available at http://web.archive.org/ web/20100527043718/http://www.ljmu.ac.uk/LBS/102316.htm. At present, monthly data for the AFX Index is prepared by Pierre Lequeux and available through a link at http://people.stern.nyu. edu/rlevich/afx_index.html. 


\section{ReferenCeS}

Abuaf, Niso, and Philippe Jorion. 1990. "Purchasing Power Parity in the Long Run." Journal of Finance, vol. 45, no. 1 (March):157-174.

Aggarwal, Rajesh K., and Philippe Jorion. 2010. "Hidden Survivorship in Hedge Fund Returns.” Financial Analysts Journal, vol. 66, no. 2 (March/April):69-74.

Aiken, Adam L., Christopher P. Clifford, and Jesse A. Ellis. 2010. "Out of the Dark: Hedge Fund Reporting Biases and Commercial Databases." Working paper: http:// ssrn.com/abstract=1519914.

Ali, Magda. 2010. "Citi Indexes Offer Low-Cost Forex Exposure.” FX Week (12 November).

Anson, Mark. 2011. "The Evolution of Equity Mandates in Institutional Portfolios." Journal of Portfolio Management, vol. 37, no. 4 (Summer):127-137.

Baba, Naohiko, and Frank Packer. 2009. "Interpreting Deviations from Covered Interest Parity during the Financial Market Turmoil of 2007-08." Journal of Banking EF Finance, vol. 33, no. 11 (November):1953-1962.

Binny, James. 2005. "Currency Management Style through the Ages." Journal of Alternative Investments, vol. 8, no. 3 (Winter):52-59.

BIS. 2010. "Triennial Central Bank Survey: Report on Global Foreign Exchange Market Activity in 2010.” Bank for International Settlements (December).

Brunnermeier, Markus K., Stefan Nagel, and Lasse H. Pedersen. 2009. "Carry Trades and Currency Crashes." NBER Macroeconomics Annual, vol. 23, no. 1 (April):313-348.

Burnside, Craig. 2011. “Carry Trades and Risk.” NBER Working Paper No. 17278 (August).

Carhart, Mark M. 1997. "On Persistence in Mutual Fund Performance." Journal of Finance, vol. 52, no. 1 (March):57-82.

Chen, Nai-Fu, Richard Roll, and Stephen A. Ross. 1986. "Economic Forces and the Stock Market." Journal of Business, vol. 59, no. 3 (July):383-403.

Chinn, Menzie D., and Guy Meredith. 2004. "Monetary Policy and Long-Horizon Uncovered Interest Parity.” IMF Staff Papers, vol. 51, no. 3 (November):409-430.

Chow, George, Eric Jacquier, Mark Kritzman, and Kenneth Lowry. 1999. "Optimal Portfolios in Good Times and Bad." Financial Analysts Journal, vol. 55, no. 3 (May/ June):65-73.

Clements, Kenneth W., Yihui Lan, and Shi Pei Seah. 2012. “The Big Mac Index Two Decades On: An Evaluation of Burgernomics." International Journal of Finance E Economics, vol.17, no. 1 (January):31-60. 
Coffey, Niall, Warren B. Hrung, and Asani Sarkar. 2009. "Capital Constraints, Counterparty Risk, and Deviations from Covered Interest Rate Parity." Federal Reserve Bank of New York Staff Reports No. 393 (September).

Cumby, Robert E. 1996. "Forecasting Exchange Rates and Relative Prices with the Hamburger Standard: Is What You Want What You Get with McParity?" NBER Working Paper No. 5675 (July).

Dash, Eric. 2009. "State Street Bank Accused of Fraud by California." New York Times (20 October).

Dash, Eric, and Peter Lattman. 2011. "U.S. and New York Sue Bank of New York Mellon over Foreign Exchange Fees." New York Times (4 October).

Dickson, Tim. 1991. "The Growing Appeal of Overseas Assets.” Financial Times, Survey on International Fund Management (18 April):IV.

Engel, Charles. 1996. "The Forward Discount Anomaly and the Risk Premium: A Survey of Recent Evidence." Journal of Empirical Finance, vol. 3, no. 2 (June):123-192.

Fama, Eugene F., and Kenneth R. French. 1992. "The Cross-Section of Expected Stock Returns." Journal of Finance, vol. 47, no. 2 (June):427-465.

-1993. "Common Risk Factors in the Returns on Stocks and Bonds." Journal of Financial Economics, vol. 33, no. 1 (February):3-56.

Flood, Robert P., and Mark P. Taylor. 1996. "Exchange Rate Economics: What's Wrong with the Conventional Macro Approach?" In The Microstructure of Foreign Exchange Markets. Edited by Jeffrey A. Frankel, Giampaolo Galli, and Alberto Giovannini. Chicago: University of Chicago Press.

Freeman, Andrew. 1989. "Now Equity Managers Cut the Risk-Currency Hedging." Financial Times, Survey on International Fund Management (26 October):VI.

Froot, Kenneth A., and Richard H. Thaler. 1990. "Anomalies: Foreign Exchange." Journal of Economic Perspectives, vol. 4, no. 3 (Summer):179-192.

Fung, William, and David A. Hsieh. 2000. "Performance Characteristics of Hedge Funds and Commodity Funds: Natural vs. Spurious Biases." Journal of Financial and Quantitative Analysis, vol. 35, no. 3 (September):291-307.

- 2002. "Asset-Based Style Factors for Hedge Funds." Financial Analysts Journal, vol. 58, no. 5 (September/October):16-27.

Galati, Gabriele. 2001. "Why Has Global FX Turnover Declined? Explaining the 2001 Triennial Survey.” BIS Quarterly Review (December):39-47.

Galati, Gabriele, and Michael Melvin. 2004. "Why Has FX Trading Surged? Explaining the 2004 Triennial Survey.” BIS Quarterly Review (December):67-74.

Givant, Marlene. 1988. "Hedged Indexes Mulled." Pensions and Investment Age (27 June):2. 
Gyntelberg, Jacob, and Andreas Schrimpf. 2011. "FX Strategies in Period of Distress." BIS Quarterly Review (December).

Hafeez, Bilal, and Daniel Brehon. 2010. "30 Years of FX Investment Returns: dbCR and dbCR+." Exchange Rate Perspectives, Deutsche Bank (10 February).

Hodrick, Robert J. 1987. The Empirical Evidence on the Efficiency of Forward and Futures Foreign Exchange Markets. Reading, U.K.: Harwood Academic Publishers.

Huberman, Gur, and Zhenyu Wang. 2005. "Arbitrage Pricing Theory.” Federal Reserve Bank of New York Staff Reports No. 216 (August).

Imbs, Jean, Haroon Mumtaz, Morten O. Ravn, and Hélène Rey. 2005. "PPP Strikes Back: Aggregation and the Real Exchange Rate.” Quarterly Journal of Economics, vol. 120, no. 1 (February):1-43.

IMF. 2010. Annual Report on Exchange Arrangements and Exchange Restrictions: 2010. International Monetary Fund.

Isard, Peter. 2007. "Equilibrium Exchange Rates: Assessment Methodologies." International Monetary Fund Working Paper No. 07-296 (December).

Isard, Peter, Hamid Faruqee, G. Russell Kincaid, and Martin Fetherston. 2001. "Methodology for Current Account and Exchange Rate Assessment." International Monetary Fund Occasional Paper No. 209 (December).

Jones, Robert C., and Russ Wermers. 2011. "Active Management in Mostly Efficient Markets.” Financial Analysts Journal, vol. 67, no. 6 (November/December):29-45.

King, Michael R., and Dagfinn Rime. 2010. “The \$4 Trillion Question: What Explains FX Growth since the 2007 Survey?” BIS Quarterly Review (December):27-42.

King, Michael R., Carol Osler, and Dagfinn Rime. 2011. "Foreign Exchange Market Structure, Players and Evolution.” Norges Bank Working Paper No.10 (August).

Kritzman, Mark, and Yuanzhen Li. 2010. "Skulls, Financial Turbulence, and Risk Management.” Financial Analysts Journal, vol. 66, no. 5 (September/October):30-41.

Kroencke, Tim-Alexander, Felix Schindler, and Andreas Schrimpf. 2011. "International Diversification Benefits with Foreign Exchange Investment Styles." Aarhus University, CREATES Research Paper 2011-10 (August).

Lee, Wai. 2011. "Risk-Based Asset Allocation: A New Answer to an Old Question?" Journal of Portfolio Management, vol. 37, no. 4 (Summer):11-28.

Leibowitz, Martin L. 2005. "Alpha Hunters and Beta Grazers." Financial Analysts Journal, vol. 61, no. 5 (September/October):32-39.

August):4, 6-7.

Leibowitz, Martin L., and Anthony Bova. 2007. "Gathering Implicit Alphas in a Beta World.” Journal of Portfolio Management, vol. 33, no. 3 (Spring):10-18. 
Lequeux, P., and E. Acar. 1998. "A Dynamic Index for Managed Currencies Funds Using CME Currency Contracts." European Journal of Finance, vol. 4, no. 4 (December):311-330.

Levich, Richard M. 2009. "Why Foreign Exchange Transactions Did Not Freeze Up during the Global Financial Crisis: The Role of the CLS Bank." VOX (July): www. voxeu.org/article/clearinghouse-saved-foreign-exchange-trading-crisis.

- 2013. "Interest Rate Parity." In The Evidence and Impact of Financial Globalization, vol. 3. Edited by Gerard Caprio. Oxford: Elsevier.

Levich, Richard M., and Momtchil Pojarliev. 2012. "Active Currency Management Part II: Is There Skill or Alpha in Currency Investing?” In Handbook of Exchange Rates. Edited by Jessica James, Ian W. Marsh, and Lucio Sarno. New York: John Wiley.

Litterman, Robert. 2011. "Who Should Hedge Tail Risk?” Financial Analysts Journal, vol. 67, no. 3 (May/June):6-11.

Lo, Andrew W. 2005. The Dynamics of the Hedge Fund Industry. Charlottesville, VA: Research Foundation of CFA Institute.

Lustig, Hanno, Nikolai Roussanov, and Adrien Verdelhan. 2010. "Countercyclical Currency Risk Premia.” NBER Working Paper No. 16427 (September).

Lyons, Richard K. 2001. The Microstructure Approach to Exchange Rates. Cambridge, MA: MIT Press.

Malkiel, Burton G., and Atanu Saha. 2005. "Hedge Funds: Risk and Return." Financial Analysts Journal, vol. 61, no. 6 (November/December):80-88.

McCrum, Dan. 2012. "Profits Still to Be Made in Zero-Sum Game." Financial Times (29 September).

Meese, Richard A., and Kenneth Rogoff. 1983. "Empirical Exchange Rate Models of the Seventies: Do They Fit Out of Sample?” Journal of International Economics, vol. 14, no. 1-2 (February):3-24.

Melvin, Michael, and Duncan Shand. 2011. "Active Currency Investing and Performance Benchmarks." Journal of Portfolio Management, vol. 37, no. 2 (Winter):46-59.

Menkhoff, Lukas, and Mark P. Taylor. 2007. "The Obstinate Passion of Foreign Exchange Professionals: Technical Analysis.” Journal of Economic Literature, vol. 45, no. 4 (December):936-972.

Menkhoff, Lukas, Lucio Sarno, Maik Schmeling, and Andreas Schrimpf. 2012a. "Carry Trades and Global Foreign Exchange Volatility." Journal of Finance, vol. 67, no. 2 (April):681-718.

- 2012b. "Currency Momentum Strategies." Journal of Financial Economics, vol. 106, no. 3 (December):660-684. 
Morris, Virginia B., and Stuart Z. Goldstein. 2009. Guide to Clearance E Settlement. New York: Lightbulb Press.

NACUBO. 2008. 2007 NACUBO Endowment Study. Washington, DC: National Association of College and University Business Officers.

Nasypbek, Sam, and Scheherazade S. Rehman. 2011. "Explaining the Returns of Active Currency Managers." In BIS Papers No. 58: Portfolio and Risk Management for Central Banks and Sovereign Wealth Funds. Proceedings of a joint conference organized by the BIS, the ECB, and the World Bank in Basel, 2-3 November 2010.

Norman, Stephen. 2010. "How Well Does Nonlinear Mean Reversion Solve the PPP Puzzle?” Journal of International Money and Finance, vol.29, no. 5 (September):919-937.

Nucera, Federico, and Giorgio Valente. 2010. "The Performance of Currency Hedge Funds and Foreign Exchange Risk Premia."Working paper (December).

Pojarliev, Momtchil. 2005. "Performance of Currency Trading Strategies in Developed and Emerging Markets: Some Striking Differences." Financial Markets and Portfolio Management, vol. 19, no. 3 (October):297-311.

- 2009. “Trading the Forward Rate Puzzle.” Journal of Alternative Investments, vol. 11, no. 3 (Winter):58-61.

Pojarliev, Momtchil, and Richard M. Levich. 2008. "Do Professional Currency Managers Beat the Benchmark?” Financial Analysts Journal, vol. 64, no. 5 (September/ October):18-32.

- 2010. "Trades of the Living Dead: Style Differences, Style Persistence and Performance of Currency Fund Managers." Journal of International Money and Finance, vol. 29, no. 8 (December):1752-1775.

- 2011a. "Detecting Crowded Trades in Currency Funds." Financial Analysts Journal, vol. 67, no. 1 (January/February):26-39.

-2011b. "Are All Currency Managers Equal?” Journal of Portfolio Management, vol. 37, no. 4 (Summer):42-53.

Pugel, Thomas A. 2011. International Economics, 15th ed. New York: Irwin McGraw-Hill.

Pukthuanthong-Le, Kuntara, and Lee R. Thomas. 2008. "Weak-Form Efficiency in Currency Markets.” Financial Analysts Journal, vol. 64, no. 3 (May/June):31-52.

Pukthuanthong-Le, Kuntara, Richard M. Levich, and Lee R. Thomas. 2007. "Do Foreign Exchange Markets Still Trend?” Journal of Portfolio Management, vol. 34, no. 1 (Fall):114-118.

Rogoff, Kenneth. 2002. “The Failure of Empirical Exchange Rate Models: No Longer New, but Still True.” Economic policy web essay (May): www.economic-policy.org/ responses.asp. 
Roll, Richard, and Stephen A. Ross. 1980. "An Empirical Investigation of the Arbitrage Pricing Theory." Journal of Finance, vol. 35, no. 5 (December):1073-1103.

Ross, Stephen A. 1976. "The Arbitrage Theory of Capital Asset Pricing." Journal of Economic Theory, vol. 3, no. 13 (December):341-360.

Rosenberg, Michael. 2010. "FX Market Insights: A Review of Global Macro Themes and Currency Investment Strategies." FX Market Insights (Bloomberg), vol. 4, no. 3 (October).

Sarno, Lucio, and Mark P. Taylor. 2002. The Economics of Exchange Rates. Cambridge, U.K.: Cambridge University Press.

Schulmeister, Stephan. 2005. "Components of the Profitability of Technical Currency Trading." Working paper, Austrian Institute of Economic Research.

Strange, Brian. 1998. "Currency Overlay Managers Show Consistency: In the Long Run, Count on Them for Adding Value.” Pensions E Investments, vol. 26, no. 12 (15 June):26-31.

Strasburg, Jenny, and Steve Eder. 2011. "Hedge Funds Bounce Back." Wall Street Journal (18 April).

Taylor, Alan M. 2010. "Global Finance after the Crisis." Bank of England Quarterly Bulletin, vol. 50, no. 4:366-377.

Taylor, Mark P., and David A. Peel. 2000. "Nonlinear Adjustment, Long-Run Equilibrium and Exchange Rate Fundamentals." Journal of International Money and Finance, vol. 19, no. 1 (February):33-53.

U.S. Department of the Treasury. 2011. "Determination of Foreign Exchange Swaps and Foreign Exchange Forwards under the Commodity Exchange Act." Notice of Proposed Determination (April).

Waring, M. Barton, and Laurence B. Siegel. 2006. "The Myth of the Absolute-Return Investor." Financial Analysts Journal, vol. 62, no. 2 (March/April):14-21.

Yao, Jian. 1997. "Essays on Market Making in the Interbank Foreign Exchange Market." Unpublished PhD thesis, New York University. 


\section{The Research Foundation of \\ CFA Institute \\ Board of Trustees \\ 2012-2013}

\section{Chair}

Jeffery V. Bailey, CFA $\dagger$

Target Corporation

Renee Kathleen-Doyle Blasky, CFA Vista Capital Ltd.

Dwight Churchill, CFA

Sunapee, NH

William Fung $\dagger$

London Business School

James P. Garland, CFA

The Jeffrey Company

John T. "JT" Grier, CFA

Virginia Retirement System
Pranay Gupta, CFA

Lombard Odier Darier Hentsch

(Asia) Limited

Walter V. "Bud" Haslett, Jr., CFA $\dagger^{*}$

CFA Institute

Daniel S. Meader, CFA*

Trinity Advisory Group

Frank K. Reilly, CFA ${ }^{*}$

University of Notre Dame

Thomas M. Richards, $\mathrm{CFA} \dagger$

Nuveen HydePark Group, LLC

John D. Rogers, $\mathrm{CFA} \dagger^{*}$

CFA Institute
Brian Singer, CFA

William Blair, Dynamic

Allocation Strategies

Fred H. Speece, Jr., CFA $\dagger^{*}$

Speece Thorson Capital

Group Inc.

Charles J. Yang, CFA*

T\&D Asset Management

Wayne H. Wagner, CFA

Venice Beach, CA

Arnold S. Wood

Martingale Asset Management

*Emeritus $\quad \dagger$ Ex officio

\section{Officers and Directors}

Executive Director

Walter V. "Bud" Haslett, Jr., CFA

CFA Institute

Gary P. Brinson Director of Research

Laurence B. Siegel

Research Foundation of

CFA Institute
Secretary

Tina Sapsara

CFA Institute

Treasurer

Kim Maynard

CFA Institute

\section{Research Foundation Review Board}

William J. Bernstein

Efficient Frontier Advisors

Stephen J. Brown

New York University

Sanjiv Das

Santa Clara University

Bernard Dumas

INSEAD

Stephen Figlewski

New York University

Gary L. Gastineau

ETF Consultants, LLC

William N. Goetzmann

Yale School of Management
Stephen A. Gorman, CFA

Wellington Management

Company

Elizabeth R. Hilpman

Barlow Partners, Inc.

Paul D. Kaplan

Morningstar, Inc.

Robert E. Kiernan III

Advanced Portfolio

Management

Robert W. Kopprasch, CFA

The Yield Book Inc.

Andrew W. Lo

Massachusetts Institute of

Technology
Alan Marcus Boston College

Paul O'Connell FDO Partners

Krishna Ramaswamy University of Pennsylvania

Andrew Rudd Advisor Software, Inc.

Lee R. Thomas

Pacific Investment

Management Company

Robert Trevor

Macquarie University 


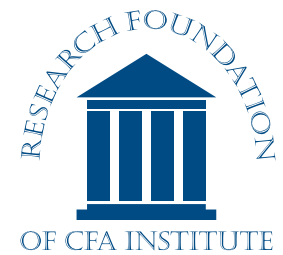

available online at www.cfapubs.org

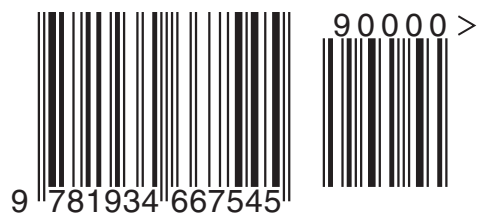

